WALDEN

UNIVERSITY

A higher degree. A higher purpose.

Walden University

ScholarWorks

Walden Dissertations and Doctoral Studies

Walden Dissertations and Doctoral Studies

Collection

2018

\title{
Pathways to Entrepreneurship Training Towards Addressing Youth Unemployment in Nigeria
}

Edward Perekebina Agbai

Walden University

Follow this and additional works at: https://scholarworks.waldenu.edu/dissertations

Part of the Business Administration, Management, and Operations Commons, and the Management Sciences and Quantitative Methods Commons

This Dissertation is brought to you for free and open access by the Walden Dissertations and Doctoral Studies Collection at ScholarWorks. It has been accepted for inclusion in Walden Dissertations and Doctoral Studies by an authorized administrator of ScholarWorks. For more information, please contact ScholarWorks@waldenu.edu. 


\title{
Walden University
}

\author{
College of Management and Technology
}

This is to certify that the doctoral dissertation by

\author{
Edward Agbai
}

has been found to be complete and satisfactory in all respects, and that any and all revisions required by the review committee have been made.

Review Committee

Dr. Richard Schuttler, Committee Chairperson, Management Faculty

Dr. Judith Forbes, Committee Member, Management Faculty

Dr. David Gould, University Reviewer, Management Faculty

Chief Academic Officer

Eric Riedel, Ph.D.

Walden University

2018 


\begin{abstract} Nigeria

by

Edward Agbai

MS, Walden University, 2015

PCE, University of Liverpool, 2014

HND, Rivers State Polytechnic, 2002

Dissertation Submitted in Partial Fulfillment

of the Requirements for the Degree of

Doctor of Philosophy

Management
\end{abstract}

Pathways to Entrepreneurship Training Towards Addressing Youth Unemployment in

Walden University

May 2018 


\begin{abstract}
The inadequacy of entrepreneurial knowledge among 21-25 year olds in Nigeria with recent undergraduate degrees has led to youth unemployment after graduating from universities. The development of entrepreneurship skills through entrepreneurship education programs for the students in tertiary institutions in Nigeria may bridge the unemployment gap. Guided by the theory of planned behavior, the purpose of this exploratory multiple case study was to gain a robust common understanding of how undergraduates from 21-25 years old can obtain the entrepreneurial knowledge required for self-employment in Nigeria. Data collection involved semistructured interviews, field notes, and archived training documents, with a purposeful sample of 15 undergraduate degree holders over 21 years old, who had been self-employed, in different industries and possessed entrepreneurial knowledge and experiences. Using Yin's 5 step data analysis process, member checking, and triangulation resulted in the emergence of codes, themes, and categories. The key themes were knowledge of business management, identification of business opportunities, information from workshop and seminars, information from social media and customer service, information on innovation, and mentor and mentee relationship. The findings from this study provide the empirical evidence needed to support entrepreneurship education as well as insight on tertiary institutions' commitment to entrepreneurship education that may lead to the creation of employment and empowers entrepreneurs towards national growth and development. The implications for positive social change include reshaping the way undergraduates prepare for self-employment, leading to a reduction of unemployment among youths in Nigeria.
\end{abstract}


Pathways to Entrepreneurship Training Towards Addressing Youth Unemployment in Nigeria

by

Edward Agbai

MS, Walden University, 2015

PCE, University of Liverpool, 2014

HND, Rivers State Polytechnic, 2002

Walden University

\author{
Dissertation Submitted in Partial Fulfillment \\ of the Requirements for the Degree of \\ Doctor of Philosophy \\ Management
}

May 2018 


\section{Dedication}

I dedicate the study of this doctoral program to God Almighty. The dedication of my doctoral goes to my wife, Ebiye, my three lovely children, Miebi, Tekena and Eladebi. To my wife for her support towards the completion of the program against all odds, I say a big thanks to you. This dedication also goes to my mother, Mrs. Iniye Claris Agbai, for her prayers, care, and understanding during the period of the study, without which the journey would have been even harder. Thank you so much for providing me with time and encouragement for me to complete my doctoral goal. 


\section{Acknowledgments}

Thank you to my chair, Dr. Richard Schuttler, for all the guidance that was provided that enabled me to go through the doctoral journey. His timely intervention and response to questions and inquiries are commendable. Resources that were provided within the classroom gave me a giant leap. I would also like to thank my committee members, Dr. Judith Forbes and Dr. David Gould, for their valuable feedbacks and comments that ensured my study conformed to the standard set out by the university. To my siblings, Eunice, Tonye, Ebi, and Godwin, I love you all. 


\section{Table of Contents}

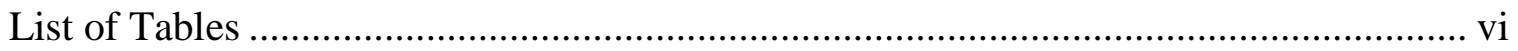

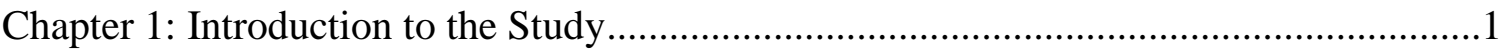

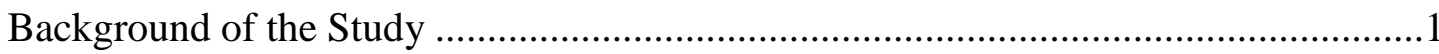

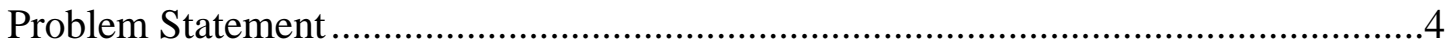

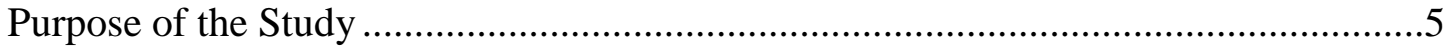

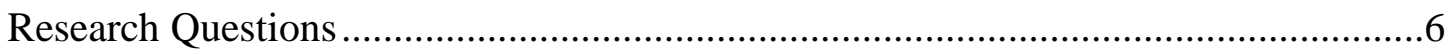

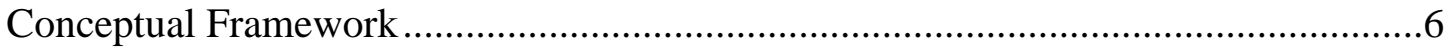

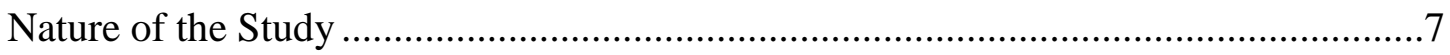

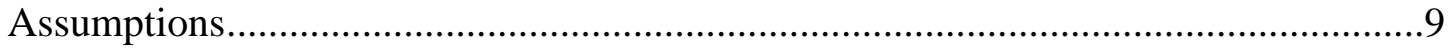

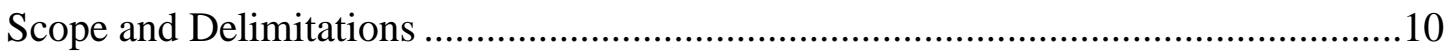

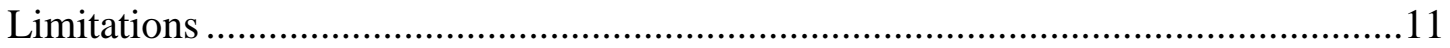

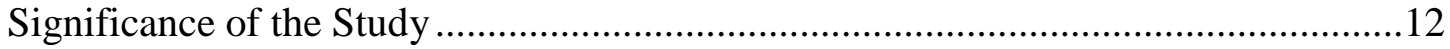

Significance to Practice................................................................................ 13

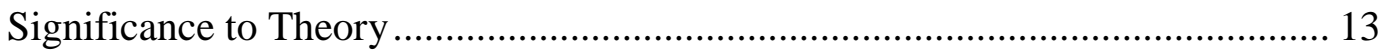

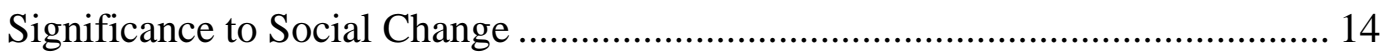

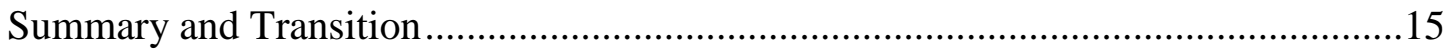

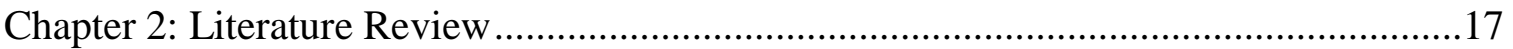

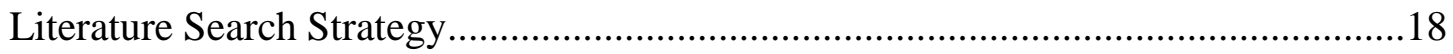

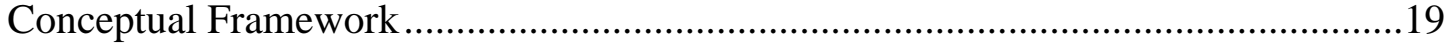

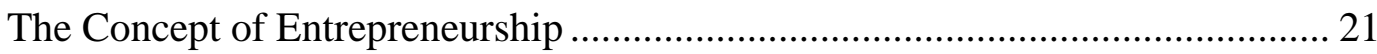

Entrepreneurial Attributes and Characteristics ............................................... 31 


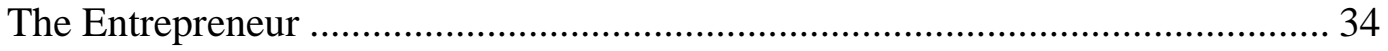

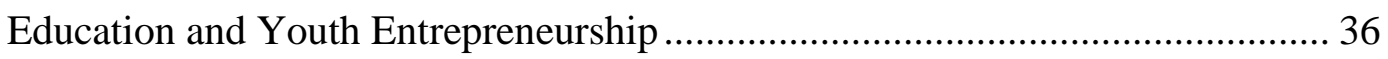

Entrepreneurship Role in Societal Development ................................................ 48

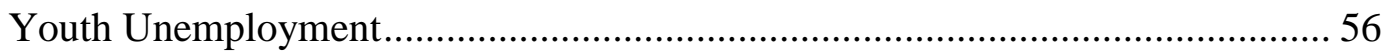

Transition from Student to Entrepreneur .......................................................... 59

Summary and Conclusions ……………………………...................................60

Chapter 3: Research Method..................................................................................62

Research Design and Rationale .........................................................................63

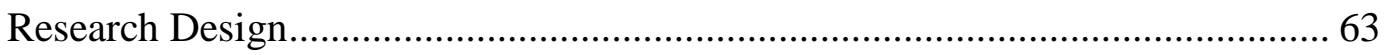

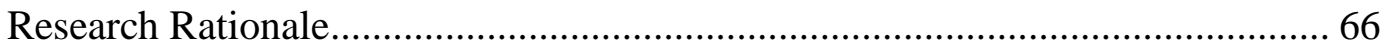

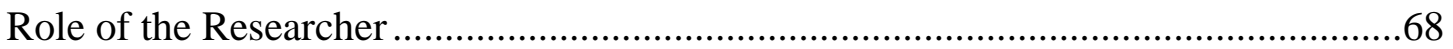

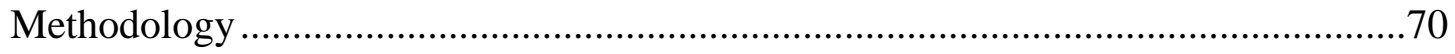

Participant Selection Logic ............................................................................ 72

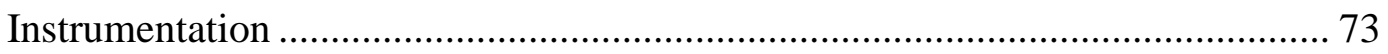

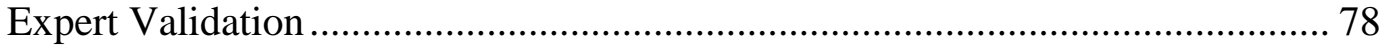

Procedures for Recruitment of Participants, and Data Collection ........................ 80

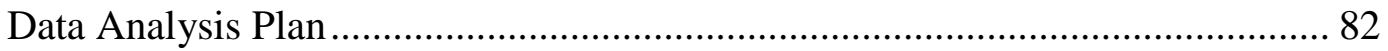

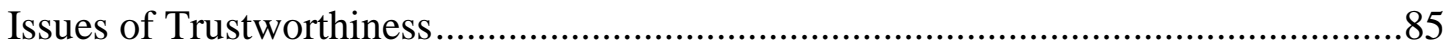

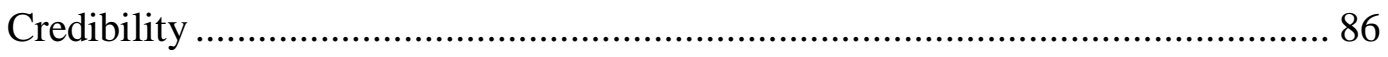

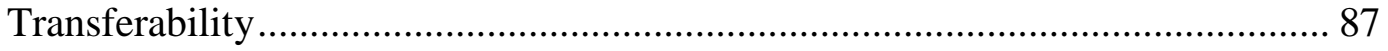

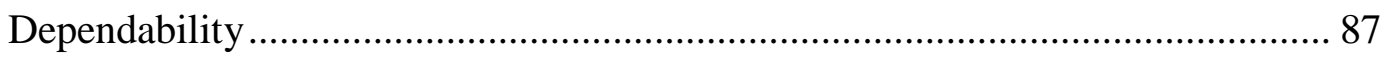

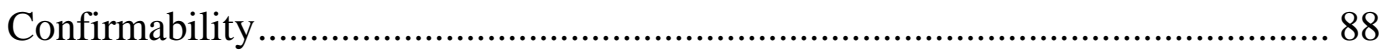




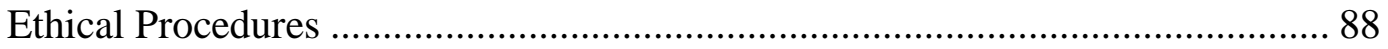

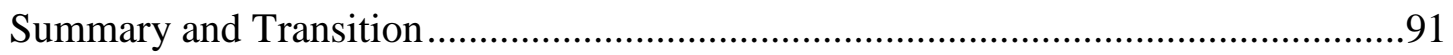

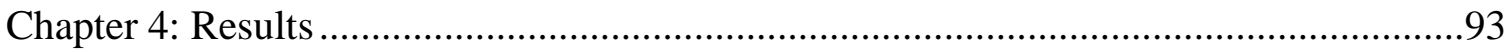

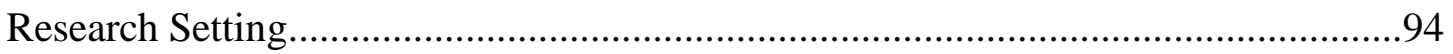

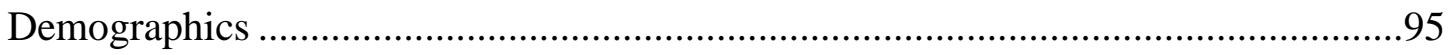

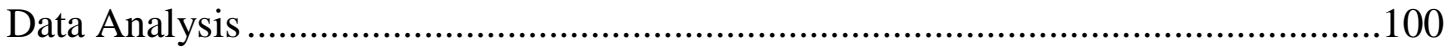

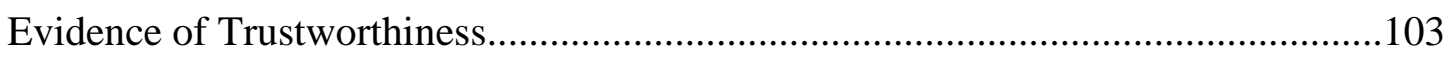

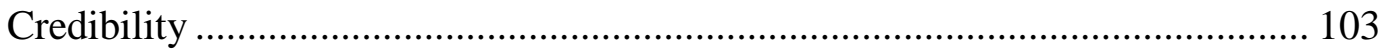

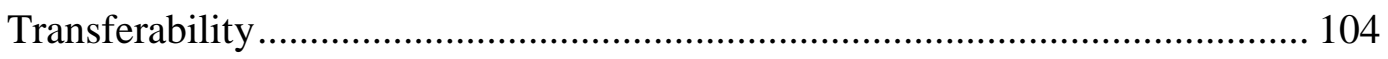

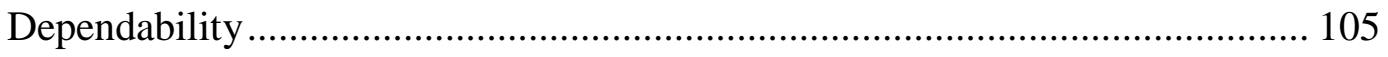

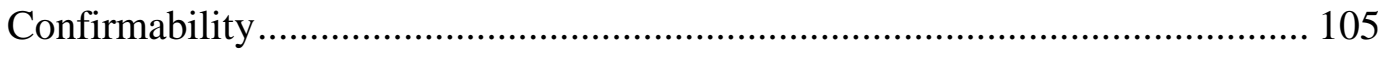

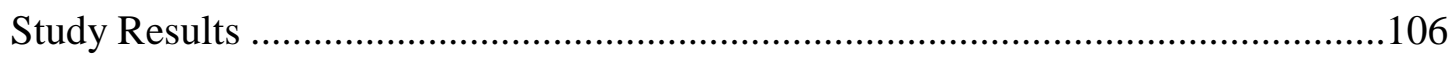

Emergent Themes ………………………………………............................111

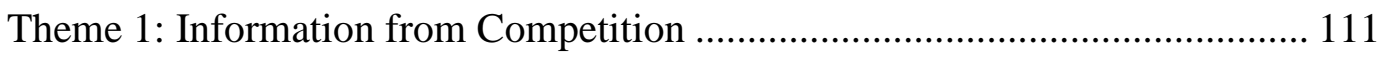

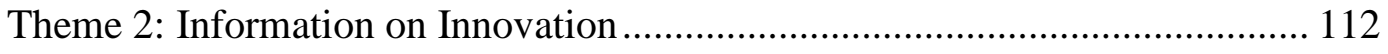

Theme 3: Information from Customers Services............................................... 113

Theme 4: Knowledge on Business Management .............................................. 115

Theme 5: Information from Social Media ......................................................... 116

Theme 6: Mentor and Mentee Relationship....................................................... 118

Theme 7: Information from Workshop and Seminars ....................................... 119

Theme 8: Information from Macroeconomics Trends......................................... 120

Theme 9: Identification of Business opportunities ........................................... 121 
Theme 10: Knowledge through Promotion of Existing Product

Theme 11: Knowledge from Feasibility Study ........................................... 123

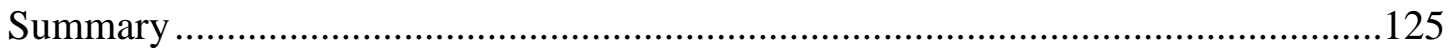

Chapter 5: Discussion, Conclusions, and Recommendations ....................................126

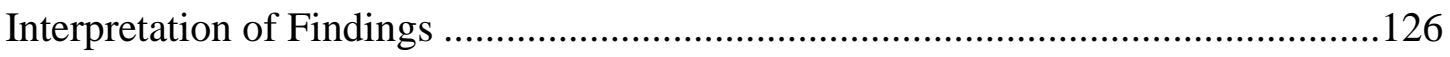

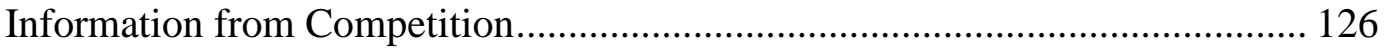

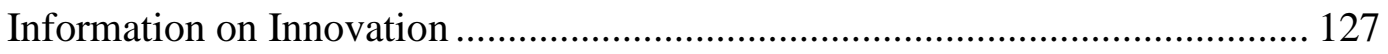

Information from Customers Services ..................................................... 128

Knowledge of Business Management.......................................................... 129

Information from Social Media ................................................................ 129

Mentor and Mentee Relationship ............................................................ 130

Information from Workshop and Seminars ............................................. 131

Information from Macroeconomics Trends ................................................ 131

Identification of Business Opportunities .................................................... 132

Knowledge through Promotion of Product ..................................................... 132

Knowledge from Feasibility Study ......................................................... 133

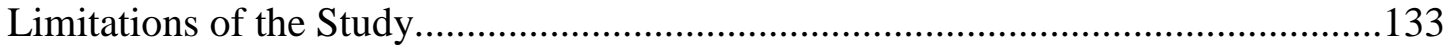

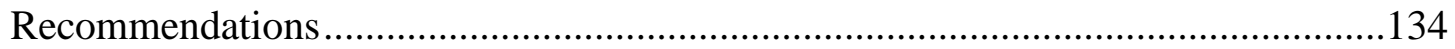

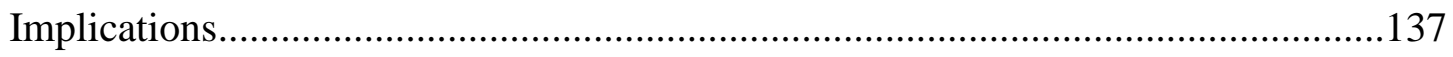

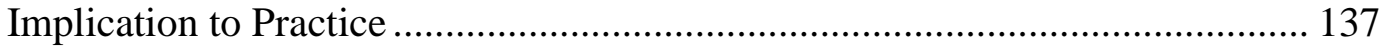

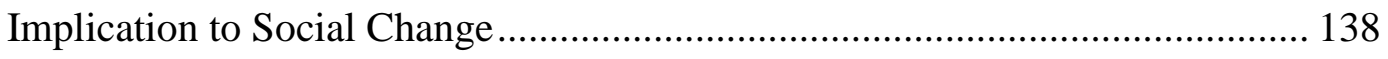

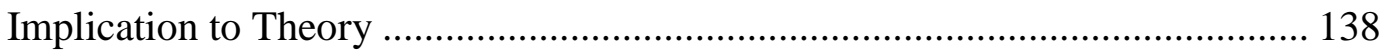


Conclusion

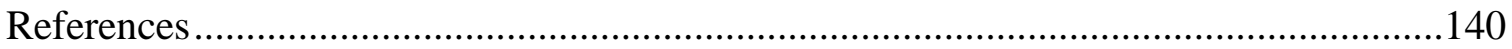

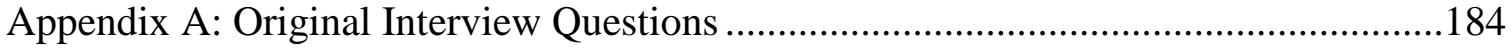

Appendix B: Request to Participate in an Expert Validation ........................................185

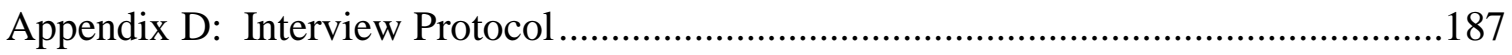

Appendix E: Email to Research Participants ....................................................................189 


\section{List of Tables}

Table 1. Demography of Research Participants.................................96

Table 2. The Gender Composition of the Sample................................97

Table 3. Case Study Research Question and Interview Questions.....................108

Table 4. Theme Generation from the Motivational Factors........................109

Table 5. Theme Generation from Personal Interest..............................110 
Chapter 1: Introduction to the Study

Nigeria is confronted with a high rate of youth unemployment as a result of inadequacy in entrepreneurship skills acquisition (Fems, Poazi, \& Opigo, 2017). With over 150 institutions of higher learning across the country, over 500,000 Nigerian graduates emerge every year from different disciplines in addition to those who study outside of Nigeria and come back to Nigeria to search for jobs (Fems et al., 2017). Although $20 \%$ of graduates with either a Master's degree or Bachelor's degree gain employment after graduation, about 5.3 million Nigerian youths are unemployed as of 2016 (Fems et al., 2017). Substantial research has been conducted on entrepreneurship development in Nigeria; however, the knowledge on entrepreneurial skills needed for self-employment have not been sufficiently explored (Aligba \& Fusch, 2017).

Consequently, many graduates continue searching for jobs because they lack knowledge on the entrepreneurial skills necessary to become an entrepreneur. The problem of unemployment has created the need for a further study of how undergraduates from 2125 years old in Nigeria can obtain knowledge on the entrepreneurship skills required for self-employment (Ackah-Baidoo, 2016). Using a qualitative multiple case study, I focused on exploring how 15 undergraduates had obtained knowledge of the entrepreneurship skills required for self-employment.

\section{Background of the Study}

Entrepreneurship training is important for the development of the social economics of any nation particularly with regards to less developed or underdeveloped countries like those found in Sub-Saharan Africa (Nielsen, \& Gartner, 2017). Most of 
those countries have natural resources and mineral deposits that could be used to improve the quality of life of its citizenry (Ackah-Baidoo, 2016). Despite the huge potential for growth, these countries leaders have not leveraged on the massive and enormous benefits derivable from these natural resources to strategically position their economies for growth (Ofili, 2014). The lack of capacity for growth has led business and political leaders to not make resources available for entrepreneurship, thereby making business expansion difficult and setting back economic growth (Othman \& Nasrudin, 2016). This setback has led to an unemployment problem within the Sub-Saharan region. In Nigeria, the problem of unemployment could be attributable to the none implementation of past industrialization policies, infrastructural development, and disorganized as well as arbitrary policies direction of government and its organs with regards to the provision of a suitable environment for job creation (Othman \& Nasrudin, 2016).

The inconsistent and disorganized policy implementation has led to high youth unemployment rates within the region which has been coupled with low incomes and living standards across a majority of the Nigerian population (Houghton, Casey, Shaw, \& Murphy 2013). The development of entrepreneurial skills through entrepreneurship education programs for the students has become imperative in universities and polytechnics in Nigeria (Mulloth, Kickkul, \& Gundry, 2016). Using the universities and polytechnics as the medium for educating young entrepreneurs through these entrepreneurship programs should attract the attention of the governments in the SubSaharan countries to develop the consciousness among its citizenry, especially in Nigeria. From extensive document review research, Ruiz, Soriano, and Coduras, (2016) concluded 
that the readiness for entrepreneurship exists in Nigeria, but a deliberate policy and implementation mechanism to develop a system that would enable students to gain knowledge on the entrepreneurship skill that leads to self-employment is lacking. Using a quantitative study of data from the National Bureau of Statistics, Siddique, Rahman, and Hook (2015) using quantitative study from the National Bureau of Statistics (NBS) highlighted the lack of functional educational facilities and the need to modify and alter education policy towards job creation through entrepreneurship education and provision of employment.

The Niger Delta region in Nigeria has significant hydrocarbon deposits. It is an oil-producing region with multinational oil and gas exploration and production companies having facilities at various locations in the region (Fems et al., 2017). The enactment of the local content policies intended to indigenize and domicile jobs in the country has increased the usage of the nation's human resources in the petroleum subsector (Ovadia, 2014). However, Ovadia (2014) articulated that even though Nigeria and Angola accounted for $75 \%$ of oil production in Sub-Saharan Africa, due to violence and poor governance structures, these volumes of natural resources had not translated to an increase in employment placement for oil-bearing communities and the host countries.

The two problems that have affected the Niger Delta region of Nigeria are youth restiveness and the falling prices of crude oil and gas in the global oil market which has led to declines in revenue and economic activities (Fems et al., 2017). Youth restiveness has resulted in oil companies relocating business offices that employ workers and its affiliated subsidiaries and enterprises away from the Niger Delta region in Nigeria to 
other regions which has significantly affected the availability of employment opportunities in the Niger Delta region (Ovadia, 2014). Because of these reasons my study that focused on how undergraduates between the ages of 21-25 years old may gain knowledge on the entrepreneurial skill required for self-employment is significant. In this study I aimed to complement previous research efforts in entrepreneurship in Nigeria by exploring the entrepreneurial skills needed by undergraduates to be self-employed and employers of labor.

\section{Problem Statement}

Youth development and the improvement of knowledge on the entrepreneurship skills required for self-employment have been excluded from the undergraduate level learning curriculum of universities in Nigeria (Ackah-Baidoo, 2016). The general problem was the exclusion of entrepreneurship skills from the learning curriculum has resulted in an increase in graduate unemployment rate from $18 \%$ in 2014 to $22 \%$ in 2015 (Achinewhu-Nworgu, Azaiki, Babalola, \& Achinewhu, 2016; Babalola \& Ayuba 2015). This exclusion and neglect of entrepreneurship led to undergraduates not taking up entrepreneurial modules during the period of their studies in the universities. Resulting in the lack of sufficient youth developmental initiative and knowledge on entrepreneurial skills required for self-employment in the larger Nigerian society (Ackah-Baidoo, 2016).

The specific problem was that undergraduates from 21-25 years old in Nigeria lack the entrepreneurial knowledge required for self-employment (see Abdullahi, Adekeye, \& Balogun 2014). The topics of youth unemployment and entrepreneurship have been studied by researchers who focused on the contribution of women entrepreneur 
to economic growth and development (Edoho, 2016; Siddique et al., 2015). However, no research had been conducted on how undergraduates from 21-25 years old could obtain the entrepreneurial knowledge required for self-employment (see Ofili, 2014; Ovadia, 2014).

\section{Purpose of the Study}

The purpose of this qualitative exploratory multiple case study was to gain a robust common understanding of how undergraduates from21-25 years old could obtain the entrepreneurial knowledge necessary for self-employment in Nigeria. The participants in this study were four graduates from each of the three local government areas (LGAs) and three graduates from the fourth LGA in Nigeria, who had had prior knowledge of entrepreneurial skills and had been self-employed for the last 3 years prior to their participation. I purposely selected the sample population of the 15 research participants and obtained data from them using semistructured interviews, field notes, and documents reviews.

Guided by the inclusion and exclusion criteria for the recruitment of the sample population, I approached the young entrepreneurs and conducted face-to-face interviews with them in locations of their choices. I took field notes during the interview sessions to obtain a better understanding of the issues under exploration and also reviewed archived documents to ascertain the correctness of some business information provided by the participants. The archived documents included years of registration and income and expenditure accounts from the young entrepreneurs that had been in business for 3 years prior to their participation in this study. 


\section{Research Questions}

The research question for this qualitative multiple case study was:

$\mathrm{RQ}$. What is the common understanding of how university undergraduates from 21-25 years old could obtain entrepreneurial knowledge required for self-employment in Nigeria?

\section{Conceptual Framework}

The conceptual framework for this study was the theory of planned behavior (TPB; Ajzen, 1991). The TPB is used to explain the process of new venture creation in entrepreneurship research (Heuer \& Kolvereid, 2014). In this study, I applied the TPB as a framework for the analysis of a voluntary-based behavioral set up including entrepreneurial behavior. The theory is applicable to the prediction of lifestyle changes and the assessment of venture creation behavior (Vanevenhoven \& Liguori, 2013). The TPB has a direct link with educational processes and intention analysis by assessing the role of education in the intention formation process (O'Connor, 2013). The TPB is a suitable lens for considering the antecedents of entrepreneurial intentions formation through perceived behavioral control; personal attitude and subject norm; these intentions in combination, these intention lead a student towards entrepreneurship as a career path (Rauch \& Hulsink, 2015).

The TPB is useful in stimulating entrepreneurial skills and knowledge as well as how economic performance links with higher level educational attainment is particularly common among entrepreneurs (O'Connor, 2013; Rauch \& Hulsink, 2015). In their study, Heuer and Kolvereid, (2014) identified a strong direct relationship among participants in 
extensive education programs in entrepreneurship and entrepreneurial intention with a longer duration accounting for increased interest and intention. In a comprehensive study that involved over 18,000 students, and spanned over 70 counties and 400 universities, Vanevenhoven and Liguori, (2013) examined the impact of education using an education project and presented interesting questions on the prediction of lifestyle changes that needed to be explored further in future research. However, the research concluded that the changes in lifestyle prediction during the early years in the university provides insights to university counselors to guide student in taking up entrepreneurial module as part of their study (Vanevenhoven \& Liguori, 2013).

\section{Nature of the Study}

I used qualitative research method for this study was qualitative research. The three possible research methodologies are quantitative, qualitative, and mixed methods (Patton, 2002). Goertz and Mahoney (2013) demonstrated that the qualitative method of study was mostly adopted and used by a researcher when an issue needs to be understood and comprehended in an in-depth and elaborate way. The qualitative method was suitable for this study because the concept I explored was entrepreneurship, and the suitability was anchored by the fact that qualitative method provides an in-depth understanding of a case (see Campbell, 2014). The qualitative interviewing of an individual helps reconstruct events that I as the researcher have never experienced, and it allows the researcher to create a portrait of a complicated process by putting together descriptions from separate participants (see Corbin \& Strauss, 2015). 
Quantitative research studies the relational, causal or predictive type of research question and deals with operationalization (Frankfort-Nachmias \& Leon-Guerrero, 2015). This method was not suitable for this study because I did not intend to identify the effect of an action on a process or the influence a decision on a process about an intervention or the relationship of an action on a process. I did not conduct this study to be deductive, nor did I test or compare any variables for acceptance or rejection of theory (see Goertz \& Mahoney, 2013). Mixed methods was also not suitable for this study as mixed methods contain both qualitative and quantitative elements of research (see Janssens, Van Zadelhhoff, Loo, Widdershoven, \& Molewijk, 2014). The quantitative research elements of the mixed methods make it unsuitable for this study.

I used a multiple case study design to gain an in-depth understanding of how undergraduates from 21-25 years old could acquire the entrepreneurial skills required for self-employment among Nigerian youths. Hollweck (2015) indicated that the case study allows for an in-depth understanding of a situation from a broader perspective with its data from several sources. The case study is appropriate when inadequate theories exist, and there is the possibility that a new theory might be developed as the result of the research (Marland \& Giasson, 2013). The case study design is predicated on the purpose of the study and the type of data to be collected (Denzin \& Giardina, 2014).

I chose the case study approach for this study over the grounded theory approach, the Delphi technique, the phenomenology approach, and the ethnography approach respectively. The grounded theory was not suitable for the study, because my goal with the study was not to birth a new theory, and appropriate explanations for the phenomenon 
of entrepreneurship already existed (see Corbin \& Strauss, 2015; O’Connor, 2013). Given that my intention was not to discover or formulate a theory, a qualitative grounded theory design was not appropriate (see Patton, 2015). The Delphi technique was not suitable for this study because I did not use organizational protocols that needed to be established to understand better divergence nor a survey of the mode of data collection; I interviewed the participants in the field (see Morse, 2015). The phenomenology design was not suitable for this study because the study was externally focused while researchers using phenomenology are focused internally on the individual and have participants describe their lived experiences of making a decision (Gee, Loewenthal, \& Cayne, 2013). The ethnography design was not suitable for this study because it does not deal with the social behavior of a group but rather deals with the knowledge of entrepreneurship skill of undergraduate degree holders in Nigeria (see Van Maanen, 2015).

\section{Assumptions}

The assumption of a study provides an alternative that was intended to materialize a solution and can be used to examine multiple courses of action that outline the steps needed to evaluate options and proceed with the most appropriate choice (Denscombe, 2013). Mertens (2016) described assumptions as models used by stakeholders in a given industry or subsector of an economy about the nature of the problems being addressed by the designs, implementation, and evaluation of an intervention to address the issue under observation or study. Morrow and Nkwake (2016) using transformative mixed methods research argued that assumptions can clarify the origins of differences in evaluation 
approaches where the program was designed to solve the problem, and the approach was to evaluate the appropriate context.

My first assumption in this study was that after graduation from tertiary institutions, participants would exhibit knowledge of the entrepreneurial skills, necessary to become self-employed and employers of labor. The second assumption was that participants provided accurate and appropriate information to the interview questions that I could use to answer the research question. My third assumption was that the interview environment was comfortable and the participants were available during the period of the interview. The fourth assumption was that the participants understood and answered the questions asked during the interview. Lastly, I assumed that the research participants will have confidence and trust in the safety of their identities that allowed them to respond cooperatively and consentingly to the interview questions reflecting their experience in gaining knowledge on entrepreneurial skills.

\section{Scope and Delimitations}

The scope of study provides for the boundaries of the study (Robinson, 2014). In this study, the main boundary was the sample population which composed of graduates from 21-25 years who became self-employed after graduating from universities. These graduates used their knowledge of entrepreneurial skills gained during their period of study in the university to become self-employed and employers of labor. The selfemployed graduates had used those entrepreneurial skills in the last 3 years to improve their businesses. The participants in the study were 15 graduates, four participants from each of the three LGA and three participants from the fourth LGA in Nigeria. I asked 
each participant to answer open-ended questions in semistructured interviews. My explanation of the findings of this study and detailed descriptions may allow readers and future researchers to make informed decisions about the issues of transferability.

The delimitations of the study allow the researcher to narrow the scope of the study by establishing the parameters of the participants and the location of study (Kirkwood \& Price, 2013). Bloomberg and Volpe (2012) described delimitations as the conditions that a researcher intentionally imposes to limit the scope of a study. The participants I selected for this study were 21-25 years old undergraduate degree holders who were entrepreneurs: Four from three of the LGAs and three from the fourth LGA in Nigeria. The participants were young entrepreneurs that had been self-employed in the last 3 years. The exclusion criteria for this study included graduates from 21-25 years old that were not self-employed but that were paid employees of other organizations.

\section{Limitations}

The limitation of a study relates to the possible intent and procedural weaknesses of the study (Morse, 2015). In a qualitative study, inherent issues exist related to validity, reliability, and generalization of the study (Katz, 2015). The first limitation of this study was the nature of the study; in a qualitative study, data are collected from the participants without empirical analysis to it (Morse, 2015). To minimize the bias associated with the collection of qualitative data, I used both transcription and member checking to ensure dependability of data collection process (see Ravitch \& Carl, 2016). The second limitation was that the participants might not be available during the data collection 
period. To reduce this limitation, I planned on a time that was convenient for each participant to participate in the data collection process.

NVivo 11 software provides the possibility of an audit trail and flexibility that might enhance the dependability and confirmability of the study (Houghton et al., 2013). I used NVivo 11 to provide an audit trail of the information obtained from the individual interviews that might be inaccurate and misleading if participants were not truthful in the answers they provided to some questions. The use of semistructured interviews does not allow for the generalization and comparability of the findings, but the findings serve and can be used for contextually understanding of the study (Miles \& Huberman, 2014).

\section{Significance of the Study}

This study was essential investigating the content and context of knowledge on the entrepreneurial skills needed to improve students' learning and the application of skills and behavior intended to create value for undergraduate degree holding entrepreneurs (see Gundry, Ofstein, \& Kickul 2014). The global economic downturn and the subsequent shift in the marketplace and societal needs of Nigeria have increased the need for talented and creative undergraduate degree holders to proffer breakthrough solutions to persisting business and societal problems. Creativity and innovation are becoming vital tools for societal growth and prosperity (Korsgaad, Anderson, \& Gaddefors, 2016). The result of this study might promote positive social change by contributing to the creation of a culture of innovation among undergraduate degree holders in Nigeria. 


\section{Significance to Practice}

The result of this study may be useful to management scholars and researchers regarding the development of new strategies for tackling the scourge of unemployment in Nigeria. The result of the study might lead to the generation of information relating to entrepreneurial learning skill development. This finding might be substantial for leaders of government for policy making, implementation, job creation and the education subsector. The results of this study might provide pieces of evidence on how leaders of tertiary institutions' commitment to entrepreneurship education could lead to the creation of employment that empowers the entrepreneur towards national growth and development and provide the empirical evidence needed to support entrepreneurship education and skill development. Finally, the result may benefit the field of management by developing a new theory that can help organizations more efficiently develop skill sets for entrepreneurs and entrepreneurial skill development.

\section{Significance to Theory}

The existing literature on entrepreneurship has not included topic on the lack of knowledge on the entrepreneurship skill required for self-employment in Nigeria (Edoho, 2016; Ofili, 2014). The research findings from this study might reveal additional information how on undergraduates from 21-25 years old could acquire the entrepreneurship skills to become self-employed and employers of labor in Nigeria. Future scholars of leadership and management might find the result of this study useful when looking at the entrepreneurship skill development as a means of resolving the unemployment dilemma in the region and proffer suggestions for growth and 
development. The results of this research might also benefit the leadership of educational institutions in better understanding of how to manage the educational policy as it relates to entrepreneurship skills development, job creation, and unemployment reduction. The finding of this study might contribute to the body of knowledge on entrepreneurship development in Nigeria and provide the basis for future research by students and researchers concerning the impact of entrepreneurship education policy on societal growth and development.

\section{Significance to Social Change}

Positive social change is about solving social issues, which leads to social progress and can also lead to an efficient economy (O’Cass \& Griffin, 2015). Positive social change is a contemporary topic that drives almost all areas of human endeavor from the academia to governance to the private and public sector including multinational corporations (Hyett, Kenny, \& Dickson-Swift, 2014). Positive social change can vividly influence the lives of many, making a little impact that positively affects the lives of others is a hugely rewarding process (Stephan, Patterson, Kelly, \& Mair, 2016). The research findings from this study might have a potential implication of positive social change in the lives of the young unemployed adult in Nigeria. Unemployment problems may be better addressed through the knowledge I obtained in this study, and this might lead to paradigm shift in undergraduate degree holders will stop the search for white collar job to becoming self-employed after graduating from universities. 


\section{Summary and Transition}

The activities of oil and gas exploration have contributed to the economic development of the Niger Delta region of Nigeria, but has also led to some environmental problems and unemployment challenges owing to companies' little compliance with the regulations and international standards and best practices concerning the environment and wealth creation ((Othman \& Nasrudin, 2016). Government at the federal and state levels have not fulfilled promises of job creation, improved standards of education, and mass education for the citizens, nor other social contracts such as the provision of a favorable environment for investment to thrive ((Othman \& Nasrudin, 2016). The purpose of this qualitative, exploratory, multiple case study was to gain a robust, common understanding of how undergraduates from 21-25 years old can obtain the entrepreneurial knowledge required for self-employment in Nigeria. In summary, Chapter 1 contained alignment of the problem statement, the purpose statement, the research question, and the conceptual framework. The participants of this study were 15 graduates from 21-25 years old who were entrepreneurs and had gained knowledge of the entrepreneurial skills necessary to become self-employed and employers of labor during their period in study in tertiary institutions.

Chapter 2 will contain the literature review, my synthesis and evaluation of previous studies, and an analysis of possible gaps in the existing literature matched to the research topic. In the literature review section of Chapter 2, I will discuss the conceptual framework of the TPB as it relates to empowering people to transcend the constraints placed on them by race, class, and gender. I will also discuss the relationship that exists 
among the promotion of entrepreneurship, stimulation of entrepreneurial skills and knowledge, how economic performance links with higher level educational attainment that is common among entrepreneurs as the underpinning theme to the study. 


\section{Chapter 2: Literature Review}

The specific problem I addressed in this study was that in Nigeria, undergraduate from 21-25 years old lacked the skill and abilities to obtain the entrepreneurial knowledge required for self-employment (see Abdullahi et al., 2014). The exclusion of entrepreneurship skills from the learning curriculum in Nigeria resulted in an increase in the graduate unemployment rate from 18\% in 2014 to $22 \%$ in 2015 (Achinewhu-Nworgu et al., 2016; Babalola \& Ayuba 2015). The purpose of this qualitative, exploratory, multiple case study was to gain a robust, common understanding of how undergraduates from 21-25 years old can obtain the entrepreneurial knowledge required for selfemployment in Nigeria. The participants were 15 graduates, four graduates from each of three LGAs and three graduates from the fourth LGA in Nigeria, who had been selfemployed within the last 3 years.

I conducted a literature review to recognize relevant and updated literature that may diverge or converge with the provision of knowledge on the entrepreneurial skills required for self-employment among youths in Nigeria. In the literature review, I evaluated the characteristic attributes of entrepreneurship which served as the background of the research question. To help in answering the research question and synthesizing the past literature on youth entrepreneurship, I appraised peer-reviewed journals articles.

In the beginning section of Chapter 2, I will present my synthesis of previous literature regarding the youth entrepreneurship process that shapes the successes and failure of several economies. In the next part of the section, I will provide the conceptual framework for the study. The last section of the literature review will contain past 
research on youth entrepreneurship and youth vocational training that had not been previously gathered to fill the gap that existed in the literature. I could find no existing literature on undergraduate in Nigeria and how they can acquire knowledge on entrepreneurship skills required for self-employment.

\section{Literature Search Strategy}

The literature review is an important part of the study because it provides the synthesis and structure of previous related studies. The literature review provides a theoretical underpinning for the planned empirical study and validates the planned research as one that has the potential of contributing to the body of existing knowledge (Salah, Ratajeski, \& Bertolet, 2014). The literature review supports the research methodologies, research questions, and the purpose of the proposed study (Santos \& Da Silva, 2013). My objective with this literature review was to present a comprehensive assessment of how undergraduate from 21-25 years old in Nigeria, can acquire knowledge on the entrepreneurship skills required for self-employment.

The literature review included findings from recent literature and studies on the topic of youth entrepreneurship and training. The articles in the review are comprised scholarly peer-reviewed journal articles published within the last 5 years. To locate these articles, I searched the following databases: Academic Source Premier, EBSCOhost, ProQuest, Emerald, Sage, and Business Source Premier. The keywords I used in the searches included capital theory, opportunity-based entrepreneurship, necessity-based entrepreneurship, entrepreneurship, the concept of entrepreneurship, entrepreneurship \& economic development, entrepreneurship intent and motivation, risk-taking in business, 
creativity, and alertness. I also conducted other searches using the following terms: management and leadership skills, optimism and self-confidence, education and youth entrepreneurship, knowledge of entrepreneurship education, higher education, entrepreneurship education, youth entrepreneurship in Nigeria, youth entrepreneurship in Ghana, and youth entrepreneurship in South Africa. To comply with the 85/15 ratio, I synthesized articles I found in journals such as International Journal of Business and Social Science, Journal of Business Diversity, International Journal of Research, Economic Insights Trends and Challenges, African Journal of Applied Research, and European Journal of Sustainable Development. Other sources included International Journal of Sustainable Agricultural Research, Public Policy, and Administration Research, International Journal of Gender and Entrepreneurship; The Qualitative Report; and Qualitative Market Research: An International Journal.

\section{Conceptual Framework}

I used the TPB (Ajzen, 1991) to guide this study as the conceptual framework. The TPB is used to illustrate the process of new business creation in the domain of entrepreneurship research (Heuer \& Kolvereid, 2014). In this study, I applied the TPB as a framework for the analysis of a voluntary-based behavioral set up including entrepreneurial behavior. Additionally, the theory finds its utilization in the forecasting or prediction of lifestyle changes in assessing venture creation behavior (Vanevenhoven \& Liguori, 2013). The TPB has a direct link to educational processes and intention analysis by assessing the role of education in the intention formation process (Kautonen, Van Gelderen, \& Tornikoski, 2013). Further research on TPB has shown to have an extension 
of antecedents of entrepreneurial intentions formation through perceived behavioral control, personal attitudes, and subject norms; in combination these antecedents affect a student choice of entrepreneurship as a career path (Asghar, Hakkarainen, \& Nada, 2016; Robinson \& Josien, 2014).

Heuer and Kolvereid, (2014) attested to a close linkage between participation in prolonged and elaborate education programs in entrepreneurship and entrepreneurial intention with a longer duration accounting for increased interest and purpose. Recent studies have found that TPB was useful in invigorating entrepreneurial skills and knowledge as well as how economic productivity links with higher level educational accomplishment that was common among entrepreneurs (O'Connor, 2013; Rauch \& Hulsink, 2015). In a comprehensive study that consisted of over 18,000 students and spanned over 70 counties and 400 universities, Vanevenhoven and Liguori (2013) examined the impact of education using an education project and presented interesting questions that needed to be explored further in future research. However, the research concluded that the changes in lifestyle prediction during the early years in the university provides insights to university counselors to guide student in taking up entrepreneurial module as part of their study (Vanevenhoven \& Liguori, 2013).

\section{Theory of Planned Behavior}

I used the TPB to explain the process of new venture creation in this study, with the central focus of entrepreneurship research. Aloulou (2016) appraised entrepreneurship as a fundamental priority that was essential for sustainable economic development and the creation of competitiveness, innovation, job creation and personal self-actualization. 
Promoting entrepreneurship is viewed as a potential solution to the unemployment of young people (Brouwer \& Mosack, 2015). Aloulou proposed that entrepreneurship was a planned behavior rather than a response to a stimulus. Aloulou used the TPB to predict the formation of entrepreneurial intentions of final year Saudi University business students. No study has been conducted on how the TPB could be used to predict the formation of entrepreneurial intentions of undergraduates in Nigeria up to this point (Thoradeniya, Lee, Tan, \& Ferreira, 2015).

Brouwer and Mosack (2015) broke the TPB down into three categories: (a) attitude towards conduct, (b) subjectivism, and (c) perceived behavioral control. Attitude towards behavior is when the intended entrepreneurs are judged by the desired behavior either good or bad (Brouwer \& Mosack, 2015). The SN refers to what the social group thinks about the intended entrepreneurs' intentions, and $\mathrm{PBC}$ is the intention to perform the behavior of entrepreneurship (Thoradeniya et al., 2015). On the other hand, Sommestad, Karlzen, and Hallberg (2015) stated that the TPB could be used as a lens if (a) the behavior is specific, (b) it is possible to conceive it as a causal factor of behavior, (c) it is conceptually different from existing predictors, and (d) it can consistently improve prediction of intentions.

\section{The Concept of Entrepreneurship}

According to literature, entrepreneurship has been a subject of deliberation between researchers and practitioners for several years (McClelland, 1965; Schumpeter, 1934). The concept has gained strength and continued to grow in part due to a younger generation that decided to take entrepreneurship as a career and be self-employed rather 
than work for established firms and organization (Schumpeter, 1934). Chief among the various reasons that made the younger generation make this decision was to earn income, generate money, and uphold values (Korsgaad, et al., 2016). Entrepreneurs consider the need to manage time and finances as freely as they can and the freedom to think through, create, execute and monitor what they want as a strong point in the aspiration to become self-employed and employer of labor (Schumpeter, 1934).

The origin of the modern-day history referencing scholarly research into the term entrepreneurship was traceable to the seminal works of Richard Cantillon, the renowned economist, whose immense contribution to the field of entrepreneurship may have given rise to as many definitions with regards to the number of scholars on the subject matter (Nielson, 2016). The absence of a standard definition of entrepreneurship makes the phenomenon complicated in practice for some people (Nielson, 2016). The definition that Schumpeter (1934) proposed formed the basis for many modern definitions, which have undergone various transformations through the years. Schumpeter described entrepreneurs as innovators who exploit opportunities in a variety of ways. In this context, change implies a means to initiate innovation and development (Korsgaad et al., 2016). The key feature of Schumpeter's definition was innovation; the definition focuses on the recognition of innovation as a key strategy to exploit market opportunities.

Drucker (1986) followed the steps of these pioneers and carried out further seminal works comparing entrepreneurship with the creation of a new venture. Ronkko and Lepisto (2015), however, disagreed and opined that creating businesses does not provide a holistic perspective of entrepreneurship. In their qualitative research that 
involved 10 Irish women business owners (entrepreneurs) as participants, Humbert and Brindley (2015) reported that the transformation and expansion of existing businesses into productive enterprises was a key feature of the definition proposed by the United Nations Industrial Development Organization. In their definition of entrepreneurship, Humbert and Brindley suggested that a relationship exists between entrepreneurship and a person's behavioral traits and cognition; nevertheless, this assertion was on the premise that people are the main agents of entrepreneurial activity in which choice plays a pivotal role. Maritz, Jones, and Shwetzer (2015) expressed entrepreneurship as a form of intentional activities. The literature also provided evidence of the close relationship among intentions, goals, and motivation, as well as the vital role they play in entrepreneurship (Baker \& Welter, 2017). Moreover, the ideologies and definitions of entrepreneurship proposed by these researchers are relatively consistent with the main theories that constitute the framework of the current study.

Other researchers further expanded that the TPB stipulates a close relationship between attitudes and behaviors (Macht \& Ball, 2016). The theory of motivation, also called the acquired-needs theory, states that individuals acquire specific needs over a given period, and the personal experiences of the individual influences need significantly (McClelland, 1965). Maritz and Brown (2013) evaluated the beliefs of people and stated the beliefs of people could reveal the distinct factors that influence an individual to engage in certain behavior differently from another individual. Maritz and Brown contended that intentions largely determine the performance of certain behaviors; they found that intention was an indication of the degree of willingness and effort of 
individuals to engage in a particular behavior. In studying entrepreneurship, intentions play a pivotal role in the relationship between an individual's beliefs and actual behavior (Baker \& Welter, 2017; Coad, Frankish, Roberts, \& Storey, 2016).

The intention to perform a specific action represents the first step towards embarking on an entrepreneurial career (Maritz et al., 2015; McClelland, 1961). Research conducted by Ronkko and Lepisto (2015) distinguished among three dimensions of motivation, namely the necessity of achievement, the need for affiliation, and the need for power. These dimensions of motivation constitute various aspects of an individual's need, particularly concerning creating the impetus for entrepreneurship (Baker \& Welter, 2017). Ronkko and Lepisto's research contextualized and asserted that motivation was a fundamental requirement for entrepreneurship; the absence of motivation impedes any plan for development because the lack of enthusiasm to earn more than was necessary for survival makes the individual devoid of the necessary impetus to accomplish specific objectives. In the following sections, I will provide an in-depth analysis of the entrepreneurship discipline about my research objectives in this study.

Entrepreneurship and economic development. The perceived role of entrepreneurship in economic development has continued to generate much research among scholars. Globally, researchers suggest that entrepreneurship was a driver of economic growth and development (Galindo \& Mendez-Picazo, 2013). In their writings and in a paper presentation on empirical analysis on entrepreneurial activities in 13 developed countries for 5 years (2002 -2007), Galindo and Mendez-Picazo presented the relationship among entrepreneurship, innovation, and economic growth argued that 
innovations and entrepreneurship share positive relationships with economic growth. For nearly a decade, a key policy objective of many countries has been to develop an economy that was inherently entrepreneurial (Edoho, 2015; Hafer, 2013).

A primary function of entrepreneurship was the creation of new ventures (Cumming, Johan, \& Zhang, 2014; Marcotte, 2014). Hence, creating new ventures was an important and globally acceptable means to generate employment opportunities (Casero, Gonzalez, Martinez, \& Mogollon, 2013) and, by extension, reduce joblessness and poverty while fostering economic growth. For example, in study conducted to evaluate the economic benefits of entrepreneurship in developing countries, Casero et al. found and acknowledged that being self-employed provides an escape route from poverty.

Similar investigations indicated that the increasing global competition, deemed as a direct effect of globalization, justifies the need to promote entrepreneurship (Dutta \& Sobel, 2013; Ebiringa, Ekwenwa, \& Ebiringa, 2015). Kasseeah (2016) expanded the discussion by also concurring and asserting that the theory of long waves propounded by Joseph Schumpeter offered the most obvious basis for the assertion that entrepreneurship drives economic growth and development. According to Schumpeter's (1934) theory, which focuses on the concept of creative destruction, entrepreneurial activities typically create new combinations through a discovery process that often results in new products and better ways to satisfy human needs. Entrepreneurship creates new ventures; the creation of new ventures creates employment opportunities, resulting in economic growth 
and development of society (Drucker, 1985; Rangnekar, 2009). Consequently, the role of innovation in societal development cannot be overemphasized.

McNaughton and Gray (2017) asserted that innovation was an essential requirement to meet the demands of customers, exploit technological advancement, and survive the growing competition. Hence, the innovative activities of entrepreneurs, through human actions, produce technological changes that enhance the economic growth of any society (Chikweche \& Fletcher, 2017). Furthermore, in evaluating the importance of promoting entrepreneurship, the role of small and medium enterprises (SMEs) cannot be overemphasized. Studies indicate that SMEs are principal drivers of economic development. SMEs represent an integral part of the private sector and have immense potential for job-creation (Chikweche \& Fletcher, 2017). Additionally, SMEs play a crucial role in reducing poverty, particularly in developing economies (Ndubisi, 2014). McNaughton and Gray (2017) reported that in Africa, for example, the SME sector accounted for over 3 million jobs and nearly $20 \%$ of Kenya's gross domestic product (GDP) in 2003; the SMEs accounted for approximately $50 \%$ of South Africa's GDP in 2004 and over $90 \%$ of the manufacturing sector in Nigeria in 2005. These statistics underscore the significant function that the private sector plays in a nation's sociopolitical and socioeconomic development and advancement, emphasizing the need for governments to pay closer attention and focus on developing the private sector.

Economists have remained unequivocal in the clarion call for governments to support the private sector (Casero et al., 2013). Kasseeah (2016) suggested the need for the Nigerian government, public establishments, and private organizations invest in 
entrepreneurship programs as a key strategy to address youth restiveness, which in turn, improve the socio-economic and socio-political climate in the region. Marcotte (2014) argued that governments owe small-scale businesses responsibility to provide both financial and infrastructural support. Hafer (2013) emphasized further the need for governments to provide education and training for workers, which are critical requirements to ensure the growth and survival of new businesses.

Although researchers have suggested that the government of a nation is responsible for creating the enabling environment to foster entrepreneurial development by instituting policies, entrepreneurship programs, and infrastructure (Binnui \& Cowling, 2016; Edoho, 2015). Entrepreneurs play a significant role in ensuring that the efforts of government realize the desired objectives (Galindo \& Mendez-Picazo, 2013). The government can achieve the fostering of entrepreneurial development through the encouragement of individual and institutions to create jobs and wealth by influencing policies that establish an environment for the provision of infrastructures that support the emergence a productive entrepreneurial hub and clusters for entrepreneurial-minded individuals to take advantage of such facilities and infrastructures. Mulloth et al. (2016) concluded using the qualitative methodology that adopted a case study design using a key enabler of Prezi's success as a focus on social value creation that entrepreneurs should see the role they play as an opportunity to change the overall patterns and systems of society. Conclusively, entrepreneurship plays a highly important role in economic development; this importance was anchored on the point that the profits made by 
entrepreneurs flow into the economy thereby increasing the nation's gross domestic product.

Entrepreneurship intent and motivation. Significant information in the literature indicated that the development of skills and knowledge of graduate alone was insufficient to address the deficiency of entrepreneurship skills among youths. Motivation in the application of expertise and understanding through the creation new undertakings would provide the desired environment for youth entrepreneurship enhancement (Valliere (2014). Using the TPB, Valliere suggested that the influence and exposure of youth could be determined by the entrepreneurial intentions that the youth possesses. This intention was dependent on determinants such as (a) cultural norms and attitudes, (b) perception of feasibility, and (c) current economic trend. Educational schemes and initiatives that are centered on or concentrates mainly on the transfer of expertise and knowledge may be inefficient without motivation on youth in applying such earned knowledge on training (Valliere, 2014).

Research studies have justified the relevance of understanding entrepreneurial intentions and development of actions (Valliere, 2017). In a study, Valliere identified the motivational factors to entrepreneurial intentions in individual as (a) freedom to work your methods, (b) feeling of accomplishment, (c) intellectual stimulation, (d) performing a wide variety of activities, (e) being respected by other, (f) having opportunity for advancement, (g) being rewarded for performance, and (h) working with congenial associates. Micozzi and Lucarelli (2016) examined how new business ventures would allow economic adaptation, facilitating and contributing to employment, growth, and 
productivity as a result of market innovation and motivation. In conclusion, entrepreneurship intention must be analyzed based on personal attributes and social context in which prospective startups and business owners could live together with external variables such as the economy, cultural, and social institutions (Baker \& Welter, 2017; Micozzi \& Lucarelli, 2016).

Sustainability of the entrepreneurial intention. The entrepreneurial intention of the ideas generated needs sustenance beyond the formation stage. In consideration of the past literature, propose further that during the post-graduation era; graduates need to sustain the entrepreneurial intention beyond the walls of the educational institution (Gunn, Durkin, Singh, \& Brown, 2008; Urbano, Aparicio, Guerrero, Noguera, \& TorrentSellens, 2016). The sustainability of the intention becomes the driving force in the quest and inherent capability for the generation of jobs and income through new ventures creation (Kuckertz \& Wagner, 2010; Wagner \& Kuckertz, 2009). Scholars in the theory of planned behavior and entrepreneurship see entrepreneurship through different perspectives; Schumpeter (1934) sees entrepreneurs as innovators due to their abilities to individually introduce changes into organized economic system (Badulescu \& Cadar, 2016).

Innovation was categorized as a form of creative destruction, the sustainability of innovative attribute of the entrepreneur would mean the implementation of efforts that lead to the creative destruction to make room for products and services that affect both society and the environment (Davidson \& Gleeson, 2014; Hens, Halkias \& Thurman, 2015). The enthusiastic and knowledgeable young entrepreneur incorporated innovative 
ideas and was considered to possess the attribute that leads to sustainable entrepreneurship (Wagner \& Kuckertz, 2009). Entrepreneurship takes it origin at the individual level, through the emergence of personal values built on a conscientious decision to pursue sustainability both at the micro and macro level of the small business (Davidson \& Gleeson, 2014; Gunawan, 2014). A recent study by Gawell (2014) involving theoretical research on the observed relationship between entrepreneurship and sustainability through a research question concluded that sustainability must provide measurable benefits for entrepreneurs and this must be incorporated into the entrepreneurs' strategies. The incorporation of the strategy would lead sustainable development (Kuckertz \& Wagner, 2010). The entrepreneurial trait most significant as indicated by the study; shows that the young entrepreneur needs to proactive, autonomous and competitively aggressive to maintain a sustainable drive that benefits the bottom line of the established firm (Badulescu \& Cadar, 2016). The second inclination to the sustainable intention of the graduate was entrepreneurship influenced by perception.

Furthermore; Koe, Omar, and Majid (2014) in qualitative research on entrepreneurial inclination towards sustainability concluded that personal perceptions might influence intention toward sustainability in entrepreneurship. The characteristic that triggers such intentions that lead to the perception of sustainability is from the environment, from cultural influences and situational (Ben-ner \& Ellman, 2013; Koe et al., 2014). Other factors include market knowledge, collaborative ability, shared knowledge and procreative culture. These factors are considered to be decisive in perceptions that lead to sustainable entrepreneurial intention in undergraduates that want 
to be employers of labor and contribute to economic development of the society (Handy et al., 2000). Necessity drives the third factor that leads to a sustainable intention of the graduate. The need to solve societal problem occasioned climate changes, inequalities in the communities, socio-economic developmental needs and the creation of new processes and structures geared towards solving societal problems (Plieth, Bullinger, \& Hansen, 2012).

\section{Entrepreneurial Attributes and Characteristics}

Lafuente, Stoian, and Rialp (2015) inferred that a student could become a successful entrepreneur even without existing entrepreneurial skills and capabilities, provided that they have the entrepreneurial attitude, desirability, and support by the community. Yousaf, Shamim, Siddiqui, and Raina (2015) identified areas of concern about the attributes of entrepreneurs as (a) how students' entrepreneurial skills and capabilities contribute in developing their entrepreneurial intentions, (b) how students' entrepreneurial attributes significantly lead to entrepreneurial intentions, (c) how the desire to be an entrepreneur really transform into entrepreneurial intentions, and (d) how subjective norms contribute in developing students' entrepreneurial intentions. Walsh and Cunningham (2017) described subjective norms as the normative belief about entrepreneurship career choice which serves as motivation in shaping a student towards becoming an entrepreneur.

Risk-taking in business. Starting a business has it associated risk; engaging in entrepreneurial activities that lead to employing other people and creating to value increases the chances of the risk occurring. Marlen, Zuzana, and Helmut (2016) 
categorized business risk into (a) earlier risk; which might be estimated before a business begins, such as budget risk, duration, or inexperience of team risk, and (b) later risk; which evolve during the course of a business such as client manager or executive sponsor change. Marlen et al. further grouped risk into external and internal risks. Taking a risk becomes part of the overall business outlook, the risk is a prospect or event that may occur, and the probability of occurrence needs to be assigned through proactive gathering or buildup of relevant knowledge (Qiuying, Yue, Udechukwu, Alasdair, \& Maxwell, 2014). Risk could be attributed to political risk, economic risk, social risk, and legal risk; uncertainty could comprise (a) of uncertainty as arising from environmental unpredictability (b) uncertainty as an effect of the inability to concisely predict the nature of the impact of change. The prospective entrepreneurs need to have a fair knowledge of the risk inherent in the businesses they are embarking. Such knowledge built the entrepreneur's capacity to have a mitigating strategy in the event of the risk occurring.

Creativity and alertness. Entrepreneurship is driven by the need to create value; creativity, therefore, becomes pivotal for enterprise development and sustainability. The ability to recognize entrepreneurial opportunities is a relevant skill set needed by the undergraduates; creativity and alertness allow the entrepreneurs to see issues from a much wider perspective (Alagba \& Fusch, 2017). Martin (2016) recognized youth creativity as derivative from the opportunity to explore, pursue, and master interest that could reach far beyond school and educational settings. Creativity and alertness offer growth and job improvement (Martin, 2016); using the internet as a source of building opportunities to grow and explore while gaining expertise and experience enhances the 
young entrepreneur's creativity (Wu, Wen, Dou, \& Chen, 2015). The youth could understand the immediate environment as part of a larger learning ecology if the framework on connected learning was adopted (Wu et al., 2015). Connected learning as a framework could only be used as principles for (a) peer-support, (b) interest-powered, (c) academically oriented, (d) production-centered, (e) shared purpose, and (f) openly networked (Chan \& Chang, 2013; Martin, 2016). Scharber, Isaacson, Pyscher, and Lewis (2016) evaluated the intersections between youth literature and social justice and stated that the intersection enhanced by technology and stated that using connected network principles, youth creativity, and alertness remained unexplored.

Management and leadership skills. Leadership plays an important role in every organization's growth and development; as the leader uses results-driven attributes and skills to influence subordinates to pursue outlined goals of the firms. The development of managerial and leadership skills are attributes that young entrepreneurs need. Eva and Sendjaya (2013) inferred that leadership development in young adults early in life promotes effective cultivation of ethical mindset and values among young adults. Most development curriculum in the production of both technical and moral business lacks the ethical rigor required for leadership skills development (Wanie, Oben, Molombe, \& Tassah, 2017). Government bodies in Nigeria have outlined the dearth in the development of young leaders across the country due to the absence of positive mentors, and meaningful programs and collaborations (Khoreva \& Vaiman, 2015). Wanie et al. (2014) developed youth advocacy for competent leadership, Eva and Sendjaya recommended creating future leaders through youth leadership development. None seems 
to evaluate or analyze how undergraduates can acquire knowledge on entrepreneurship skills needed to provide jobs for themselves.

Youth optimism and self-confidence. Developing a mindset that radiates optimism and self-confidence was another attribute that the young entrepreneurs should possess. Tarling, Jones, and Murphy (2016) using qualitative research evaluated the influence of family business, and awareness of business ideas arising from immediate and extended family members create on the self-confidence of a young entrepreneur. Tarling et al. concluded that providing entrepreneurship education for a graduate increases the optimism and confidence in them to start up business. Students and graduates require entrepreneurship skills to improve employability profiles and navigate the job market in contributing to economic growth (Tarling et al., 2016). Eva and Sendjaya (2013) inferred that developing leadership attributes in young adults would result in the effective cultivation of ethical mindsets and values, as well as enhancing youth positive optimism and self-confidence.

\section{The Entrepreneur}

With the advancements in technology comes a new way of conducting business which has both positive and negative consequences. Technological advancements have opened many doors for the technological industry, education and organizations resulting in positive outcomes (Barr, Baker, Barkham, \& Kingon, 2009; Imaroh, 2016). Day-today the technology industry is thinking of new innovative ways to improve on the latest technology. Universities are shifting to offer more learning patterns that highlights endeavor suitable for gaining knowledge and skill that would lead to confidence for those 
in pursuit of education beyond the traditional format. Accordingly, just as the technology industry is improving on its technology and universities are as well seeking to expand knowledge gaining frontiers beyond the learning patterns (Imaroh, 2016).

The entrepreneurial-minded undergraduate is a person that is innovative, identifies new ideas and markets either through existing processes or creates new ventures by expanding the mode of doing business that leads to value creation within the society (Barr et al., 2009). Such personalities are characterized by their abilities to break new grounds and achieve greater potentials; they possess strong personal values and high leveled discipline both in the conduct of business on and off office environment with the potential to control event around them (Halkias, Nwajiuba, Harkiolakis, \& Caracatsanis, 2011). College students with such possibilities and personalities need to be discovered while still schooling.

The schools that have established policies and program to develop an entrepreneurial mindset to be discovered and nurtured enhance the chance of such student taking up entrepreneurship post-graduation (Magd \& McCoy, 2014). Such students are mentored and provided with the need knowledge on entrepreneurial skill development for business startups. On graduation; graduates with these sorts of qualities can contribute to the growth and development of the local economy around them through active engagement in new ventures that leads to the promotion of poverty alleviation initiatives and reduction of potential obstacles within the business environment. 


\section{Education and Youth Entrepreneurship}

Significant findings in research demonstrating that the concept of entrepreneurship is increasingly being accepted abound, particularly in the structure and composition of possible efforts and grand plan designed to enhance business startup and create new jobs for youths by agencies of government (Bennett \& Woods, 2014; Tschannen-Moran, Bankole, Mitchell, \& Moore, 2013). These efforts serve as a pivotal means and a useful strategy to boost livelihoods while ensuring the economic independence of the youths. Singh and Nayak (2016) evaluated that the rate of unemployment in a nation and stated that the unemployment rate is a reflection of the state of the economy. In a study conducted to examine the limitation and conditions that impede and militate against youths in search of jobs and the need to educate citizens of developing economies to imbibe self-employment and entrepreneurial knowledge and skills through vocational and entrepreneurial training programs.

Bennett and Woods (2014) observed the need to provide entrepreneurship development programs (EDPs) for youths. Similarly, Tschannen-Moran et al. (2013) analyzed, from their quantitative study of 860 students chosen from eight countries, the significant role that entrepreneurship education plays in promoting the interest of youths in entrepreneurship. According to Tschannen-Moran et al., the EDPs are instrumental in informing youths about business, giving them the needed insight into entrepreneurship and creating opportunities for them to start businesses.

Eva and Sendjaya (2013) inferred that training and education could improve entrepreneurs' tenacity and decision-making ability. The role of education, in influencing 
the decision students to pursue entrepreneurship and in ensuring entrepreneurial success, has remained a dominant subject among researchers (Eva \& Sendjaya, 2013). To expand this discourse on entrepreneurial training, it was relevant to explore two key aspects of education concerning entrepreneurship, namely higher education and entrepreneurial education. The literature is replete with varied ideologies on higher education and entrepreneurial education as well as the role of the undergraduates in entrepreneurial development. In the following subsections, I will focus on exploring the role of higher education and entrepreneurship education in fostering entrepreneurship development.

Higher education. The literature revealed two main forms of entrepreneurship, formal entrepreneurship and informal entrepreneurship (Eva \& Sendjaya, 2013). Eva and Sendjaya matched formal entrepreneurship with learned entrepreneurs in society, who remit taxes. The learned entrepreneurs endeavor to register businesses with the government. In contrast, informal entrepreneurs do not remit taxes to the government, they may have little or no education, and such businesses may not be registered. The growing number of educated entrepreneurs gave rise to formal entrepreneurship, particularly in western developed nations (Hannula, 2015). This ideology accentuates the claims that higher education plays a significant role in influencing the decision to become entrepreneurs and, by extension, seems to validate the argument that educated and graduate entrepreneurs are the key drivers of a nation's economy.

Entrepreneurship education. Gaining entrepreneurial education by prospective entrepreneurs is becoming increasing accepted globally. Seikkula-Leino, Satuvuori, Ruskovaara, and Hannula (2015) evaluated the YVI project (2010-2014), a national 
project in Finland aimed at developing entrepreneurship education among undergraduates on vocational education. The evaluation indicated that project sub-targets included developing pedagogy and systems in entrepreneurship education, developing a virtual learning environment for entrepreneurship learning, and creating strategies and curricula for entrepreneurship classes. In another quantitative study with 100 responses, Mandel and Noyes (2016) classified entrepreneurship education as both a method of learning and as content of knowledge. Results from the findings inferred that entrepreneurship education was about learning to become an entrepreneur, learning from the concepts in entrepreneurship, and by practical uses of entrepreneurship source of livelihood.

Knowledge sharing potential of educational institutions. The advancement in information and communication technologies has increased the need for educational institutions to remain competitive in a globalized economy. The educational institution provides the platform for knowledge sharing, knowledge sharing is an approach used by individual and institutions in the identification, acquisition, application, development, preservation, and measurement the knowledge depth of the institution (Al Saifi, Dillon, \& McQueen, 2016; Chawla \& Saxena, 2016). This has justified the need for leaders in an educational institution to take leadership positions in the determination of how effective the various faculties and departments of the institutions are in the sharing of knowledge gain through training, participation, experiences, and experiments. These institutions are designed and set out primarily to provide training and skill to the younger generation and serves as a reservoir of knowledge for organizations within and outside the regions. 
To sustain the universities' roles in the society, they have become proactive in their collective drive to lead and sustain the growth and development of the society. One of such drives was the provision of entrepreneurial skills needed by graduates to open businesses after graduations and generate profit through the reorganization and redistribution of wealth. Despite the laudable role of the educational institution in the sharing of knowledge for societal growth, limitation and impediments exist as barriers to the propagation of knowledge and its subsequent redistribution. These barriers include the attitude of the leadership of the educational institutions, the prevailing organizational culture within the educational institutions, the vision and mission of the university, the internal working environment and the perception of the faculty and staff towards knowledge sharing.

Globalization aids knowledge-sharing in the educational institution and the need to provide entrepreneurial skills. Globalization has made the world smaller; entrepreneurially minded students could take advantage of the technological age and get information from institutions that are affiliates of their institutions and share ideas that expand the knowledge gained on entrepreneurship. Educational institution share knowledge, expertise and experiences to ensure the spread of developmental initiatives and that these initiatives are sustainable. The institutions could achieve such developmental spread by setting up structures, process, and techniques used to compound human effort that drives anti-poverty agenda and initiative using technological innovations and trends that would culminate in the reduction of the global poverty level as they empower more graduates to open businesses and new frontiers. 
The envisaged future of young entrepreneurs would be a person who is adaptable, innovative, community-minded and creative to provide alternative platforms for the desired future. The future belongs to young entrepreneur with a global-minded yet local with the capacity to develop peak performance through talents and potential of a diverse character and ability (Dunn, 2012). This would imply that such entrepreneurs develop a framework that awakens and arouse the geniuses in them and evoke the prospects to excel in the anticipated new environment of interconnection and interrelationships in business.

Educational policy in favor entrepreneurship. The new realities are indicative that businesses profit from solving social problems, reducing pollutions and emission produces profit and this can be achieved in part by adopting a shared value. Addressing a social issue with a business model is when an entrepreneur creates a social value and an economic value simultaneously by being innovative and unleashing possibilities to address these social issues that entrepreneurs and individual in an organization can profit through better working condition for themselves and other stakeholders (Farhan, Brevetti, \& Laditan, 2016; Secundo \& Elia, 2014). Educational institutions as active members of the business communities that trains and prepares the human resources needed by the organization are obliged to lead in the vanguard for turning a social problem into a profitable business.

The role of educational institutions has traditionally been characterized by research and concentration on striving for academic excellence by faculty and students. Education serves as the pivotal and decisive element is gaining knowledge and plays a 
prominent and principal role in the overall development of the individual. Such roles have continued to evolve with the emergence of a new perspective on the production of knowledge and the desire of the educational institutions to respond to the social needs of the society. These roles include the contribution towards economic growth and development by actively participating innovative ideas and innovation systems both as a provider of human and technology capital (Secundo \& Elia, 2014).

Such evolution that has propelled the interest in looking for solutions in developing entrepreneurial behavior for student and faculty alike in higher educational institutions has not commensurately provided robust information and tools for the monitoring and evaluation of the effect of entrepreneurial performance post-graduation. The need for the monitoring and evaluation of the successes and failure of the graduates that have taken to entrepreneurial venture must go beyond financial returns, employment of labor and becoming self-employed. It must be taken a step further to social and economic benefits that gained knowledge, and the creation intangible asset adds to the new business venture (Secundo \& Elia, 2014). The educational institution management and policymakers owe the future and graduate entrepreneurs obligation to provide a system that strategically monitors the progress of young entrepreneurs both medium and long-term for sustainability. The school-based policy on entrepreneurship could have a direct influence on the entrepreneurial intentions of the students and a corresponding indirect influence through the encouragement in other forms of enterprise venture in a voluntary engagement that occurs through collaboration (Farhan et al., 2016; Kwong \& Thompson, 2016). 
The objective of such educational policy is to develop an entrepreneurial culture within the school environment and provides an endearing measure that effectively establishes business startup activities in the minds of the students thereby creating a better understanding of ways the school system can support the development of such students. The realities of the present time necessitate that the young entrepreneur becomes conversant with happening and events around them, these possibilities are greatly enhanced when such entrepreneurs are educated and are in tune with trend around the globe making them better agents of positive social change (Kwong \& Thompson, 2016). The attitudinal transformation that accompanies the engagement of these graduates in entrepreneurial activities needs to sustain beyond the walls of the school. Perceived desirability and attractiveness of entrepreneurship to them and the development of a positive attitude toward entrepreneurship is one way to keep the tempo and assess for low interest and loan term loans needed to start a business (Kwong \& Thompson, 2016).

\section{Leadership roles in higher institution towards entrepreneurship. Leadership}

particularly focused on entrenching entrepreneurial practices in the institution of learning has become relevant. Peng and Weichun (2011) viewed leadership as a dominant process which allows for the engagement of people's emotions and intellect to enable them to excel in any given role or task. Leadership is the potential and possibility generated when younger persons are introduced to career experiences formulated and intended to develop their talents; it entails the ability to cope with changes at various levels including the institutional level, the marketplace and in technological advancement (Chadwick-Coule, 2011). The term leadership aligns people to the new direction envisioned by the 
organization through the concise communication of new ideas and strategy, through policy statements of the vision, to avoid the workforce or followers pursuing different agendas. Vision serves one of the major leadership tools used to enlist the followers towards a defined objective and is focused on the constructive role of the educational institution within its operating environment. Leadership styles are linked to and determined by the cultural environment within a given group (Chadwick-Coule, 2011), it is important to have a mindset of a new leader and to be guided by beliefs and personal value. The leaders of business entities need to operate in an atmosphere that encourages innovation and support risk-taking.

The core responsibility of the leader is to make the objective of the organization very clear to everyone concerned with a clear sense of direction. The leadership, faculty, and staff play significant roles in modeling graduates to manage the transition, stabilization, and adaptation from a classroom-based student into young entrepreneurs. The leadership element is critical in a bid to drive the changes in the process of development. Such changes and transitions are achieved through the creation and articulation of a vision that provides strategic direction for the desired change initiative (Neiva, Odelius, \& Ramos, 2015; Samanakoopt, Songkram, \& Thongdeelert, 2015). Such period of changes, upheaval, and transformation require institutional leadership style and direction by faculty fit for such purpose; it includes day to day monitoring and evaluation.

The leadership style gives the role model greater agility and flexibility to cope with the diverse nature of the student entrepreneur and allows for more knowledge- 
sharing, confidence building and the encouragement of open-mindedness to experiment and seek opportunities for alternative ways to impact greater knowledge (Pepper, 2010; Valand \& George, 2014). Internal forces exist that drive the transformation of student mindset towards gaining knowledge on entrepreneurial skill to become self-employed. These forces include the technology deployed, the primary focus of the course, the administrative structures and the formation of the study procedures, the learning culture and environment (Cepureanu, 2015; Medeiros, 2016; Peng \& Weichun, 2011).

Mentoring. Young entrepreneurs need to be mentored for guidance and stability of their businesses. Reuter (2013) summarized five steps students might use as a guide toward graduating from student to graduate entrepreneur. The student should be able to recognize his/her skills and ability, have specific and broad knowledge of the customer's demand, produce products that would satisfy the customer, develops a business plan. Savickas (2012) interpreted career guidance to involve evaluating the developmental status of the student, education of entrepreneurial developmental tasks, and awareness on improvement in attitudes and competencies that are required for self-efficacy, and entrepreneurship.

Research into extant literature and both qualitative and quantitative studies, policymakers of the educational system suitable for entrepreneurship are encouraged to include mentorship as part of the entrepreneurial development program (Cumming \& $\mathrm{Li}$, 2013; Sommer, Markopoulos, \& Goggins, 2013). The practice of mentoring is designed to guide the younger persons in a chosen field. Mentoring has seen a period of evolution over the past decades; it represents a relationship where a person nurtures, guides and 
imparts unconventional wisdom and knowledge to a much younger person that has a lesser level of experience on the subject matter (Adams \& Miles, 2013; Allen \& Poteet, 2011). Such protection is sought by younger persons (undergraduates and graduates) to know what actions need to be taken during times of distress and how to find an individual with higher knowledge and experience to protect them against business threats, stressful challenges and running a business outfit. Making mentorship experiences that drive entrepreneurs towards mentoring relationships should be part of the learning experience of the student in higher institutions towards becoming young entrepreneurs that would be self-employed and employer of labor (Amesi \& Akpomi, 2014; Banerjee-Batist, 2014; Dziczkowski, 2013).

Chun, Sosik, and Yun (2012) in their research recognized that a correlation exists between the successes of American laureates and the mentoring experiences they encountered. Such experiences were given higher preeminence in the corporate sector when Roch, the CEO of an executive search firm, asserted that the majority of new employees with a mentor attached to them enjoyed better and rewarding careers more than those without mentors (Cassar, 2014; Maloney, 2012). Mentorship relationship between the mentor and the mentee takes a transactional approach, an approach that allows the mentor to pass on his/her experiences and expertise to a mentee in trade-in where the mentor derives benefit from the process (Ghosh \& Reio, 2013; St-Jean \& Audet, 2013; Terjesen \& Sullivan, 2011).

Entrepreneurial training in Nigeria. Entrepreneurial training and education are gradually taking a positive position in the economic development of Nigeria. Through 
their qualitative research, Menkiti and Ward (2016) explained the role of creativity in entrepreneurship education and how such creative ability influences innovative ideas in new venture creation for young leaders. Menkiti and Ward expanded the frontiers of the entrepreneurial education debate by focusing on the context that aids the students' learning process and creative behaviors add value to the firm when they start businesses. Boukamcha (2015) inferred that appreciating the significance of entrepreneurship education on innovative behavior in an organization was a significant step in investigating how the skills obtained by students during the program can be transferred and enacted into business ventures. Galanakis and Giourka (2017) examined the impact that a training program in Denmark on entrepreneurship fosters the mindset of the participants in the program. The targeted participants were teachers with varied professions from three of Denmark's University with the aim of influencing the program participants' perceptive on entrepreneurship education when provided with the needed tools and skills on the wider perceptive on a cross-section of university students (Galanakis \& Giourka, 2017). Galanakis and Giourka concluded that teacher-focused education activity was beneficial in building awareness of and competency in method useful in adapting skills to teaching entrepreneurship education.

Deakins, Bensemann, and Battisti (2016) recognized in a comparative study of literature on the designing process of entrepreneurship education through current developments in entrepreneurship in the last decade. The study led to identified categorization that includes learning outcomes, curriculum design, pedagogical tools and effectiveness of teaching entrepreneurship skills. Deakins et al. focused on 
entrepreneurship education concerning the basic domain knowledge suitable for transforming this knowledge into practical skills. Lassalle and McElwee (2016) concluded that when the necessary skills are imbibed through an intensive program on entrepreneurship, a resultant intention on new ventures creation was established that show potential beyond the personal development and career planning capabilities of the student.

Lassalle and McElwee (2016) appraised on the vast array of literature to establish the effectiveness of entrepreneurship education and its training program. The appraisal inferred that for success to be achieved in an educational program suitable for training students' entrepreneurs, the goals and learning outcome need to be outlined, and the curriculum design needs to include innovations \& creativity (Pefanis-Schlee, Stewart, \& Summers, 2013). The pedagogical tools should be inculcated to develop multiple skills and finally, the effectiveness of the entrepreneurship course to impact and create an impression on self-efficacy and intentions of the students (Claudia, 2017; Lassalle \& McElwee, 2016). The study on youth entrepreneurship was helpful in appreciating the impact that training schemes have on a new business when such training was conducted by a bank to gain loyalty of the trained firm to the training organization and reduce the possibility of changing to other banks after concluding the training program (Deakins et al., 2016). Available research studies on entrepreneurship evaluated the apparent contradictions in providing leadership education and advice for new and small firms (Feder \& Nitu-Antonie, 2017; Mohamad, Lim, Yusof, \& Soon, 2015). The evaluations 
concluded that entrepreneurship and new firms when offered training improves the survival rate and capability, and growth of the new businesses.

Boukamcha (2015) conducted an analysis of the experiential aspect of entrepreneurship education and the offering it provides to undergraduates colleges of entrepreneurship in the United States. The study provides an insight into the experiences gained when students engage in entrepreneurial studies due to the practical component of the study programs and mode of study. The engagement of universities and agencies of government in youth entrepreneurship initiative was designed to discover obstacles that exist in offering experiential entrepreneurship to determining and choosing alternatives to the present systems that are cheap and viable (Cacciotti \& Hayton, 2015; Gielnik et al., 2015). Feder and Nitu- Antonie (2017) opined that based on study conducted that leaders of businesses, heads of departments in University involved in entrepreneurship education excel in various functions held. Youth entrepreneurship study may be useful to the prospective student interested in exploring the vast opportunities that abound in the field of learning, and such knowledge and experiences could lead to skill development and possibility add to the reduction in unemployment plaguing the nation.

\section{Entrepreneurship Role in Societal Development}

The society provides a platform for the interplay of different systems, the judicial system, educational system, financial system, based on the availability of basic infrastructures like electricity supply, water supply, and a good transport system and general government policies encourage entrepreneurial skill development (Edoho, 2015). Edoho provided an insight into the critical and vital position of entrepreneurship in the 
overall development of societies. In Nigeria, the lacks of these basic infrastructures that boost entrepreneurship are challenges that confront entrepreneurs (Edoho, 2015). In leveraging on the Indian example, Sserwanga, Kiconco, Nystrand, and Mindra (2014) advocated that entrepreneurs adopt intelligent ways of surviving within the prevailing economic structures. The government and public institutions could provide the right institutional systems and framework that supports entrepreneurship, findings in the study indicated that innovation, higher human capital results in higher economic growth (Sserwanga et al., 2014).

Djip (2014) conducted a study on how innovation serves as the backbone of economic growth of a country. The study was based on the need to inculcate the right entrepreneurial skill at all stages of education in the country. The study could be used to achieve through the presence of entrepreneurship development cell (EDC) in the educational institution of learning and foster growth and innovation through entrepreneurship (Djip, 2014). Djip recommended that policymakers seek better ways to understand how universities could contribute to the national economy of nations through developing institutional mechanism aimed at creating an entrepreneurial culture that encourages the growth of innovation and entrepreneurship that creates a fresh breed of young entrepreneurs to contribute to the economy.

Chikweche and Fletcher (2017) evaluated the impact of violent conflict on the fortunes of entrepreneurship and entrepreneurial skill and education on a developing nation and stated that it affects the long-term economic activities of the affected countries. Countries with such history include Sierra Leone, Columbia and India, Nigeria 
and how violence impacts at the micro level of the firm and the entrepreneur's conflict (Chikweche \& Flectcher, 2017). The conflicts among countries in the housing sector have an economic effect due to the depletion of capital stock, the human population, and the quality and quantity of the labor force (McNaughton, Grey, \& Brendan, 2017). As the focus on the production side thus helps us to understand the potential channels of the impact of violent conflict. Gawell (2014) provided insight into entrepreneurship beyond the employer of labor to the creator of value and manager of businesses in a sustainable way that leads to steady inflow of capital and provides a different narrative beyond the violent conflict. Gawell examined the increase in resource in human capital that consists of education, skill, knowledge, and experience in entrepreneurship and its effect on opportunities identification could result in a stimulus for economic growth and development through the acquisition of real-life entrepreneurship experiences and skills.

The population spread in the country demography that divided settlements into municipal and rural communities, and the spread of wealth in the different settlements (Sankaran \& Demangeot, 2017). The process of opportunity recognition in both settlements and the human capital that support entrepreneurial opportunity identification; as well as the leveraging of organizational resources using interpersonal communication skills and economic negotiation skills are a prerequisite to succeed in entrepreneurship (Gawell, 2014). In entrepreneurship, training affects people perception and acceptance; the policymakers need to develop a roadmap for incorporating training, permanence and greater equality into the economic system (Chikweche \& Fletcher, 2017). By providing basic tools required to close the gap in the rural and urban settlement dichotomy and the 
balancing of the inequality of property rights, trusts, limits, prices, and dividend could reduce the rural-urban drift (Djip, 2014).

Sserwanga et al. (2014) inferred that students are not ready to take on entrepreneurship ventures beyond the school environment due to the fear of emotion on entrepreneurship that border on the fear of failure. Engaging in entrepreneurial ventures, the young entrepreneur should exhibit passion about the business, should be enthusiastic, ambitious, and resilient to overcome the fear of failure on the entrepreneurship endeavor (Edoho, 2015). It bothers on the barrier of individual's aspiration to succeed, the source of his/her strength and the commitment to overcome as an entrepreneur (Edoho, 2015).

Yaghoubi, Karami, and Motaghed (2017) evaluated the theory of planned behavior through the integrated model of entrepreneurial career intentions incorporating the role of motivational factors along with entrepreneurial knowledge. Yaghoubi et al. through data analysis using 150 students studying computer-related subjects from Iranian universities indicated that the magnitude of the effects on various antecedents of entrepreneurial intentions are different and includes factors like attitudes towards entrepreneurship and behavioral control. Entrepreneurs are seen as coordinators of the production process, agents of change and innovation and the importance the entrepreneurs are observable in an economy predominantly driven by knowledge, innovation, and competition (Edoho, 2015; Sankaran \& Demangeot, 2017). An entrepreneur is a person that undertakes endeavors that are innovative in finance using business acumen to transform innovations into economic goods (Cacciotti \& Hayton, 2015). Entrepreneurs are problem solvers, they opportunities in problems through the 
actions they take to identify the solutions to those problems (Cacciotti \& Hayton, 2015). Galanakis and Giourka (2017) identified the qualities suitable for an entrepreneurial role in a changing business environment includes:

Planning and evaluation. The young entrepreneur to be successful in business needs to have a plan needing continuously evaluated. Galanakis and Giourka (2017) inferred that the entrepreneur as a business owner who conducts business with qualities of goal setting to be achieved with constraints of time and finance. The goal setting quality allows the entrepreneur to provide a sense of direction through the evaluation of what are the entrepreneur's achievement and failures (Cacciotti \& Hayton, 2015). Such assessments allow the young entrepreneur strategize for optimum performance and success. The planning and evaluation component of the qualities of the entrepreneur serves as a critical success factor moving forward.

Risk-taking. The starting point in setting up a risk goal and objective is to define the organization shared vision. The entrepreneur needs to set the priorities right through the entrepreneur's vision for the business, with the vision been articulated, the potential risk management goal and objective and the risk appetite can then be defined (Pepper, 2010; Valand \& George, 2016. The goal helps to translate what was to be accomplished in line with the business strategy and information from competitors ( Laksmana \& Yang, 2015). With the identification of the risk inherent in the business venture, the entrepreneur needs to outline his risk appetite that suits the business plan of activities (Pepper, 2010; Valand \& George, 2016). Studies indicated four strategies used for exploring the positive risk in a business venture, exploit the opportunities, share the 
substantial risk, enhance the working and accept the total experience (Morris \& Pinto, 2007; Project Management Institute, 2013).

The entrepreneur needs to take a risk attitude that is averse, by deliberately taking steps to identify risk in my business and accept the risk as part of our operation with an emergency response plan if the risk does occur. The ability to take appropriate risk requires an underlying understanding of the challenges that exist. Managing risk involves the working of the human brain as decisions taken are influenced by a complex interplay of conscience and subconscious factors. So risk attitude applies to the decision making of a person or group (Sobel \& Reding, 2004). The graduate venturing into a business venture needs to operate with a level of comfort to the risk to be in; but with a risk response plan in place in the case of an eventuality. The internal and external risk open to new business venture includes risk associated with the employee, working capital, production, computer systems and fixed assets for internal and changing market, changing technology, natural disasters and changes in laws or government regulations for external (Stulz \& Nocco, 2006). The ability to start a business from scratch mean engaging in a risky venture as no guarantee for success was assured (Edoho, 2015). The startup of the business involves the entrepreneurs investing time and resources (Deakins et al., 2016). Taking risk is one attribute that the young entrepreneur needs to have and imbibe.

Creativity. The young entrepreneur needs to be creative and innovative. Phan, Jing, and Abrahamson (2008) justified in a special research paper presentation on creativity, innovation, and entrepreneurship that considered the interactions that exist, 
individuals, processes and institutions on the emergence of new business startups concluded that financial freedom and productive innovation embedded in creativity are drivers of the entrepreneurial processes. Creativity is about focusing on what consumes the inner person, thinking about what makes differences in other people's lives and surrounding oneself with good people because people are what determine your success in the future (Inkle, 2013; Schmidt, Soper \& Bernaciak, 2013). Entrepreneurial processes are likened to creative destructions, the entrepreneurs as lonely riders affect the economic dynamism of the local economy using entrepreneurial efficacy and the creation of innovative products and services (Ahlin, Drnovsek, \& Hisrich, 2014). The ability to see opportunity where others see a problem is one rear attribute of an entrepreneur (Akesson, Skalen, Advardsson, \& Stalhammar, 2016; Lassalle \& McElwee, 2016). Morgan (2016) indicated that the entrepreneur's creative ability becomes his/her biggest asset as they can recognize new, exciting, and better way of doing business and provide reliable service delivery.

Determination and dedication. For business startups, the need for determination and dedication to the success of the business becomes a priority. Feder and Nitu-Antonie (2017) asserted that entrepreneur as a business owner whose determination is the attribute that sets the young entrepreneur apart from others business ideas creators who could not implement their thoughts. The entrepreneur needs to work harder to succeed as some obstacles and challenges must be overcome (Mohamad et al., 2015). The ability to devote time and resources to the actualization of the business objective set should be paramount in the entrepreneur's determination to succeed (Acharya, Prakash, Saxena, \& Nigam, 
2013; Cain \& McKeon, 2016). The entrepreneur driving the business must be passionate enough and have a strong will to implement the framework for success set out in the vision and mission statement (Acharya et al., 2013). The entrepreneur needs to be sensitive to know what impact the business, the operating environment and what could appear as a contribution to sustainable development in a broader social context (Acharya et al., 2013).

Smartness and flexibility. The ability to position new business and respond to changing conditions should be a survival strategy (Lassalle \& McElwee, 2016). The entrepreneurs need to be updated on global trend in the chosen areas of investment and specialty and know the changing demands of the marketplace and the customer (AckahBaidoo, 2016; Wu, Kung, \& Lin, 2017). Ackah-Baidoo analyzed the ever-changing and dynamic world; smartness in all areas of business endeavor is a survival strategy. Lassalle and McElwee explained that smart entrepreneur adopts a corporate culture that can adapt to change with the sweeping changes in the organizational environment irrespective of the brief notices given and in real time.

Leadership. The survival of the business and its ability to remain sustainable is anchored in part to its leadership and its commitment the entrepreneurship (Adekiya, Adewale \& Ibrahim, 2016). The entrepreneur is encouraged to articulate a vision and ready to adapt to change occasioned by factors external to the business (Adekiya et al., 2016). Visionary leadership is at the heart of the need to craft reforms as a strategy for long-term sustainability of the firm (Lassalle \& McElwee, 2016). The entrepreneur needs to drive the process and initiative through actions and plans that are geared towards a 
culture that endears professionalism and competence (Adekiya et al., 2016; Lassalle \& McElwee, 2016; Mohamad et al., 2015). The leaders of business startups should lead by example; command a high level of enthusiasm and zeal towards achieving set targets and growing the business.

\section{Youth Unemployment}

Youth unemployment has been a social problem leading to various vices around the world. Ackah-Baidoo (2016) appraised the problem of the youth unemployment in countries situated in the Sub-Saharan region of the continent of Africa with rich resources base with a focus on the continuous inflow of revenue and investment to the extractive industry within the last 8 years. Such inflow of revenue has not translated to any noticeable reduction in poverty level within these countries (Grimmer \& Hobbins, 2014).

Due to the skewed nature of such investment and the greed associated with the management of the extractive industry in these countries, the revenue inflow has negatively affected such economies and the growth rate (Grimmer \& Hobbins, 2014). Mohamad et al. (2015) used qualitative case study to explore the issue further on how to engage youth in entrepreneurship education and explained that the extractive industries by design do not create a huge volume of jobs for the locals. This was due to the lack of technical expertise within the localities, leading to the import of technical expertise from other countries outside the region, thereby breaking the value chain for local human resources.

The high unemployment rate among graduates each year exacerbates the unemployment challenges in Nigeria, Mohamad et al. (2015) opined on the need to 
involve agencies of government to be proactive and address the issues of unemployment. The study on youth entrepreneurship engagements indicates the need for policymakers to take far-reaching decisions that are decisive towards discouraging sharp practices within such industries and develop the technical capacity of young people towards opening businesses that add value to the extractive industries thereby generating employment (Mohamad et al., 2015). Further research is needed on the involvement of young people in policy formulation and implementation of the intervention programs; the study would look at the impact market growth and how it is linked educational opportunities (BaahBoateng, 2015; Dieckhoff \& Gash, 2015).

Nigeria as a country belongs to this region (Sub Saharan) and is mostly based on receipts from the sale of oil and gas for revenue generation. The country has her fair share of youth unemployment problem. A study about the problem of youth unemployment would provide valuable insight on how entrepreneurship could help reduce the negative impact on the society (Mohamad et al., 2015). Student entrepreneurship clubs in institutions of higher learning could help arouse students' interest in entrepreneurship thereby providing the practical experiences and platform for out-of-classroom training on entrepreneurship.

Causes of unemployment in Nigeria. In the last decade, Nigeria became associated with militancy, youth restiveness, and other forms of social vices attributable predominantly to low employment rates (Okpara, 2012; Owualah \& Obokoh, 2008). Other reasons could be adduced as causes of unemployment, Lynne and Bolanle (2016) outlined several factors that could be the possible causes the unemployment dilemma 
among youths in Nigeria. The increased growth rate of the labor force, the universities have been turning out graduates every year to the labor market that do not have enough jobs and employment opportunity to contend with an increase of graduates (Orji, Nwosu, Anthony-Orji, \& Mba, 2016). Youth unemployment has increased exponentially the unemployed in the country (Lynne \& Bolanle 2016). The rural-urban migration occasioned by the lack of basic amenities, high unemployment rate and the abandonment of the farms that are mainly in the rural areas making rural life unattractive adds to the challenges (Emile, 2012). The centralization of utilities in the cities has led to this migration occasioned by neglect to spread these amenities through a deliberate policy to the rural populace (Olanrewaju, Anavhe, \& Hai, 2016).

In addition to the factors above, the rapid population growth is estimated to be 180 million according to the 2006 census in Nigeria of 140,431,790, and 3.2 growth rates of $3.2 \%$ are exacerbating the problem (Raimi, Akhuemonkhan, \& Ogunjirin, 2015). The inability of stakeholders to recognize the education policies and curricula that are out of tune with present realities and to reflect changes through the drive for entrepreneurship and develop employable skills was another problem (Raimi et al., 2015). The old curricula produce graduates that are retrained by employers before they can be used in the organizations (Bukar, Rusmawati, \& Shaufique, 2015; Fayolle, 2013). The curriculum of most university education in Nigeria lack entrepreneurial contents designed to prepare undergraduates to be self-employed and employers of labor (Mustapha et al., 2015). This lack of content for entrepreneurial knowledge in the tertiary institutions has affected the industries, as the once vibrant manufacturing sectors that can absorb unemployed youths 
in Nigeria are closing. In 2009 alone, over 800 firms and 37 factories closed in Nigeria (Akhuemonkhan, Raimi, Patel, \& Fadipe, 2014). Another half of the existing companies might not survive for a much longer time as they have been tagged ailing (Akhuemonkhan et al., 2014).

\section{Transition from Student to Entrepreneur}

Students that engaged in one form entrepreneurship training or education need to put what they have learned into practice. Lorz, Mueller, and Volery (2013) appraised the transition from studenthood to entrepreneurship and the preparation put into the process. The increased interest in entrepreneurship education by American scholars indicates that approximately 120,000 scholars engage in and partake in entrepreneurship program per year (Katz, 2003). The student with an increased interest and intention to become an entrepreneur must undergo a process of the transform of the mind and learning that would equip them the relevant skills.

They receive information about opening small-scale business and the attainment required for entrepreneurship (Scholtz, Calitz, \& Haupt 2018). Thaddeus, Chinemerem, and Edith (2015) inferred that the transition affects the clarity of financial knowledge, financial education, adequate saving behavior, and access to low interest, long-term financial capital from financial institutions. A significant portion of the transition plans would involve perceived attitudes toward investment and savings by the aspiring entrepreneurs through the formation of cluster groups for peer reviewing, motivation and support (Segal-Karpas \& Werner, 2014). A robust policy deployment, infrastructure development, proper institutional governance framework and a learning environment aid 
a smooth transition for the undergraduates into entrepreneurship (Arthur, Hisrich, \& Cabrera, 2012).

The purpose of this qualitative exploratory multiple case study was to gain a robust common understanding of how undergraduates from 21-25 years old can obtain entrepreneurial knowledge required for self-employment in Nigeria. Research concerning entrepreneurship, particularly from the gender perspective and youth employment continues to be a flourishing topic (Edoho, 2016; Siddique et al., 2015). A gap in the literature subsists regarding research about how undergraduates from 21-25 years old in Nigeria can acquire knowledge on entrepreneurship skills required for self-employment. Eva and Sendjaya (2013) and Mandel and Noyes (2016) evaluated how youth may gain vocational skills through entrepreneurship education and identified higher education as a potent medium of learning for young people to develop skills required for entrepreneurship. Bennett and Wood (2014) appraised youth entrepreneurship and education in the Western countries, and Martin (2016) described youth creativity and alertness as an element to be developed in the youth for promoting entrepreneurship among youths. Despite the high rate of youth unemployment and all the previous studies on youth entrepreneurship development and education, none have described how undergraduates from 21-25 years old in Nigeria can acquire knowledge on entrepreneurship skills required for self-employment.

\section{Summary and Conclusions}

The search strategy and sources of information for the literature review were part of this section; it highlighted previous literature on youth entrepreneurship are considered 
in the chapter. Chapter 2 contained the conceptual framework that served as a lens in the study. The relevance of the conceptual framework was analyzed and synthesized in Chapter 2. The conceptual framework focused on the TPB that highlights the entrepreneurial behavior of the students. Other themes analyzed are entrepreneurship education, higher education among youths, creativity and alertness among youths, and optimism and self-confidence among youths. Chapter 3 will contain information on the research methodology of the study. I will explain the methodologies, the design, data collection, and analysis to obtain information aimed at filling the knowledge gap. 


\section{Chapter 3: Research Method}

Chapter 3 will contain a discussion of the research method used for this study and includes the research design, the instrument, the data collection, and data analysis plan that I used for this study. The purpose of this qualitative, exploratory, multiple case study was to gain a robust, common understanding of how undergraduates from 21-25 years old can obtain the entrepreneurial knowledge required for self-employment in Nigeria. I conducted this qualitative study using semistructured interviewing methods with openended questions, and collect observational field notes, and carrying out document review. This chapter will include information on the research methodology and design of the study that aligned with the problem statement, purpose statement, and research question.

The research approach, the functions, and role of the researcher will be other areas given attention. Furthermore, the logic behind the selection process of the research participants, instrumentation, the procedures for recruitment of participants, and data collection will also be discussed. I will close the discussion by reflecting on the issues of trustworthiness and ethics in line with conducting the study. The final section of chapter will be a summary of the main points and a transition to Chapter 4 .

Research question. Research questions signify the aspects of inquiry that the researcher wants to study in identifying and guiding in data collection process (Lewis, 2015). Through the research question, a researcher attempts to find out and address a gap in the research and ascertain how data were collected (Achinewhu-Nworgu et al., 2016; Lewis, 2015). The research question that I developed to guide this study was: What are 
the common understandings of how university undergraduates from 21-25 years old could obtain the entrepreneurial knowledge required for self-employment in Nigeria?

\section{Research Design and Rationale}

I used a multiple exploratory case study design in this study. The multiple case study design was chosen for this study to facilitate the acquisition of detailed information from research participants and gather insight for obtaining answers to the research question. The multiple case study design allowed for an extensive and thorough understanding of the issues from a broader perspective with data from various sources, and it was based on the premise associated with the purpose of the study and data collection method (Witon, 2015). The qualitative research approach was the most suitable to address the research problem identified in my study.

\section{Research Design}

Researchers are advised to identify research designs methodically congruent with the intent of inquiry (Van Maanen, 2015). The types of qualitative research designs include the Delphi technique, ethnography, grounded theory, narrative research, phenomenology, and case study, (Marshall \& Rossman, 2014). I chose the case study approach after a careful assessment. In the following subsections, I will discuss the options for research design in greater details.

The Delphi technique. The Delphi technique is suitable as a research design when organizational protocols needs to be established to understand better divergence and a survey need to be done using an electronic medium (Fletcher \& Marchildon, 2014). The technique is gaining acceptance as a research approach when a researcher need to 
achieve consensus using a series of questionnaires and the provision of feedback to participants who have expertise in key areas (Green, 2014). The significant requirements for using the Delphi technique as a research design tool are the need for experts' judgment, group consensus to achieve the results, anonymity in data collection that ensures zero influence on the expert answers; and a complex, multidimensional, and interdisciplinary problem (Fletcher \& Marchildon, 2014; Green, 2014). Cassar, Marshall, and Cordina, (2014) suggested that Delphi approach becomes useful when the researcher needs to collect ideas from isolated experts on a specific topic and establish an agreement to discover the underlying assumptions or perspectives among the experts. In this study, I intended to interview the research participants in the field and not from isolated locations, so this design was not appropriate (see Lewis, 2015).

Ethnography. Ethnography is useful when studying the culture of a people through face-to-face interviews with the participants when the findings are related to cultural activities (Goffin, Varnes, Van der Hoven, \& Koners, 2012). The research design of ethnography addresses the learned behavior of a group (Weis \& Fine, 2012). Ethnography involves a study of a cultural group and findings about cultural activities that focus on marginalized groups in societies (Mutchler, McKay, McDavitt, \& Gordon, 2013; Van Maanen, 2015). Because I used a broader-based methodological research participation in this study, the ethnography research design was not be suitable.

Grounded theory. Grounded theory is used as a research design when the aim of the study is to birth a new theory or conduct research with little theoretical foundation (Gambetti, Graffigna, \& Biraghi, 2012). This study had a broad-based foundation, and 
appropriate explanations abound for the concept of entrepreneurship (see Johnson \& Bloch, 2015; Kenny \& Fourie, 2014). Furthermore, in the grounded theory approach researchers have a goal of generating a theory, in this study, my intention was not to formulate a theory, making the use of the design in-appropriate (see Kenny \& Fourie, 2014).

Narrative research. A narrative research design focuses on data collection from the storytelling perspective, and the design is appropriate when data are collected from stories told by participants (Manning \& Kunkel, 2014). The narrative design is focused on the life experiences and stories of participants presented in a story form (Boccuzzo \& Gianecchini, 2015; Ivana, 2016). The use of narrative design in data collection is not suitable when the focus is on identifying broader strategic issues (Morse, 2015; Thomson, 2015), therefore this design did not meet the needs of this study and was not used.

Phenomenology. Phenomenology places emphasis the individual, is internally focused, and is suitable when people describe their lived experiences of what and why they embarked on a decision or process (Tight, 2016; Yuksel \& Yildirim, 2015). The phenomenological approach derives its strength from when the researcher tries to understand the principles of the lived experience of an individual or a related group of persons by collecting required information relating to the subjective interpretations, beliefs, perceptions and specific human experiences (Denzin \& Lincoln, 2014). These experiences create various descriptions of the essence of the experience (Denzin \& Lincoln, 2014; Yuksel \& Yildirim, 2015). Because this study was externally focused and 
dealt with externalities that sought to gain insight on how graduates gain entrepreneurial knowledge, the phenomenology approach was not appropriate.

Case study. The case study research design is preferred when insufficient knowledge on the theories exists, and the likelihood or chances that a possible new theory might be developed through the outcome or result of the research being undertaken exist (Yilmaz, 2013). This research design is based on the premise of the purpose of the study and the types of data to be collected (Denzin \& Lincoln, 2014; Halkier, 2013). The qualitative exploratory case study design was the most practical design to be used in this study. The case study allowed me to explore how undergraduates from 21-25 years old in Nigeria can acquire knowledge on entrepreneurship skills required for self-employment through the provision of a suitable environment for entrepreneurial skill development.

\section{Research Rationale}

The goal of the study was to use the guiding ideology of the TPB to provide an explanation of and elucidate on the activities and the processes leading up to the emergence of new ventures in the field of entrepreneurship research that could help reduce unemployment for a better Nigerian society. The study was worth conducting because the result might help policymakers develop policies that would encourage entrepreneurship and reduce unemployment. The result of this study may add a new perspective and knowledge on the unemployment issue facing the region.

This exploratory case study allowed me to explore and capture the participants' experiences and develop themes from emerging data. To conduct the case study phase of this study, I followed Bailey's (2014) suggestion that an exploratory case study design 
adopts a step-by-step process for a better understanding of a given outcome. The basis for the adoption and use of multiple studies was to follow the path of the epistemological stances of positivism. I took an epistemological stance in this study to concentrate on the natural aspect of knowledge, its nature and how such knowledge can gain or obtained (Tadajewski, 2016). Positivism provides the possibility to accomplish an impartial, unprejudiced and value-free social research and consider the form the foundation for a final arbiter in theoretical disputes (Grant \& Osanloo, 2014). Such position gives the researcher the opportunity to look for the complexity of views of the research participants rather than being restricted to the meaning of the study into few ideas (Ross, Clarke, \& Kettles, 2014).

I recruited 15 recent graduates who were self-employed and employers of labor in the last 3 years. I approached the young entrepreneurs, guided by the inclusion and exclusion criteria for the recruitment of the sample population, and interviewed them in a location comfortable to them. I scheduled and conducted one-on-one interviews with each of the 15 graduates to check whether the sample size sufficiently obtained the richest data possible, collect field notes through observations, and review archived documents to gain a common understanding to answer the research question. The interviews for this study were recorded using a digital audio recorder; I then transcribed the interviews obtained from these recorded sections and collated codes into potential themes by identifying themes and units of meaning from the participants' words/sentences expressed in the interviews. Follow up explanations served as a suitable criterion for interpreting the findings to achieve stronger results. 


\section{Role of the Researcher}

I was the primary data collector in this study (see Nadal et al., 2015). The data collection processes involved semistructured face-to-face interviews and field notes that allowed me to see and record first-hand activities that the participants were engaged in and the context in which those activities happened (see Nadal et al., 2015). My role as the interviewer was to take control of the various aspects of this study, including choosing the right method and design, collection of data, and conduct data analysis and reporting. This function and role were outlined as I explored and participated in the interactions that evolved during the data collection processes. During the data collection processes, I employed interpretive and naturalistic approaches aimed at gaining an understanding of the people's lived experiences. This study provided me with the opportunity to inquire about the participants' behavior during individual interviews and the significance of these actions in context through observations. The use of other sources of data like field notes and document review supported the data from the face-to-face interviews and served as a model for an exploratory case study as well as satisfied the requirement for triangulation of the data by using three related data collection methods to reduce bias associated with the use of a single source (see (Leedy \& Ormrod, 2013).

I made sure my biases did not impede or affect the progress of the study by ensuring that my reflections and other observations were put in a reflexive journal to minimize biases and issues related to the confidentiality of information and anonymity of the research participants were given high priority. Safe data management and security strategies were adopted to keep data safe and secured especially in this age of information 
(see Braunack-Mayer et al., 2015). Of utmost importance was the researcher's bias when conducting qualitative research methodology. I monitored my biases as they might have affected the integrity of the reports generated during the study. This monitoring was achieved by ensuring that ethical standards and conducts of qualitative research were integrated into the research processes. The credibility of the qualitative approach adopted hinges to a large extent on the researchers' skills, competences, and rigor during fieldwork as issues regarding things going on in the researcher's personal life could prove to be a distraction (see Patton, 2015).

The study was in Nigeria, and I live in Nigeria. I ensured that no personal or academic relationship between me and the graduates that form the sample population of the study. The use of other sources of data like field notes and document review supported the face-to-face interviews and served as a model for an exploratory case study and satisfy the requirement for triangulation of the data by using three related data collection methods to reduce bias associated with the use of a single source. The data triangulation involved the analysis of multiple data sources that included the interviews transcripts, the field notes, and reviewing archived documents. I was deeply engaged in the process through the interview protocol to extract and guide the semistructured interviews, to ensured dependability, improve consistency and reduced unforeseen problems. I played the role of an active listener who listens deeply and allowed the participants finish their line of thoughts and perspective to emerge to reduce inconsistency and unplanned problems. I recorded the interview using an audio recorder and then transcribe the interviews verbatim for coding purposes and ensured that the 
participants received manuscript of the transcribed interview for comment and correction through their e-mails within 48 hours for any additions, corrections, and approval (Collins \& Cooper, 2014).

\section{Methodology}

The research approach for this study was the qualitative methodology and the concept to be investigated was entrepreneurship. The research methodologies are quantitative, qualitative, and mixed methods (Wisdom, Cavaleri, Onwuegbuzie, \& Green, 2012). The choice of qualitative method was anchored on the basis that it provides guidelines and equips the researcher to understand the case to be studied (Guth \& AsnerSelf, 2017; Lee, 2012). The study was epistemological as it related to the research conducted in an environment that allowed the researcher to understand the actual experiences of young entrepreneurs; how they acquired knowledge, the nature of the knowledge as it was constructed.

In contrast to the qualitative inquiry, the quantitative method addresses statistical analysis that was not the focus of this study. Statistical computation and probability analysis are some of the fundamental features used when a quantitative research approach was adopted, and it involved examining relationships among variables (FrankfortNachmias \& Nachmias, 2007; Parker, 2014). Quantitative research method allows the researcher to pose interview questions that are relational, causal or predictive in outlook and allows for comparison of variables for acceptance or rejection and therefore was not suitable for this study (Patton, 2015). These aspects of asking interviews that are relational, causal and predictive are not necessary for me to have a robust understanding 
of how undergraduates gain knowledge on entrepreneurial skills. This would imply that a qualitative approach would provide more detailed information from the individual graduates.

In this study; an expert validation was conducted to get expert advice/feedback on the initial interview questions (see Appendix A). The feedback from the experts served as the final interview questions contained in Appendix C (Guth \& Asner-Self, 2017; Ravitch \& Carl, 2016). This process aided in the comprehension and better understanding of how the chosen method aligned with both the problem statement and the research question. The conduct of face to face interviews in qualitative research method allowed for the reconstruction of events that I had never experienced, as it put together description from separate participants which enabled me to create a picture of a complicated process (Bailey, 2014).

Participants in this study included the individual 15 graduates in Nigeria who have been self-employed within the last 3 years. The sample population consisted of 15 individuals who represent the case; the selection criteria of graduate 21-25 years old who have been self-employed within the last 3 years was based on Patton's (2002) justification that focused on the selection of information-rich cases, the study of which illuminated the question under investigation (Haahr, Norlyk, \& Hall, 2013). In this study, I adopted the purposeful sampling approach to select the 15 research participants that provided data suitable for exploring how undergraduates 21-25 years old, gain knowledge on entrepreneurial skills. The inclusion criterion was that the entrepreneurs are graduates 21-25 years old who have been self-employed within the last 3 years and are employers 
of labor. The exclusion criteria are graduates from 21-25 years old that are not selfemployed but are paid employees in other organizations were not included in this study.

The guiding criteria were as outlined in inclusion and exclusion criteria for the recruitment of participants to the study. I scheduled the semistructured face-to-face interviews in the office locations or site chosen by the participants. I interviewed each participant with respect in a clean, safe, and friendly environment, as recommended by Adams and Miles (2013). The other sources of data that were used for the case study to ensure triangulation are field notes through observations and document review of the young entrepreneurs (Gorissen, Van Bruggen, \& Jochems, 2013).

\section{Participant Selection Logic}

I purposely sampled the 15 research participants to ensure a diverse representation of the case. Purposeful sampling was based on intent and emphasizes choosing information-rich cases through a selective method (Rubin, 2015). The individuals selected to participate in the research were selected for reasons that included previous experience, knowledge of entrepreneurship, resided in an area that was linked or associated with the purpose of the research and the research questions (Haahr et al., 2013). The major advantage of adopting purposeful sampling receded in the selection of information-rich cases for in-depth studies (Haahr et al., 2013). It was important to align the strategy of selecting the samples with the qualitative research methodology. The purposeful sampling of a total of 15 graduates in Nigeria, with a background in entrepreneurship who display readiness, willingness, and knowledge in entrepreneurship attitude, behavior and have been self-employed within the last 3 years formed the case. 
The inclusion criteria were (a) graduates with knowledge on entrepreneurial skills and, (b) graduates who have been self-employed and employers of labor in the last three years. The choice of the first 15 participants was justified as I interviewed the first 12 participants to determine whether common understanding was achieved. Where getting 15 research participants become difficult and the participants are up to 12 , I transcribed the interview data to obtain emerging themes and use other sources of data like field notes and archive document to triangulate the data. According to Guest, Bunce, and Johnson (2006), common understanding occurs within the first 12 interviews. To attempt to achieve common understanding, I coded the interview data three times, and 15 interviews are enough to achieve common understanding for a study to describe a shared perception, belief, or behavior across a group. The common understanding could be improved by analyzing the data at the individual level, the collection of field notes through observation and document review (Guest et al., 2015). Axial or thematic clustering coding process was used for this study as it involved an inductive approach starting with a chunk of data to coding categories where themes and patterns were observed and used for analysis (Miles, Huberman, \& Saldana, 2014; Ravitch \& Carl, 2016).

\section{Instrumentation}

I was the primary data collector as the researcher for this study. Ho (2012) asserted that the primary data collection instrument in qualitative research is the researcher. Interviewing was the major source of qualitative data collection of rich, indepth, and individualized form (Meho, 2006; Oye, Sorensen, \& Glasdam, 2016). It 
provided an opportunity for the interviewer to interact with the participants on individual bases as they shared experiences and opinions. The interview was mainly conducted in two primary forms, one-on-one (individual) or focus groups. However, in recent years, technology has widened the processes of conducting these interviews to include a telephone interview, email interview, and other internet interviews like Skype (Leedy \& Ormrod, 2015).

Individual interviews are one-on-one moments between the interviewer and the participant where the interviewer asks either structured, unstructured, or semistructured questions for the participant to respond. Individual interviews intended to obtain independent, in-depth personal data from each of the participants (Oye et al., 2016). The main factors of selecting participants were the purpose of the study, research question of the study as the interviews were conducted independent of each participant, and the information were confidentially processed. For the data collection, I used individual interviews, field notes through observation, and document reviews.

Individual interview. The individual semistructured interviews with open-ended questions asked of the participants were central to the data collection processes. Face to face interviews provided an opportunity to obtain extensive insight into the persons acting as a participant; how they felt, what they think, what are the effects of certain events (Hazzan \& Nutov, 2014). The interviews consisted of a guide to specific questions or a protocol to delineate the process. The interview was centered on well-chosen questions aligned with the central research question of what are the common understandings of how university undergraduates from 21-25 years old could obtain 
entrepreneurial knowledge required for self-employment in Nigeria to launch a business after graduation. The private setting was conducive to individual forthrightness and deep introspection. These interviews were highly structured allowing me to exercise control over the direction of the data collection processes.

The participants were asked about their availability for interviews via letters of introduction that informed participants of the basic nature and purpose of the research. The responses to interview questions prompted vital information needed to address the purpose of the study. The interview questions asked to the participants were directly related to the research question of the study and responses obtained became part of the database built to manage the enormous amounts of data to be generated. The interviews were audio-recorded, and participants had the opportunity to review the transcribed interviews to confirm that the produced transcripts represented what transpired during the interview process and was a reflection my interpretation and meanings of participants' interview responses before data analysis began.

Where the information shared by the participants made me uncomfortable, I understood that the participants deserved to be heard, this was in addition to the anonymity, confidentiality, and safety of the participants (Corbin \& Strauss, 2008). A strategy to reduce bias was to position me in the studies by sharing my possible biases (Stahl, Doherty, Shaw, \& Janicke, 2014). A second strategy was to circumvent the risk of bias by analyzing all the 15 sets of responses I received from the participants. By the avoidance of the temptation to select only 12 responses, I ensured that I had incorporated 
all the participants' ideas into the themes and patterns that were reported in my conclusion.

To obtain the thematic expression from the transcripts, I coded the transcripts to extrapolate patterns or description of labels; these labels were generated from each line of thought, sentences or phrase of the participants (Rubin \& Rubin, 2012). The codes gave a clear understanding from the participants' perspective in a way that was distinct from each of them. The categorization of the codes served as a gathering point for codes or family of codes (Ravitch \& Carl, 2016). The categorization led to the theme; themes explained what had happened, its meaning or how the participants felt about the subject matter that helped drew conclusions and reflected the intent from the participants (Braunack-Mayer et al., 2015).

An interview question protocol (see Appendix D) was preestablished to include: (a) opening and welcome note, (b) interview questions and, (c) a closing summary thanking the participants. The interview protocol ensured the direction of questions and uniformity in the interview process (Fakis, Hilliam, Stoneley, \& Townend, 2014). The consents of the participants were sought before proceeding with the interviews. All the interview data and documents reviews were screened to remove personal information to prevent the identification of the participants. To maintain ethics in the interview process, it was important to know that the interest of the study was to understand the case being explored and the meaning the participants may make from the case being studied (Seidman, 2013). 
Field notes. The field notes generated insight into the roles been observed and reflective engagement into the data collection activities. An observation and field note in a qualitative study is a data-collecting tool that allowed the researcher to acquire data from participants in the context of the activities or the environment (Leedy \& Ormrod, 2015; Ravitch \& Carl, 2016). Groenewald (2004) explained that the field note was commonly used by qualitative researchers to collect an observational field note that includes: (a) notes that recorded occurrences and events as they happen in the course of the interview (b) notes were taken which reflected the preliminary understandings and connotation that were given to the meanings (c) procedural notes and protocols were written to serve as a reminder to the researcher on certain steps to be taken at the designated time and (d) memos were taken to close out each interview session, that served as a brief abstract of summaries. While conducting the interviews, I took field notes that considered any pertinent occurrences or thoughts. The field notes generated insight into the roles being observed and reflective engagement into the processes or activities (Yilmaz, 2013).

Document review. The third instrument used was document review. Yin (2014) explained that documentation was a significant source of relevant information for case studies; it included letters, e-mails, and companies' formal reports available through search engine platforms. Document review was stable, specific, and broad; it covered an extended period and many settings. In conducting an examination of records, I searched across a broad range of databases, such as papers, articles, government websites and public libraries. Dworkin (2012) noted that the document review process was an adequate 
method for collecting data needed to provide answers to the research question and to demonstrate methodological triangulation.

The documents that were reviewed provided practical and heuristic proof needed to advance entrepreneurship education and skill development. It provided support for the clarification of the research question and its significance both in practical and theoretical terms that detailed the methods used to answer the research question. The document review served as a point of convergence and alignment of the researcher's goal, values, and ideas about the research and the strategy needed to propel and move the research process forward (Parker, 2014). I searched across a broad range of databases, such as papers, articles, and report to create a database of participants' experiences with entrepreneurship activities.

\section{Expert Validation}

The procedures for the conduct of an expert validation involved the sending of invitational e-mails to qualitative research subject matter experts as contained in the information from the Walden University faculty expert directory (FED). The expert validation method, where feedbacks are obtained from experts in qualitative research design was used by researchers to check for the alignment of the research question to the interview questions and get qualitative research subject matter experts' feedback (Anseel, Beatty, Shen, Lievens, \& Sackett, 2015). Using the FED, I sent invitational email to 11 qualitative research SMEs (see Appendix B) containing an attachment of the abridged proposal that includes the title page, the problem statement, the purpose statement, the research question, and the initial interview questions (see Appendix A). 
The 11 qualitative research experts acknowledge receipts of the email; however, only three experts responded to my inquiry. The comments from the three experts provided the insight for revising the initial interview questions that became the final interview questions (see Appendix C). The experts were kind enough to highlight some of the elements that were omitted and provided further insights into ways of improving the quality of my proposal (Sue \& Ritter, 2012).

The first qualitative research expert, subject matter expert \#1 asserted that the problem statement needs to be revised and reworked to align with the purpose statement and the research question. I sent a reply email explaining how the problem statement aligned with both the purpose statement and the research question. The second subject matter expert \#2 made suggestions on possible corrections on the problem statement and the purpose statement but affirmed that the problem statement, the purpose statement, and the research question were aligned. I have made corrections to the suggested areas. The third subject matter expert \#3 advised that I revise Interview Questions 4 and 5. Further communication between me and the experts was conducted via e-mail and the feedback obtained became the final interview questions (see Appendix C). The evaluated interview question and the inputs from the subject matter experts would enable me to make the necessary revision and improve the quality of my work and facilitate the collection of relevant data from the proposed research participants that were used in answering the research question and addressed the gap in the literature. 


\section{Procedures for Recruitment of Participants, and Data Collection}

The recruitment of participants for this study occurred after obtaining approval from the Institutional Review Board (\#2018.01.2618:04:93-25'1'). I sought and obtained approval from the Walden University IRB to access the letter of cooperation and expression of interest form (see Appendix E) and consent form and the application of these forms to the present study. I sought and obtained permission from the University's IRB (Walden University) to conduct this study and produce a detailed schedule for the interview and data collection processes. I sought and obtained consent from the individual participants to carry out the interviews with the participants to collect data through audio recordings of the interviews. I transcribed audio-recorded interviews and performed member checking by allowing participants to confirm that the produced transcripts represented what transpired during the interview process and was a reflection my interpretation and meanings of participants' interview responses. I finally imported transcribed text into Microsoft Word to start the data analysis stage.

Letter of cooperation. A draft letter of cooperation (see Appendix E) was sent to IRB for approval and was later sent to the research participants after approval. The letter of cooperation was sent to the research participant in each of the four local government areas in Nigeria. The letters of cooperation were required to gain access and permission to the respective participants' office sites and locations.

Expression of interest. The Expression of Interest (see Appendix E) was the notification e-mail that I sent to the research participants in each of the four LGAs in Nigeria. The e-mails were necessary to select the individuals that might be interested in 
participating in the study. The e-mails contained a brief description of the study. Detailed information about the research procedures and participation was contained in the consent form sent.

Consent form. Communication using informed consent was one way suggested by Kaiser (2009) towards protection of shared experiences of the participants and meeting the ethical requirement. Kaiser advocated for a two-step approach to the informed consent process: First, agreeing with participants on the use of data and confidentialities, second, modifying the informed consent process to have a re-envisioned informed consent. Participants' questions and concerns before, during, and after data collection was always given attention to guarantee the understanding of the participants about the process and interview questions and that the responses obtained remained anonymous (Hazzan \& Nutov, 2014). The consent form contained significant information on the rights of the research participants. Information included in the consent form includes the privacy and confidentiality of the participants, the liberty to quit from the research process at any time without any retribution or sanction, the voluntary nature of the study, the duration of the interviews, and secured data storage was aimed at protecting the interests of participants.

Data collection plan. A collection of data in a qualitative method is often susceptible to subjectivity since as McCusker and Gunaydin (2015) indicated that a dominant and prevalent theme in qualitative research was the understanding derived from the linguistic meaning within the textual material. Serious consideration was attached to the selection criteria for research participants and data collection. Careful planning before 
and during the data collection preceded data analysis, as it was imperative for obtaining valuable information from the study (Marshall et al., 2013). I reviewed relevant literature to guide the data collection and sampling process that was consistent with the case study design. The timing for the face to face interview was 30 minutes and data collection techniques like interviewing were adopted.

Techniques such as triangulation supported quality in research with the involvement of multiple sources of data (Patton, 2015). Data triangulation enabled crossdata validation and provided checks for the various data sources to achieve accurate and valid findings. The involvements of multiple sources of data like the transcribed interviews, filed notes, and archived document and seeking convergence among them to form themes enhanced the validity of the study. I maintained objectivity through entries into the reflexive journal (Kvale \& Brinkmann, 2015).

\section{Data Analysis Plan}

Data analysis was performed on the data collected from the semistructured individual interviews, field notes through observation, and from document reviews. Yin (2014) pointed out that one dominant practice during the analysis phase of qualitative research was the return to the original propositions; the reason adduced for this was that the practice led to a focused analysis when attractions to analyze data outside the scope of the research question came up. The qualitative data analysis processes involved coding of the data, categorizing the coded data, and subsequent generation of themes in line with the research questions being addressed by the study (Godden, 2014). 
To obtain the thematic expression from the transcripts, I coded the transcripts to be able to extrapolate patterns or description of labels; these labels were generated from each line of thought, sentences or phrase of the participant (Rubin \& Rubin, 2012). Axial or thematic clustering coding process was used, it involved an inductive approach starting with a chunk of data to coding categories where themes and patterns were observed and used for analysis (see Miles, Huberman, \& Saldana, 2014; Ravitch \& Carl, 2016). The codes gave a clear understanding from the participants' perspective in a way that was distinct from each of them. The categorization of the codes served as a gathering point for codes or family of codes. The descriptive categorization as an iterative process allowed the theme to stay close to the research question through its emic attributes (Ravitch \& Carl, 2016). The categorization led to the theme; themes explained what had happened, its meaning or how the participants felt about the subject matter that helped drew conclusions and reflected the intents from the participants (Braunack-Mayer et al., 2015).

Upon completion of the transcription of the audio recordings of the semistructured interviews, member checking followed by allowing participants to confirm that the produced transcripts represented what transpired during the interview process and was a reflection of my interpretation and meanings of participants' interview responses. The textual transcribed data was uploaded into NVivo 11 software from the word document to obtain an organized set of data that was sorted into groups and themes. Miles and Huberman (2014) asserted that the determination of the means of data collection, data organization, and data storage were important considerations before the commencement of data collection as it saved the time taken in the data management 
process. The development of a data framework was used for the data collected, as it served as a guide in furtherance of knowledge for future researchers. The use of case study enhanced the analysis of data as it had a set of routine procedure suitable for the identification of themes that provided meanings to the research question (Fakis et al., 2014). The data sources and a first-hand report consisted of individual interviews, field notes and document review.

The data from the interview transcripts were organized into rows and columns; the interview questions on how the participants obtained knowledge for entrepreneurship after graduation were stored in the columns, and the responses that provided by participants occupied the rows. NVivo Version 11 was the software that was used to organize the data. The NVivo was prominent software used by qualitative investigators to organize, manage, and shape qualitative data (Richardson, Earnhardt, \& Marion, 2015). During data analysis, I read through the interview field notes and transcripts to have a better understanding of the issues under exploration. Flicker et al. (2013) and Maxwell (2013) agreed that beginning the analysis of the data should start during field work; with the analysis plan fitting into the data and research questions.

The goal of coding was to break the data into stages to help in comparisons and the evolution of theory and concepts; Miles et al. (2014) noted that codes were labeled to assign meaning to information and indicated that coding allowed for interpretation of data meanings. Structured coding or precoding provided a framework for me to focus on the data collection efforts. Precoding was deductive; however, it was up to the researcher to follow-up with inductive coding as themes emerge from the data. It may be beneficial to 
the interviewer, for proper focusing of the interview process and avoiding data overload while remaining open to emerging themes and ideas.

I developed a precoding structure using the experience gained as a researcher to relate the conceptual framework, the document review, and responses to the research questions to derive themes. Precoding assisted me with ensuring congruence with the conceptual framework and research questions. The precoded structure allowed me to analyze the data iteratively to ensure the efficacy of the data collection and organization processes. I interviewed the first 12 participants before the last three participants to monitor for data saturation. The justification for the 15 participants was based on running analysis for the first 12 participants and the themes to be generated. Where data saturation was not achieved with the 12 participants, I interviewed the last three participants to seek for generation of new themes or convergence of themes and ideas to monitor for data saturation. I categorized the codes and themes into the dimension that aligned with the framework used in the study. I reviewed the dimensions to ensure pattern correctness and precision.

\section{Issues of Trustworthiness}

Pieces of evidence to demonstrate of rigor in qualitative research needed to be established; it was critical in ensuring that research findings have integrity in the process to make an impact. Trustworthiness of the qualitative research process was the anchor point of giving integrity to the effort put in the study (Houghton et al., 2013).

Trustworthiness in qualitative research entails four areas that when addressed ensured the credibility of the study; the areas included credibility, transferability, dependability, and 
conformability (Carter, Bryant-Lukosius, DiCenso, Blythe, \& Neville, 2014; Cope, 2014). The extent of the reliability of the research process was the level of compliance with the rigors, demand, and ability to demonstrate evidence of the results reported in these four areas. I ensured trustworthiness through triangulation, which used the three related data collection methods to reduce bias associated with the use of a single source (Simundic, 2013). The use of triangulation ensured credibility, dependability, and conformability of the study and served as an audit trail and reflexivity, while transferability was left for the reader to decide (Carter et al., 2014). I ensured that I followed the interview protocol to keep track of the questions for uniformity in the data collection processes.

\section{Credibility}

In a qualitative study, the researcher needed to engage the study participants and community long enough to gain and earn trust through the establishment of rapport. With the establishment of the rapport comes the ability of the researcher to gain an extensive and thorough understanding and information from the participants. Harper and Cole (2012) described credibility as the process a researcher engages in to ensure that findings are accurate. The prolong engagement of the study participants brought out relevant characteristics peculiar to the issues been investigated thereby bringing out details that gave new perspective and insight to the topic under investigation. I took measures to ensure its wider application to a larger population as the case study was focused on a small number of participants. Sufficient time was spent during the interview process to gain a sound understanding of the case under investigation. I transcribed the 15 
individually recorded interviews verbatim and ensured that the participants received manuscript of the transcribed interview for comment and correction through e-mails.

\section{Transferability}

The need exists for thoroughness in the processes leading to the identification of the research participants and the overall data collection and analysis processes. Providing a detailed protocol, explicit in the description of the steps to take might guarantee external validity; it served as the ability of the outcome and findings of the research to be transferable. Transferability refers to the ability to reapply a research finding in another study (Collins \& Cooper, 2014; Sinkovics \& Alfoldi, 2012). I ensured the provision of a detailed account of the natural settings where data were collected and provide an in-depth explanation of the data collected and analyzed. Future researchers and readers will then be presented with the opportunity of the findings and to evaluate the extent to which these findings will be transferable to similar settings and larger population (Marshall, Cardon, Poddar, \& Fontenot, 2013).

\section{Dependability}

The issue of dependability focused more on the technical aspect of the research; dependability refers to how well-established the data used in a study are ( $\mathrm{Su}, 2014$; Tobin \& Begley, 2004). Member checking ensured dependability of the qualitative research been undertaken and the synergy that was derived from membership verification gave validity (Munn, Porritt, Lockwood, Aromataris, \& Pearson, 2014). The collection of the field note, memos, and comments that revealed reflexivity in the research process, the design layout of the research gave a vivid picture of the research strategy, and the 
operationalization of this strategy gave the research process its dependability attributes. I addressed the issue of dependability of the findings, in ensuring that if the study were to repeat, given the same context, method and same participants that similar result will be obtained bearing in mind that each situation of study is unique in its entirety. In my effort to enhance dependability; I explored and ensured that all the processes were adhered to in arriving at the findings and described the processes to be followed in the study.

\section{Confirmability}

The need for the justification of the rationale behind the preference of the data collection methods chosen and how they aligned with the research question and problem statement were made known. Confirmability refers to the objectivity and correctness of data (Abend, 2013; Houghton et al., 2013). I provided a detailed explanation of the data analysis process to demonstrate and exhibit transparency of the process. In checking for conformability, the recommendations of the result indicated what the experiences and thoughts of the individual interview respondents are, rather than the researcher's prejudices (Anney, 2014). I documented the various reflections obtained in both the personal experiences, cultural biases, and provided explanations on what informed my decision and possibly influenced the research process (Nimon, Zientek, \& Henson, 2012).

\section{Ethical Procedures}

To maintain ethical standards, I communicated the aim of the study, the possible benefits derivable and the expectations of the research with the research participants before interviews were conducted. The purpose of this action was to protect them from harm and ensure the process was in line with the established professional and ethical 
behavior (Cope, 2014; Komic, Marusic, \& Ana, 2015). I informed the participants about the ethical standards, and the informed consent process before conducting the interviews (Sanjari, Bahramnezhad, Fomani, Shoghi, \& Cheraghi, 2014). As a researcher, I had an ethical duty to protect the study participants from harm (Flicker et al., 2013). As noted by Yin (2014), special considerations must and were emphasized to all human elements of the research, from the participants to personal records. The protection of the participants' right was paramount as I maintained ethical standards associated with the use of human samples, the data collection and analysis was developed in a manner understandable to the research participants.

The benchmark or selection criteria for the participants indicated a detailed selection process with indications that minimized the adverse effect of using only one data collection source using triangulation. I informed the participants of the right to accept or reject the offer to participate in the study. The right to participate or withdraw at any time from the interview process without penalty was stated in the expression of interest form and the informed consent form respectively. The participants were assured of the safeguard of data collected by the encryption of the files and locking up paperwork related to the research in a safe location with proper locking mechanics. This was done with the intention of reducing the risk of data theft as the site was not disclosed.

The first step in minimizing harm to participants in the research process was to ensure consent from the participants. Informed consent entailed having consented to use the data so that the data are not interpreted as stolen data, and this goes for participants' data from recordings and notes taking (Desai \& Von, 2008: Ritchie, Lewis, Nicholls, \& 
Ormston, 2013). The consent sought was for individuals who participated in voice recording and using transcription to code the research. Information made known to the participants included the time required for the interview, member checking and the questions that were asked. I took these necessary steps during data collection and analysis to ensure that I had a verbal recording of the participants stating that they are consenting to the data collection and analysis process and procedures and are fine with the interview being recorded and transcribed. This ethical practice helped minimize harm to others and ensured that the participants were given the opportunity to pull out of the process at any time during the interview session.

Confidentiality. The participants of the interviews trusted that their contributions given in the interview processes were indeed confidential and would not end up in the wrong hands when I told them that the information provided would be safe and secured. Protecting the privacy of participants included both confidentiality and anonymity (Cope, 2014; Ritchie et al., 2013). Confidentiality referred to a participant's privacy, and what information about the participants were distributed (Anney, 2014; Ratvich \& Carl, 2016). Ways I took to ensure confidentiality included using pseudonyms and changing identifying information (Bojanc \& Jerman-Blazic, 2013). I showed respect for the participants that were interviewed and prevented issues that might compromise the confidentiality of the research participants; I asked the participants to confidentially provide any additional comments or revisions to the transcript through e-mail. I protected the data and records of the research participants by using a hard drive on a secure computer that had password protected preventing access to unauthorized users. 
Protecting participants from harm. In the study, I was responsible for the information of the participants on the purpose of the study, gained the understanding the participants of the risks associated with the research process. The benefit derivable from the study and the right to pull out from the study if they don't feel convinced or secured in participating in the study was explained (Bojanc \& Jerman-Blazic, 2013). During and beyond the period of study, the communication channels remained open and cordial. Where the need arose, I disclosed all activities that might become potentially harmful and risky to the participants. Question and follow-up questions asked were related to the research question.

Protecting researcher from risk. In the likelihood that an anticipated risk occurs during the research processes, the participants were briefed on the mitigating strategies to adopt. I showed awareness of the cultural biases that exist among the research participants (Shenton, 2004). If the study had taken place in a cross-cultural research environment where social gaps exist, I paid attention to the salient and hidden biases that could have affected the study. The participants were commensurately motivated to partake in the interview section through the building of trust that encouraged openness in the interview sections (Shenton, 2004).

\section{Summary and Transition}

Chapter 3 contained an overview of the research design and describes the qualitative method that served as underpinning guide for the study. The purpose of this qualitative exploratory multiple case study was to gain a robust common understanding of how undergraduates from 21-25 years old can obtain entrepreneurial knowledge 
required for self-employment in Nigeria. The rationalization of the research design employed in the study served as a guide for the interview questions to extract information to answer the research question. I interviewed the 15 graduates in Nigeria, who have been self-employed within the last 3 years. I purposely sampled the 15 research participants and gained data from semistructured individual interviews with open-ended questions. The various sections of Chapter 3 included details of the role of the researcher, the sampling population, the data collection and analysis strategies and techniques used to maximize reliability. The other sections that attracted important contents and attention were issues of trustworthiness that was achieved through research credibility, transferability, dependability, and Confirmability. Chapter 4 will cover the research settings, information on the participants, presentation of data collection and analysis. Evidence indicating trustworthiness and the research results is part of Chapter 4. 
Chapter 4: Results

The purpose of this qualitative, multiple, case study was to gain a robust, common understanding of how undergraduates aged 21-25 years old can obtain the entrepreneurial knowledge required for self-employment in Nigeria. To address the research question and purpose of the study, I conducted a qualitative analysis the results of my semi-structured interviews with the 15 participants, four participants from three LGAs and three participants from the fourth LGA in Nigeria, who had prior knowledge of entrepreneurial skills and had been self-employed for at least the 3 years prior to the study. I purposely selected the sample population of the 15 research participants and obtained data from them using semistructured face to face interviews, field notes, and reviewed archived documents of training documents to ascertain the correctness of some business information of the participants.

In this chapter, I will describe the methodology I used for the data analysis of this study to provide a common understanding of the findings from the research question and interview questions (Hyett, et al., 2014). I collected the data in the interviews using nine open-ended questions to address the central research question: What are the common understandings of how university undergraduates from 21-25 years old could obtain entrepreneurial knowledge required for self-employment in Nigeria? The data resulting from the 15 interviews with the participants served as the input for analysis after using NVivo 11 software to organize the data.

Chapter 4 of this study entails the purpose overview, the design of this study, and the implementation of the research setting, demographics, data collection, analysis, and 
the general analysis strategy used for this study. I illustrated the data collection procedures that were analyzed using coding and themes to reflect the findings ascertained from the stored data collection consisting of 15 respondent audio recordings and transcriptions. Chapter 4 is a reflection of the attempts I provided in this study that was note-worthy of trust and integrity to recap the findings from this study.

\section{Research Setting}

To recruit participants for this study, I sent 15 young entrepreneurs who were recent graduates from 21-25 years old direct e-mails. I interviewed four participants each from three LGAs and three participants from the fourth LGA in Nigeria. The interviewing process and member checking occurred in the four LGAs and spanned 3 weeks in the office premises of the participants. I administered and disseminated the script and the Consent Agreement Form (see Appendix D) to the research participants and explained the primary focus of the study prior to asking them the interview questions.

Some potential participants declined to be a part of the study based on their busy schedules while others did not respond to my email. Some potential participants did not have email addresses; therefore, I contacted them and learned that they did not have the qualifications to participate per the inclusion criteria. As a result, I sent recruitment emails to other possible participants not covered earlier, they responded, and I sent consent forms and interview protocols to the participants that responded. I obtained the necessary number of participants and setup interviews. The interviews lasted approximately 30-45 minutes. I sent the transcripts to the participants the day after their interview over the 
course of the data collection process, to ensure their immediate review for the strength, validity, and reliability of the study.

All 15 participants asked for copies of their final transcripts, and four participants requested copies of the final dissertation. The strength of the study reflects a mixture of interviewees' expertise varying from their area of specialization of trade. The professional knowledge shared by the participants during the face-to-face interviews for the selected times showed depth of their knowledge of the experiences on entrepreneurship that they shared with me without any signs of discomfort.

\section{Demographics}

The sample for this study consisted of 15 recent graduates who had had prior knowledge of entrepreneurial skills and were self-employed for at least the last 3 years. The purposeful sampling allowed me to intentionally select this sample size which constituted the demographics aligned with the criteria for participation in this qualitative study. Tables 1 and 2 depict the demographics of the research participants. The study population was composed of four participants each from three LGAs and three participants from the fourth LGA in Nigeria. In alignment with the objectives of the study, I used the sample size of 15 to establish data saturation and appropriately answer the central research question. 
Table 1

Participant Demographic

\begin{tabular}{|c|c|c|c|c|c|}
\hline Position & Gender & $\begin{array}{l}\text { Education } \\
\text { level }\end{array}$ & $\begin{array}{l}\text { Years of } \\
\text { self- } \\
\text { employment }\end{array}$ & Types of business & $\begin{array}{l}\text { Local } \\
\text { government } \\
\text { areas }\end{array}$ \\
\hline Participant 1 & Female & Bachelor & 3 & Catering services & Port Harcourt \\
\hline Participant 2 & Female & Bachelor & 2 & Graphic design & Obio Akpor \\
\hline Participant 3 & Male & Bachelor & 3 & Building materials & Obio Akpor \\
\hline Participant 4 & Male & Bachelor & 3 & Water treatment & Port Harcourt \\
\hline Participant 5 & Male & Bachelor & 3 & Telecoms.services & Port Harcourt \\
\hline Participant 6 & Male & Bachelor & 2 & Water treatment & Port Harcourt \\
\hline Participant 7 & Male & Bachelor & 1 & Soap production & Obio Akpor \\
\hline Participant 8 & Female & Bachelor & 3 & Hair stylist & Eleme \\
\hline Participant 9 & Male & Bachelor & 3 & Paint production & Obio Akpor \\
\hline $\begin{array}{l}\text { Participant } \\
10\end{array}$ & Male & Bachelor & 3 & Barbing salon & Eleme \\
\hline $\begin{array}{l}\text { Participant } \\
11\end{array}$ & Female & Bachelor & 3 & Paint production & Eleme \\
\hline $\begin{array}{l}\text { Participant } \\
12\end{array}$ & Male & Bachelor & 3 & Estate surveyor & Eleme \\
\hline $\begin{array}{l}\text { Participant } \\
13\end{array}$ & Female & Bachelor & 3 & Real estate & Emouha \\
\hline $\begin{array}{l}\text { Participant } \\
14\end{array}$ & Male & Bachelor & 3 & Supermarket & Emouha \\
\hline $\begin{array}{l}\text { Participant } \\
15\end{array}$ & Male & HND & 2 & Food processing & Emouha \\
\hline
\end{tabular}

Note. $\mathrm{HND}=$ Higher National Diploma. Telecoms. Services=Telecommunication Services 
Table 2

The Gender Composition of the Sample Size $(N=15)$

\begin{tabular}{llll}
\hline $\begin{array}{l}\text { Local Government } \\
\text { Area }\end{array}$ & Male & Female & Participants \\
\hline & & & \\
Port Harcourt & 3 & 1 & 4 \\
Obio Akpor & 3 & 1 & 4 \\
Eleme & 2 & 2 & 4 \\
Emouha & 2 & 1 & 3 \\
\hline Total & 10 & 5 & 15 \\
\hline
\end{tabular}


Table 2 indicates that the assortment of participants' gender included a purposive selection of male $(n=10=67 \%)$ and female $(n=5=33 \%)$ that made up the sample size $(N=15)$. I initially interviewed $12(80 \%)$ participants, three each from the four LGAs. Saturation occurred after three additional interviews reaching the total interview count of 15 participants. The participants were self-employed and were start-ups in different industries and were the owners of the businesses. The interviewees were from the four LGAs of Obio-Akpor, Port Harcourt, Eleme, and Emouha.

\section{Data Collection}

After receipt of approval from the Walden University IRB

(\#2018.01.2618:04:93-25'1'), I commenced recruitment of the research participants, four participants each from LGAs and three participants from the fourth LGA in Nigeria. The 3 LGAs where the participants were four each are Port Harcourt City, Obio-Akpo and Eleme while the fourth LGA with 3 participants was Emouha LGA. I completed data collection through semi-structured interviews with the young entrepreneurs. E-mails (see Appendix E) were sent to the potential participant and this formed the basis for the formal approval given by Walden University IRB for data collection. Participants had to sign the informed consent forms to formally express their willingness to participate in the study.

I completed the interview of the participants using a digital audio recorder to record the responses of each of the 15 research participants. I obtained permission from the participants to record their responses. The duration of the interviews ranged from 30 minutes to 40 minutes with an average of 35 minutes and 12 seconds per participant; the 
whole data collection process took about 3 weeks. I listened to the audio recordings of the interviews several times, transcribed the interviews, and used member checking to ensure that I captured the correct responses during the interviews. The transcripts were saved as Word document in a laptop; I emailed the transcript to the participants who had internet access, and I took hard copies of the transcripts to the participants who had no Internet access to verify the accuracy of the information presented. I asked the participants to provide feedback within 48 hours if changes were necessary. I did not receive responses or complaints from any of the participants and assumed that the participants were satisfied with the contents of the transcripts. All the 15 participants requested for their transcripts and four requested for a copy of the dissertation after completion.

I had to make small changes to the data collection plan outlined in Chapter 3, I initially intended to interview and analyze data from 20 research participants but ended up only interviewing 15 participants. Each participant was available on time during the interviews process. After completing the interview, I reviewed documents with each of the respective participants at their offices at an agreed upon date. I also collected field notes during the face-to-face interview session of each participant. The interview location was based on the preference of the research participants. The interview protocol (see Appendix D) served as the data collection framework that I consistently used throughout the data collection process. I will store all the data collected for 5 years before destruction.

In this study, I used in-depth, open-ended interview questions to generate responses that uncovered important themes, categories, and subcategories in question. I 
used the same interview questions (see Appendix B) in each my interview with the 15 participants. I was the data collection instrument; collecting data from the 15 interviewees using the research question and interview questions (see Appendix B). All 15 participants provided feedback that supported the research question and interview questions. I used one audio recorder and hand coding during the data collection procedures. The hand-coding process was a significant factor that supported the development of codes. I used the hand coding process as a backup strategy to fully capture the data for understanding the respondents' feedback for coding, analyzation, and for transcript development.

\section{Data Analysis}

My data analysis plan was deployed as previously outlined in Chapter 3. The selected instruments for data collection for this study included semistructured, face-toface interviews, fieldnotes from observation, and archived document reviews. I used these sources of data to answer the research question: What are the common understandings of how university undergraduates from 21-25 years old could obtain the entrepreneurial knowledge required for self-employment in Nigeria?

I used the data analysis approach of Yin (2014) for the data analysis which comprised (a) data compilation (b) dissembling (c) reassembling (d) interpretation and (e) conclusion of data to get meanings in alignment with the research question. I listened to the audio recordings of the interviews several times, transcribed the interviews into a word document, and I read the interview transcripts, observation field notes, and documents to elicit an initial categorization. I organized all responses from the interviews 
according to each interview question into Excel spreadsheet on separate files and then transferred all the 15 respondents to all the interview questions to another big file to elicit the groups and themes. I used manual hand-coding in extracting the codes and allocating themes to the transcribed interview questions.

I used NVivo 11 software to organize the data by uploading the textual transcripts into NVivo 11 which helped the categorization and comparison of the data (Miles et al., 2014); the deployment of the NVivo11 augmented the manual hand coding to ensure reliability. I read the field notes and review the copies of the training documents of the young entrepreneurs and their employees; the usage of the field notes and review of documents aided the collaboration of some of the evidence from the transcripts obtained from the interviews. I stored the transcripts in the backup file to protect from loss or damage; this was an aspect of my data analysis plan; the data collection plan entails a concern for the issues of trustworthiness towards the replication of further analysis in the future (Yin, 2014).

The data analysis for each interviewee was done using the procedure outlined in the interview protocol (see Appendix B). I setup a column consisting of assigned anonymous codes adjacent to each respondent. The data were a compilation of nine tabs to represent 15 interviewees. In the data analysis, I used information from the audio recorder, the hand-coded transcripts; the field notes for comparison, the combination of the information facilitated the identification of codes, themes, and likely patterns (Myers, 2013). 
The keys word highlighted during the comparison were used to identify codes and themes in the first coding attempt. In the second attempt, I reviewed the audio recorder, transcripts, and field notes to discover common patterns as part of the analysis process by organizing and arranging the data to record an emergence of codes, themes, and patterns for interpretation. The list of emerging codes developed in this study facilitated the identification of thematic development and patterns after numerous reviews of the transcripts. I reviewed the transcripts six times each for each interviewee to ensure that the verified transcripts reflected the appropriate categories and sub-categories, and identified patterns. After running an analysis on the first $12(80 \%)$ interviewees that generated 10 themes, the explanation for the total 15 respondents resulted into conducting one more analysis that generated one more theme.

I provided codes that generated emerging thematic categories from the research question and interview questions (Myers, 2013). A common understanding of findings from this study reflected additional research knowledge for positive social change initiatives for young entrepreneurs who are graduates (Hyett, et al., 2014). The use of the hand coding and audio records facilitated the emergence of themes.

I used highlighted keywords and or statements from the transcripts to identify the codes, themes, and patterns as part of the process. The keywords that reappeared and emerged from the data collection included: competition, creativity, customer friendliness, university, social media, mentor, economic factors, inflationary trend, environmental study, identification of business opportunities, marketing, and workshop \& Seminars. As I continuously listened to the audio recorder, I gained an all-inclusive perspective from 
the participants and their expert advice. Yin (2014) asserted that philosophical and worldview perspectives remain influential in research studies. The continuous assessments of the transcripts, audio recordings, and notes enabled me to have an understanding concerning each interviewee's learning path and entrepreneurial progression, their contributions, and social change perspective. Each participant expressed concerns about wanting to make a difference socially; therefore, their responses helped to formulate the emerging codes and themes.

\section{Evidence of Trustworthiness}

Pieces of evidence to demonstrate of rigor in qualitative research need to be established; it was critical in ensuring that research findings had integrity in the process to make an impact. Using basic analytical processes enabled me to ensure the support of the evidence and trustworthiness from the data collected (Marshall \& Rossman, 2014). Chapter 3 contained the same approach to confirm credibility, transferability, dependability, and confirmability as provided in this chapter. The approach described in Chapter 3 was adapted to supports the results of this study and validate the evidence of trustworthiness. I ensured that I followed the interview protocol to keep track of the questions for uniformity in the data collection processes. The strength of this evidence obtained and the methodology used was demonstrated.

\section{Credibility}

I engaged the study participants to gain and earn their trust through the establishment of rapport. I spent sufficient time during the individual interview process to gain a sound understanding of the case. The responses of the participants were verified 
and validated numerous times to accentuate the credibility of this study. Credibility was important qualitative research undertaking; the strategies used to ensure credibility require techniques to facilitate the management of findings for the study (Berger, 2013). Member checking, field notes taking, review of the audio recorder and transcripts provided the basis for triangulation that established authenticity and credibility. After each interview, I transcribed the recorded interviews verbatim and ensured that the participants received manuscript of the transcribed interview for comment and correction through their e-mails within 48 hours for any additions, corrections, and approval.

\section{Transferability}

The results of this study demonstrated the appropriate outcome to establish the strength of transferability. By providing a detailed protocol, explicit in the description of the steps to take guaranteed external validity; it served as the ability of the outcome and findings of the research to be transferable. Transferability refers to the ability to reapply a research finding in another study (Collins \& Cooper, 2014; Sinkovics \& Alfoldi, 2012). As stated in Chapter 3, I applied the same research processes that established transferability. I ensured the provision of a detailed account of the natural settings where data were collected and provided an in-depth explanation of the data to be collected and analyzed. Future researchers and readers will then be presented with the opportunity of the findings and to evaluate the extent to which these findings will be transferable to similar settings and larger population (Marshall, Cardon, Poddar, \& Fontenot, 2013). 


\section{Dependability}

Dependability is a component of trustworthiness used in research to demonstrate integrity (Hesse-Biber, \& Leavy, 2006). The appropriate detailed procedures were followed to identify the evidence of dependability. When I used the same techniques addressed in chapter 3, replication occurred. Miles and Huberman (1994) asserted that researchers evaluating the qualitative data would be able to justify the system followed. As for each interviewee, I followed the same procedures using the ethical guidelines that required repetitive reviewing throughout the entire study. I noticed the repeated responses that came from the respondents and the formulation and unfolding of saturation. I used Microsoft Word and Excel applications to develop codes and thematic categories with the selected conceptual framework that guided this study, all of which established the consistency of strength in every aspect of this study.

\section{Confirmability}

In Chapter 3, I outlined the appropriate steps I used to ascertain confirmability for this topic of study. The need for the justification of the rationale behind the preference of the data collection methods chosen and how it aligned with the research question and problem statement were made known. Confirmability refers to the objectivity and correctness of data (Abend, 2013; Houghton et al., 2013). I provided a detailed explanation of the data analysis process to demonstrate and exhibit transparency of the process. I used a systematic strategy to ensure credibility that required the use of varying techniques to help manage a common understanding (Hyett, et al,, 2014) of the findings from this topic of study. In checking for conformability, I reviewed the audio recorder 
numerous times comparing it to the hand coding, transcripts, notes, and established codes and themes to ensure accuracy. The recommendations of the result indicated what the experiences and thoughts of the individual interview respondents were, rather than my prejudices as I remained objective and unbiased (Anney, 2014). I followed the ethical standards, as the interviewees' responses supported the purpose of the study.

\section{Study Results}

This study was a multiple case study of young entrepreneurs who are graduates of 21-25 years in LGAs in Nigeria towards gaining an understanding of what are the common understandings of how university undergraduates from 21-25 years old could obtain entrepreneurial knowledge required for self-employment in Nigeria? I purposively selected 15 participants in alignment with the research method and methodology of this research study; I recruited 15 the participants after getting the Walden University IRB approval, and I interviewed the 15 participants as outlined in Chapter 3. The responses from the 15 participants formed the basis for the generation of the themes and analysis of the themes was based on the interview questions in alignment with the central research question. Participants' interviews were transcribed and the transcription served as evidence to the theme formation. I transcribed the interviews word for word, but removed such words as Umms, ahhs, and repeated the participants' words as interviewed. I presented the themes in the highest order of occurrence and order of the interview questions using the semistructured interview protocol. I also included the themes that emerged from the field notes, and observation along with the interview questions to triangulate the data. 
Research question. The central research question for the study was: What are the common understandings of how university undergraduates from 21-25 years old could obtain entrepreneurial knowledge required for self-employment in Nigeria? 
Table 3

Case Study's Research Question, Interview Questions, and Proposed Data Analysis

\begin{tabular}{|c|c|c|c|}
\hline Research Question & Interview Questions & Types of Data & Analysis \\
\hline $\begin{array}{l}\text { What are the common } \\
\text { understandings of how } \\
\text { university undergraduates } \\
\text { from } 21-25 \text { years old could } \\
\text { obtain entrepreneurial } \\
\text { knowledge required for self- } \\
\text { employment in Nigeria? }\end{array}$ & $\begin{array}{l}\text { 1. What degree of entrepreneurial } \\
\text { knowledge did you acquire in the } \\
\text { university that prepares you } \\
\text { towards your pursuit of } \\
\text { entrepreneurship? }\end{array}$ & $\begin{array}{l}\text { Semi- } \\
\text { structured, } \\
\text { open-ended } \\
\text { question, } \\
\text { notes and } \\
\text { documents } \\
\text { reviews }\end{array}$ & $\begin{array}{l}\text { Via Coding, } \\
\text { Themes } \\
\text { Frequencies }\end{array}$ \\
\hline
\end{tabular}

2. What challenges have you encountered after acquiring entrepreneurial knowledge?

3. What strategies have you used to address the challenges mentioned in question 2 above?

4. What were the contributions of your parents towards your acquisition of entrepreneurial knowledge?

5. What are the motivational factors you derived from being self-employed?

6. What are some of your university degree experience that influenced your becoming an entrepreneur?

7. How has your personal interest in becoming selfemployed influenced your choice of entrepreneurial career?

8. What did you have to learn after you started your business?

9. What other factors or life experiences shaped your decision to become an entrepreneur? 
Table 4

Theme Generation from Motivational Factors

\begin{tabular}{|c|c|c|c|}
\hline Codes & Themes & $\begin{array}{l}\text { Number of } \\
\text { Occurrence }\end{array}$ & $\begin{array}{l}\text { Percentage of } \\
\text { Occurrence }\end{array}$ \\
\hline $\begin{array}{l}\text { Getting to know } \\
\text { your competition is } \\
\text { an effective way to } \\
\text { knowledge about } \\
\text { your product }\end{array}$ & $\begin{array}{l}\text { - Information } \\
\text { from } \\
\text { Competition }\end{array}$ & 9 & $60 \%$ \\
\hline $\begin{array}{l}\text { When you have a } \\
\text { business idea that } \\
\text { you can explore }\end{array}$ & $\begin{array}{l}\text { - Information } \\
\text { from } \\
\text { Innovation }\end{array}$ & 10 & $66.7 \%$ \\
\hline $\begin{array}{l}\text { Getting positive } \\
\text { feedback from } \\
\text { client serve as } \\
\text { motivation }\end{array}$ & $\begin{array}{l}\text { - Information } \\
\text { from } \\
\text { Customers }\end{array}$ & 12 & $80 \%$ \\
\hline
\end{tabular}


Table 5

Theme Generation from Choice of Entrepreneurship as Career

\begin{tabular}{|c|c|c|c|}
\hline Codes & Themes & $\begin{array}{l}\text { Number of } \\
\text { occurrence }\end{array}$ & $\begin{array}{l}\text { Percentage of } \\
\text { Occurrence }\end{array}$ \\
\hline $\begin{array}{l}\text { Personal interest on } \\
\text { studies for business } \\
\text { management }\end{array}$ & $\begin{array}{l}\text { Knowledge from } \\
\text { Business } \\
\text { Management }\end{array}$ & 13 & $86.7 \%$ \\
\hline $\begin{array}{l}\text { Getting knowledge } \\
\text { from social media }\end{array}$ & $\begin{array}{l}\text { Information from } \\
\text { Social Media }\end{array}$ & 10 & $66.7 \%$ \\
\hline $\begin{array}{l}\text { Having a Mentor } \\
\text { serve as guide to } \\
\text { becoming self- } \\
\text { employed }\end{array}$ & $\begin{array}{l}\text { Knowledge from } \\
\text { Mentor }\end{array}$ & 11 & $73.3 \%$ \\
\hline $\begin{array}{l}\text { Using Economic } \\
\text { Factors }\end{array}$ & $\begin{array}{l}\text { Information from } \\
\text { Workshop and } \\
\text { Seminars }\end{array}$ & 11 & $73.3 \%$ \\
\hline $\begin{array}{l}\text { Using Inflationary } \\
\text { Trend }\end{array}$ & $\begin{array}{l}\text { Information from } \\
\text { Macroeconomics } \\
\text { Factors }\end{array}$ & 13 & $86.7 \%$ \\
\hline $\begin{array}{l}\text { Identification of } \\
\text { new Business serve } \\
\text { as motivation }\end{array}$ & $\begin{array}{l}\text { Identification of } \\
\text { Business } \\
\text { Opportunity }\end{array}$ & 14 & $93.3 \%$ \\
\hline $\begin{array}{l}\text { Knowledge gained } \\
\text { through seminars }\end{array}$ & $\begin{array}{l}\text { Knowledge on } \\
\text { Aggressive }\end{array}$ & 15 & $100 \%$ \\
\hline $\begin{array}{l}\text { and workshop } \\
\text { A feasibility Study } \\
\text { reveals business } \\
\text { information }\end{array}$ & $\begin{array}{l}\text { Marketing } \\
\text { Knowledge from } \\
\text { Feasibility Study }\end{array}$ & 15 & $100 \%$ \\
\hline
\end{tabular}




\section{Emergent Themes}

\section{Theme 1: Information from Competition}

The first emergent theme resulted from an analysis and interpretation of the data collected from the semistructured interview question, field notes, and document review. Nine participants $(1,2,3,5,6,7,8,10$, and 12) who represent $60 \%$ responded that competitors business is a source of knowledge on entrepreneurship. I discovered that undergraduates from 21-25 years who became self-employed obtained entrepreneurial knowledge by accessing a competitor and starting to model their business using competition as benchmark. Participant 1 stated that "I got my business idea from someone whose business I admired as lucrative, so I had to watch closely what the business owner was doing, and that was how I started my business as a student.", Participant 2 mentioned that "a brilliant way to become self-employed is to observe who is succeeding in business and copy what the business owner is doing right." Participant 3 noted that

I started my business after a close watch of a friend who was supplying eggs to hotels, so, I became interested in same business, but I changed location to enjoy a wider market share. Today, I am one of the biggest suppliers of egg and food items to hotel in Delta state, and I started while I was in school.

Participant 4 mentioned that she had to befriend a competitor to understand the nature of business, the money required starting, and the risk associated in the business. Participant 5 mentioned that "I watched a close acquaintance business model to understand the dos and don'ts of business." Participant 6 stated that "I learn from the 
competitor whose business was the envy in the market." Participant 7 mentioned that "one great way to get viable idea of business is to use a competitor's business as model." Participant 8 stated "I believe through healthy competition, your competitors could reveal information that could be considered as private." Finally, participant 9 agreed that using a competition's business as model is a quick way to become an entrepreneur.

\section{Theme 2: Information on Innovation}

The second emergent theme resulted from an analysis and interpretation of the data collected from the semistructured interview question, field notes, and document review. Ten participants $(3,4,7,8,9,11,12,13,14$, and 15) agreed that innovation created by entrepreneurs create know knowledge for prospective entrepreneurs to have knowledge on becoming entrepreneurs. Participants 3 inferred that "the information technology (IT) innovation resulted to more innovation in the IT world," Participant 4 stated "I was influenced to start the line of production due to the innovative knowledge I derived from recent innovations in the industry." Participant 7 mentioned that "new innovation create market and opportunities for more innovation in that same industry." Participant 8 mentioned that "I was motivated by the positive comments I received from people on my innovations, that created in me the drive to want to start my company."

Participant 11 said "I become motivated when I realized that my start-up business was refer to as innovation by people around me," Participant 12 stated "my ability to create a product that could satisfy the needs of people was a source of motivation for me," Participants 12 and 13 inferred that been innovative is a source of motivation for 
wanting to become self-employed to derive the satisfaction of craftsmanship. Participant 14 mentioned that

Realizing that been innovative was a source of knowledge to become selfemployed, I had to look inward to see where my passion lies and I found my real self which had made me become what I am today. I will encourage all youth to have a self-reflection, self-evaluation, and selfdiscovering on who they are, as more potentials could be realized than we naturally thought we could have.

Participant 15 stated that

I had all the motivation from the fact that I could be innovative and people noticed that my music production was good for their listening pleasure; been innovative is a characteristic we all possess which must be improved by youth to create opportunities.

\section{Theme 3: Information from Customers Services}

The third emergent theme resulted from an analysis and interpretation of the data collected from the semistructured interview question, field notes, and document review. Theme three appeared twelve times (80\%) from the 15 participants used as the sampled population. Participant 2 stated that

As a student, I wanted to commence business to assist my parents in the financial aspect of my studies. One useful area I could know the right business to start was through asking potential customers of the business I 
intended to start their major needs; I was clear and knowledgeable on how to serve the customers better than competitors.

Participant 3 mentioned that "I gain insight into my business activities when I receive complaints from customers. Providing customer services had been a useful means to gain knowledge on business knowledge.” Participants 4 and 5 inferred that customer service is the first indices used to know if a business idea is right or wrong; the feedback from customers when served provide some indication on how to shape the business. Participant 6 stated that

I gained knowledge of what area of business to start through customers as an apprentice during my school. I was doing a holiday job and there I got to understand what customer desired in the food industry that was the insight to my becoming self-employed today.

Participant 7 stated "through accurate customer service, one can gain insight into business ideas which can lead to diversification of business sustainability. That was how I started as table water supplier in restaurant while in school." Participants 8 and 9 inferred that through effective customer service, one can understand what service appeal to the customers and what services or product to discontinue from client as that could mean the beginning of self-employment. Participant 12 mentioned that "as you provide good customer service, your customers would mention to you what competitors are doing right or wrong, and such information could help shape your business.” Participant 13 mentioned that "satisfying customers gives the desired passion to become a business owner to satisfy more customers if making people happy is a passion to the business 
owner." Participant 14 mentioned that "the one true way to business idea and becoming self-employed is through information from customers who are satisfied or dissatisfied;

therefore, all information from customers and potential customers are vital." Participant 15 stated "I started my own company as a result of many people I help in my area run errand keep asking for more support in library services, so I developed a library service business where I now borrow books in my neighborhood."

\section{Theme 4: Knowledge on Business Management}

The fourth emergent theme resulted from an analysis and interpretation of the data collected from the semistructured interview question, field notes, and document review. Theme four appeared 13 times $(86.7 \%)$ from the 15 participants used as the sampled population. Participant 1 stated "My knowledge on business management was the bedrock to my becoming self-employed despite the fact I had the interest right from time," Participant 2 mentioned that "since I had business management knowledge, becoming self-employed after school was pretty simple." Participants 4, 6, and 7 inferred that business management was knowledge from home. Their parents taught them business management since their parents were all involved in managing business for people. So that was how the interest and knowledge was grounded. Participant 8 stated As a graduate of business management from one of the famous university in Nigeria, my head of department told us in class that the first job of a business management graduate was to create jobs for people rather than seeking employment. That was the foundation of my motivation and I had to start looking 
from my business management studies the area I was to become self-employed. In the end I became a fashion design coordinator.

Participant 9 mentioned that "studying business management was the beginning of knowledge creation for becoming self-employed," Participant 11 said

I studied business management from the field of business and not from university as I read Microbiology in school. During my spare time, I go to library to inquire some business ideas which I apply in the field and they worked out for me becoming self-employed today.

Participant 12 stated "I got knowledge of business from studying business management in school." Participant 13 stated "I had to study hard the requirements of becoming self-employed from case studies of those who were self-employed before me; that information was available in the elective course in business management courses." Participant 14 said "studying business management or getting to know what it takes to manage business is the first step I will recommend to anyone aspiring to become selfemployed." Participant 15 mentioned that becoming self-employed is about knowing what business management lesson taught on self-employment as not all self-employed people are still in business."

\section{Theme 5: Information from Social Media}

The fifth emergent theme resulted from an analysis and interpretation of the data collected from the semistructured interview question, field notes, and document review. Theme five appeared 10 times (66.7\%) from the 15 participants used as the sampled population. Participants 1, 2, and 4 shared similar response that through social media 
such as Facebook, Twitter, and WhatsApp, one can have a business idea that could lead to becoming self-employed. They gave instance of bloggers who become very successful business owners. Participant 5 stated "through the social media, lots of ideas could be gained that could aid someone becoming self-employed."

Participant 6 also shared how he become self-employed as a result of reading an article on Facebook and he decided to give the business a try. Participant 7 mentioned that "business ideas fly all over social media these days that one cannot be idle in this information world," Participant 8 stated that "one can virtually learn anything through YouTube of Google to become self-employed." Participant 10 noted that "through social media, I could know the business to engage in and I started the business while doing the compulsory national service duties." Participant 12 stated that "I become self-employed as a result of knowledge gained from reading from social media and I study further the nature of the business; today I am self-employed and happy.” Participant 14 mentioned that

Through reading from social media how people could start their business and become successful after several listen and practices sessions, I became motivated to start a laundry business while in school. Today, I am one of the leading providers of laundry services in my local government area. Although I started very little while in school, using information I read from social media and videos on laundry business, I have improved and I have adequate client base. 


\section{Theme 6: Mentor and Mentee Relationship}

The sixth emergent theme resulted from an analysis and interpretation of the data collected from the semistructured interview question, field notes, and document review. Theme six appeared 11 times (73.3\%) from the 15 participants used as the sampled population. Participant 1 stated that "to become self-employed, I was mentored by a very dedicated mentor. I was a mentee and I learned from him how to become self-employed." Participants 3, 4, 5, and 6 inferred that the best way to learn to become self-employed is to have a mentor and serve as apprentice while in school. After graduation, one could easily become self-employed after also graduating from the mentor. Participant 6 stated I had a mentor while in school, who I served as an apprentice during my holidays. I was paid during the mentoring period but an agreement guiding the mentee on punctuality and discipline during the period of holidays was provided. I would rather become a mentee again if I have a new line of business I want to venture into, as a mentor-mentee relationship is the fast track to self-employment or becoming an entrepreneur.

Participant 8 mentioned that "through the guardians of a mentor, I could easily learn the tricks to the game of business; hence becoming self-employed." Participant 9 mentioned that "to become self-employed, one requires a mentor for a given period of time." Participant 10 stated, "I was a mentee; I provide mentorship to people who want to become self-employed; to me, that is a sure way to the game." Participant 11 mentioned that "while in school, I had a mentor who was a graduate from my school. He became self-employed after school, so I became a fan and learned from him; that decision has 
helped me become self-employed today." Participants 12 and 14 inferred that becoming self-employed could mean making ones parent a mentor if the parent was self-employed. Participant 12 was raised by a self-employed father while Participant 14 was trained by an uncle.

\section{Theme 7: Information from Workshop and Seminars}

The seventh emergent theme resulted from an analysis and interpretation of the data collected from the semistructured interview question, field notes, and document review. Theme seven appeared 12 times $(80.0 \%)$ from the 15 participants used as the sampled population. Participant 1 stated, "I attended workshop and seminars while in school on entrepreneurship; those seminars were the foundation of my becoming selfemployed." Participants 3, 4, 5, and 6 inferred that they attended seminars that practically changed their lives forever. They claimed that those seminars were where they found passion not to seek white collar jobs, rather become self-employed. Participant 7 stated "it was at a workshop that I attended that the business which I am doing today first came into my head. I will encourage any would-be entrepreneur to attend business seminars." Participant 8 mentioned that "the business workshop I attended provided the platform to refine my crude ideas into workable vision."

Participant 9 stated that "I attended seminars and workshop on several topics; some I paid for and some were free. I benefited from all the seminars and that has helped me to become a better entrepreneur." Participant 10 stated that "becoming self-employed is a lot of investment; I started attending workshop and seminars before gaining admission to the university. Today, I am happy I made that investment in learning." 
Participant 12 mentioned that "knowledge from seminars and workshop were instrumental in making the decision to become an entrepreneur.' Participant 13 mentioned that "while in school, apart from going to classes, I also listen to tapes on business seminars records; I attend business meetings and seminars where I learn the steps of starting a business."

\section{Theme 8: Information from Macroeconomics Trends}

The eighth emergent theme resulted from an analysis and interpretation of the data collected from the semistructured interview question, field notes, and document review. Theme 8 appeared 13 times $(86.7 \%)$ from the 15 participants used as the sampled population. Participant 1 mentioned that

Knowing the macroeconomic trend such as inflation and exchange rate fluctuations can help the individual gain knowledge of which business to commence or stop to practice. For instance, I started rice farming when I learned that government would ban the importation of rice to Nigeria. Such information could hasten any delay decision of an intended entrepreneur. Knowing that new government policy would favor a business one intends to start could fast track the decision to become self-employed.

Participants 2, 3, and 4 also commented that the macroeconomic indices could serve as motivation or deter the decision to start a business. For instance, a government policy to devalue currency could affect the exchange rate which would increase the cost of importation of goods and service. Such government policies serve as a framework for entrepreneurship decisions. Participant 5 stated "my business started when I heard that 
government want to ban the importation of used cars to Nigeria. I started selling new cars as a result of that news." Participants 6,8 and 9 mentioned that "business knowledge could be gained from the macroeconomics trend in a country. That for instance, the budget of 2018 had made lots of entrepreneurs to go into construction of roads as government had budgeted for infrastructural activities in 2018."

Participant 11 stated that "I started business as a bureau de change practitioner when the $\mathrm{CBN}$ rate of exchange rate was far from the parallel market rate, which enabled me to make lots of profits during that period." Participants 12 and 13 mentioned that the macroeconomics trend provide useful information on areas to invest or reduce investment." Participant 14 mentioned that "the macroeconomic trend provide business direction for investors and owners of business." Participant 15 noted that "the microeconomic trend can determine if people are going into paid employment or becoming self-employed."

\section{Theme 9: Identification of Business opportunities}

The ninth emergent theme resulted from an analysis and interpretation of the data collected from the semistructured interview question, field notes, and document review. Theme nine appeared 14 times $(93.3 \%)$ from the 15 participants used as the sampled population. Participants 1, 2, 3, and 4 inferred that the first basic knowledge required to becoming self-employed and an entrepreneur is to identify a business opportunity where ones product or services would be needed. They also said that this identification of business opportunity would have been done by a parent and who eventually handed over 
the business to the heir apparent. The identification of business opportunity is the gap identified that the entrepreneur is required to fill. Participant 5 stated that Identifying a business need or service need is a critical knowledge requires commencing the thought of becoming service provider or product manufacturer. I identified a business in my estate which was to have an eatery as no eatery was in the estate. Today, my profit is three times higher than when I started.

Participant 6 mentioned that "knowledge of a gap in the market in product or services create the drive to become a service provider and hence an entrepreneur." Participant 7 stated "I started my business when I realized that no one in the school had a barbing place for the guys, I collaborated with a roommate and we started using the corridor of our room as office." Participant 8 mentioned that "market opportunity is a huge knowledge that people pay money to have if one exists. So having a clear knowledge of a gap to be filled is like finding crude oil to exploit." Participant 9 said I become interesting in starting a business when I realize that I was the only person doing the business. I rushed into providing dry cleaning services on campus and I was able to pay my school fess through the proceeds from laundry services.

Participant 10 stated that "Information from business identified is important to an entrepreneur. The entrepreneurs by quickly starting such business in providing the identified business need become an entrepreneur." Participants 12 and 13 inferred that when a new business is identified, the entrepreneur has all the motivation to start. Participants 14 and 15 cited different examples of how they started business. While 
Participant 14 said he started as an apprentice with a friend who started a spa business as a result of business opportunity identified, Participant 15 stated that "the father introduced him into a family business that started as a result of a business opportunity identified."

\section{Theme 10: Knowledge through Promotion of Existing Product}

The tenth emergent theme resulted from an analysis and interpretation of the data collected from the semistructured interview question, field notes, and document review. Theme 10 appeared 15 times (100\%) from the 15 participants used as the sampled population. All participants (1-15) agreed that through promotion of existing product, a prospective entrepreneur could gain knowledge and improve on such product. For instance Participants 4 and 5 stated that they learned about advertising business as a result of a business promotion done on campus. Participant 6 said, "I was impressed with the promotion of a new product that I knew anything could sell even if not in a perfect state."

\section{Theme 11: Knowledge from Feasibility Study}

The eleventh emergent theme resulted from an analysis and interpretation of the data collected from the semistructured interview question, field notes, and document review. Theme 11 appeared 15 times (100\%) from the 15 participants used as the sampled population. All participants (1-15) agreed that through asking questions on a product introduction into a new market, new ideas could emerge. Participant 1 stated that "my first line of business was stopped by me when I realized the packaging was not suitable for the culture of the market I intended to serve." Participants 2, 3 and 4 claimed they obtained knowledge in the field during market feasibility study on how to 
commence their businesses and the income of the people to be served. Participants 5 and 6 inferred that it was during the feasibility study that they knew the financial implication of starting a new business and the legal framework. Participant 7 mentioned that "I understand detailed of the product, place, promotion and the right price of the product and services during the field work prior to commencing the business."

Participant 8 mentioned that "through engaging a legal practitioner, she was able to gain knowledge on the legal implication of most services she was to provide." Participant 9 stated that "by engaging in a feasibility study, I realized that my knowledge in the business prior to the feasibility was too shallow to have started. I gained more knowledge after the feasibility study." Participant 10 mentioned that "by carrying out a feasibility study, I was able to gain much knowledge on the product and services.', Participant 11 mentioned that "after the feasibility study on my business, I realized I had become the entrepreneur I have wished to become; I gained much knowledge."

Participant 12 mentioned that "without the feasibility study for a business, the projection of the business is clueless; I gained much knowledge from feasibility study." Participant 13 stated that "I gained all the knowledge I required from carrying out a detailed feasibility study prior to commencing business." Participant 14 mentioned that "I used the feasibility study to explore and gained an in-depth understanding of the business I eventually launched.” Participant 15 stated

Prior to commencing my practice as entrepreneur, I had some thoughts and desires; a market I wanted to serve out from my passion and emotions. But after a feasibility study, I realized that I had little or no knowledge of 
the business and the business environment. I have to realign my product and services with the demand of the market. I could see my strength, weaknesses, opportunities, and threats. I also was able to evaluate the political, economic, social, technology, environment, and legally expected of the business. I was better-prepared success as a result of the feasibility study.

\section{Summary}

In Chapter 4, I explained the setting of the research concerning the demographics and schedule for interviews. I presented the demographics of the participants drawn from the four LGAs in Nigeria that made up the multiple case study. The research question was used to identify the common understanding from the findings in the areas of entrepreneurial knowledge needed for self-employment by graduates. I discussed the trustworthiness and its application to the study. The chapter comprised the study results that encompassed how I generated the codes that entailed the themes in alignment with the interview questions and participants' quotes supporting the themes. Chapter 5 will reflect the findings from the study, including the clarification and considerations to support additional research knowledge, the limitation of the study, the recommendation, and the implication of social change for the study. 
Chapter 5: Discussion, Conclusions, and Recommendations

The focus of this study was to gain a robust common understanding of how undergraduates from 21-25 years old can obtain the entrepreneurial knowledge required for self-employment in Nigeria. I used a purposive sample of 15 research participants from four LGAs in Nigeria. A qualitative approach was appropriate for this study because the qualitative research method explores potential antecedents and factors that researchers do not know or intend to explore (see Khan, 2014). The participants in this study to answered my interview questions and contributed to the development of emerging themes to address the research question.

\section{Interpretation of Findings}

The research question that guided this study was: What are the common understandings of how university undergraduates from 21-25 years old could obtain entrepreneurial knowledge required for self-employment in Nigeria? I manually coded the data from the transcribed interviews of the research participants, my field notes and document review to generate the themes to address the research question. Eleven significant themes emerged and I aligned the themes with my finding from the literature review in Chapter 2 to ascertain the concurrence and the study findings to corroborate with the previous research framework as outlined in the literature review and the conceptual framework.

\section{Information from Competition}

The first theme resulted from an analysis and interpretation of the data collected from the semistructured interview questions. I found that the common understandings of 
how university undergraduates aged 21-25 years old could obtain the entrepreneurial knowledge required for self-employment was through information from competition. This first theme supported Laksmana and Yang's (2015) findings on competition information. Laksmana and Yang inferred that the activity of the competition could be a framework to predict the future of the business. Abdoh and Varela (2018) found that the products, investment, and cash flow of a competitor or a potential competitor could be used to evaluate the health of the competitor's business. The technological design of competition can also be used as a model for how a business can be set up for profit, growth, and sustainability (Mai \& Winata, 2014). The findings confirmed Laksmana and Yang's position as stated in Chapter 2. Using the business of the competitor can be a contextual lens into a new business (Mai \& Winata, 2014).

\section{Information on Innovation}

The second theme resulted from an analysis and interpretation of the data collected from the semistructured interview question. Information on innovation was another way that participants felt undergraduates could obtain the necessary entrepreneurial knowledge. The second theme on information from innovation is aligned with the findings from Li and Nguyen (2017). Li and Nguyen evaluated the academic and practitioners of working with collaboration of technology information and innovation with a review of significant topics such as the determinants of innovation activities, innovation and imitation, the impact of competition, collaboration versus competition, and a review of the theoretical approach of innovation. Some information from innovation that can be useful for entrepreneurs are (a) economies of scale, (b) knowledge 
sharing, (c) market size and volatility, (d) strategic partner selection, (e) intellectual property rights, (f) collaboration costs, (g) trust and commitment, and (h) opportunism and overall collaboration strategy (Akesson et al., 2016; Hollebeek \& Andreassen, 2018). The findings from this study confirmed Akesson's et al. (2016) finding as discussed in Chapter 2.

\section{Information from Customers Services}

Participants through information from customer services were a potential source of entrepreneurship knowledge for undergraduates. The findings of information from customers' services confirmed the previous research of Wu et al. (2017). Wu et al. evaluated customer service to have evolved from goods dominant logic to service dominant logic. Making inquiries from customers can be a source of knowledge on how services could be improved or retained (Wu et al., 2017). Witell, Gustafsson, and Johnson (2014) added that investigating how customers expressed the desire for a new product or services could bring forth new knowledge on product creation or improvement. Obtaining customer information during the new product development process is considered significant in improving business performance (Witell at al., 2014). Obtaining information from customers also reduces the cost of wastage in serving a product that does not meet the required needs of the customers (Cheung \& To, 2015). Cheung and To (2015) identified that complaints from customers could also help in shaping products development. Customer information is vital to an undergraduate in gaining knowledge on entrepreneurship. 


\section{Knowledge of Business Management}

The fourth theme also came from my analysis and interpretation of the data collected from the participant interviews. From the participants' perspective the knowledge of business management was important for the undergraduate to possess for entrepreneurial knowledge. This finding on the knowledge of business management confirmed Scholtz et al. (2018) finding as previously presented in Chapter 2. One of the biggest challenges confronting organization is the management of sustainability in the collection, integration and reporting of sustainability information (Scholtz et al., 2018).

Knowledge gained from business management helps in managing sustainability and business formation (Scholtz et al., 2018). Business intelligence served as a tool in business management, which is used for gathering, storing, and processing information for business (Ruiz, Soriano, \& Coduras, 2016). Through business management knowledge and entrepreneur could learn that business creation requires innovation which leads to job creation, wealth creation, and business growth (Ruiz et al., 2016). Imparting entrepreneurial knowledge is therefore vital to ensure progress in the steps to becoming self-employed (Anderson, Ljungkvisk, \& Svensson, 2015). The components of knowledge needed for an entrepreneur that are taught in business management are (a) business identification, (b) market to serve, (c) economy, (d) personal factors, (e) internal capability, and (f) competitive strategy (Anderson et al., 2015; Ruiz et al., 2016).

\section{Information from Social Media}

The fifth theme of information from social media was also derived from my analysis and interpretation of the data collected from the participants' interviews. The 
theme on information from social media supported the findings of Tan and Goh (2015). Tan and Goh (2015) identified that social media could be used to provide insight into entrepreneurship, including information on the time to set up a business, location for set up, environment, and competition. Information on social media comes in a large variety of forms and sources. The information from social media is user-generated content that is retrieved as needed by users (Wagner, Vollmar, \& Wagner, 2014). Undergraduates could use the Internet to get information from social media, where large amount of information from other continents and countries could be retrieved. Social media information can also be cross-examined with other sources to prove their reliability (Shen, Murzintcev, Song, \& Cheng, 2017).

\section{Mentor and Mentee Relationship}

My analysis and interpretation of data from participants' interviews also resulted in the emergence of the sixth theme of mentor and mentee relationship. The findings of mentor and mentee relationship as sources of information for university undergraduate who require entrepreneurial knowledge confirmed the results of Lejonber, Elstad, and Christophersen (2015). A mentor serves as guide to the mentee, and the business of a mentor serve as a framework for practical classes for a mentee (Lejonberg et al., 2015). The daily supervision and coaching provided by a mentor is a useful resource for business establishment of the mentees business (Ting, Feng, \& Qin, 2017). The mentee could learn under the mentor either for a short-term or on a long-term basis, depending on the nature of business (Ting et al., 2017). 


\section{Information from Workshop and Seminars}

Participants' responses in the semistructured interviews also resulted in the seventh theme of information from workshops and seminars. This finding confirmed the research of Baired and Munir (2015) who described a workshop as an event intended to augment the professional competence of instructors, supervisors, or workers. Workshops are specialized short-term institutional programs on recent advances, chiefly on methods and techniques (Baired \& Munir, 2015). In workshops, experts provide training for skill development to the participants who in turn use that information to improve their skills or knowledge (Peacemaker \& Roseberry, 2017). While new knowledge could be gained through workshops and seminars, old knowledge could also be refined for effectiveness (Peacemaker \& Roseberry, 2017).

\section{Information from Macroeconomics Trends}

The eighth theme of information from macroeconomic trends resulted from my analysis and interpretation of the data collected from the participants' interviews. The theme on macroeconomic factors confirmed existing literature (see Sharma \& Setia, 2015; Tanha, Dampsey, \& Hallahan, 2014). Tanha et al. (2014) identified the following macroeconomic factors could be useful to undergraduates in becoming entrepreneurs: the GDP of the country, the unemployment rate, the national income, the price index, inflation, savings per head, investment, international trade and finance, economic growth and government economic policies. 


\section{Identification of Business Opportunities}

The ninth theme of identification of business opportunities resulted from my analysis and interpretation of the data collected from the field notes. The theme on identification of business opportunity confirms previous literature by Brookers, Altinay, Wang, \& Yeung, (2016) who inferred that new businesses spring up as a result of gap identified in the market. Such gap could be human gap, material gaps, or technological gaps (Ge, Sun, Chen, \& Gao, 2016). University undergraduate could obtain entrepreneurship knowledge by identifying business opportunities and exploring the business to provide goods and services to the market. New businesses are difficult to manage due to competition and product cycles which could be a new product (Ge et al., 2016).

\section{Knowledge through Promotion of Product}

The tenth theme of knowledge through the promotion of product resulted from my analysis and interpretation of the data collected from the documents reviewed. The theme on knowledge through promotion of product confirms previous literature (Keel \& Padgett, 2015). Keel and Padgett (2015) identified that through promotion of a product or services, an entrepreneur could receive feedback that will help in modifying, redesigning, and re-pricing of a new product. Promotion of a product also facilitates in generating more prospects that could help in sustaining the product brand. Mushketova, Bydanova, and Rovel (2018) described promotion as the creation of awareness for a new product or new service. The knowledge gained through promotion is sufficient for the entrepreneur to remain in business (Huang, Chang, Yeh, \& Liao, 2014). University undergraduate 
could gain entrepreneurship knowledge through engaging in product and service promotion.

\section{Knowledge from Feasibility Study}

The eleventh theme of knowledge from feasibility study resulted from my analysis and interpretation of the data collected from the participants' interview, field notes, and documents reviewed. The theme on knowledge from feasibility study confirms previous literature (Irwin, Slay, Choo, \& Lui, 2014). Engaging in a feasibility study is an essential activity performed by the entrepreneur to obtain more information to enable business startup (Kani, 2017). Feasibility involves market analysis, financial analysis, legal framework, financial analysis and structural analysis (Irwin at el., 2014). Carrying out a feasibility study helps entrepreneurs prevent loss of funds and litigation.

\section{Limitations of the Study}

The scope of this case study design was limited to four local government areas in Rivers State, Nigeria, and this might detract the validity of the findings and generalizability of the research findings to other local government areas in Nigeria as stated in Chapter 1. I was the sole instrument of data collection and due to elements of subjectivity from both the researcher and participants regarding the purposeful sampling approach used in the data collection process, it has an inherent bias. Thus, the research result from the sampled population cannot be generalized to a larger population (Acharya et al., 2013; Patton, 2002).

I used a qualitative multiple case study design for this inquiry. This design entailed the selection of participants from four local government areas of Rivers State in 
Nigeria, which limited the representation of the population sample and this situation restricted the validity and generalizability of the research findings to the sampled population (Morse \& McEvoy, 2014). I was the sole instrument of data collection; this situation may have affected the responses of the participants due to the open-ended nature of questions that have influenced the veracity of statements and personal interests. I upheld a high standard of academic integrity and followed the procedures for the data collection and interview protocol.

Also, some of the participants may have omitted some details in their responses, and some may have exaggerated in their responses. I used member checking to establish the reliability and validity of this study and verify the participants' statement within a limited time-frame, this may have impacted on the responses of the participants due to lack of sufficient time for proper reflection (Harvey, 2014). The consideration for time restraints, rescheduling, and cancellations was a contributing factor that might have limited this study (Denscombe, 2013). I used NVivo 11 software for the data organization and audit trail to elicit reflexivity towards enhancing dependability and confirmability of the study (Houghton et al., 2013). The use of hand coding, note taking, and digital audio recorder for the interviews facilitated the validation and confirmation of the data collection. Consistent checking for reliability, validity, and accuracy of the data ensured that the study did not have any missed data or inconsistencies.

\section{Recommendations}

The study findings have created future opportunities for further research. The purpose of this qualitative multiple case study was to gain a robust common 
understanding of how undergraduates from 21-25 years old can obtain entrepreneurial knowledge required for self-employment in Nigeria. An exploratory multiple case study research design was used for this study; the research method was qualitative. The first recommendation for future research is to increase the number of the selected local government areas from four to eight from different geographical locations. This will provide an opportunity for future researchers to compare the result of this study with future outcomes.

The second recommendation for future research is to consider using a focus group to gauge the responses of the participants in a group setting. A researcher can have recourse to focus groups as valuable data collection for a qualitative case research study (Thomas \& Quinlan, 2014). This will help to facilitate member checking and triangulation. The third recommendation for future research is to consider using a mixed method approach for this study. A mixed method approach will deploy both qualitative and quantitative means to get data from the sample population; the mixed method approach will enable the researcher in future research to augment the qualitative method with the quantitative method in this study. A mixed methods research deploys the bestsuited synergy of quantitative and qualitative approaches towards the optimization of the results of the study (Morse \& Cheek, 2015). The following is a compilation of recommendations based on the findings from this topic of study and could be supported by government policies to ensure adequate implementation of findings:

\section{Entrepreneurship and Vocational Module Inclusion to Academic Curriculum}


Using the National University Commission (NUC), the federal government of Nigeria could make it mandatory that all universities and secondary schools must have vocational, and entrepreneurship module included in the academic curriculum. A foundational knowledge on vocational studies and entrepreneurship will increase the number of young adults who would become self-employed after graduating from university, thereby reducing the unemployment rate in Nigeria. To substantiate this recommendation, I refer to Themes 2 and 4 in Chapter 4 . The participants indicated that becoming innovative and gaining knowledge on business management was taken by them before becoming self-employed. By introducing entrepreneurship into the educational curriculum of both universities and polytechnics in Nigeria, more students will attain entrepreneurship knowledge before graduating from a higher institution.

\section{Regular Seminars and Workshop Programs in Universities and Polytechnics}

The educational policymakers such as the NUC and the ministry of education should include in the school academic calendar regular workshops and seminars from business owners, business experts, and employers of labor where undergraduates would have the opportunities to ask first-hand questions from practitioners on how to become self-employed and an entrepreneur. To substantiate this recommendation, I refer to Themes 6, 7, 8, 9, and 11 in Chapter 4. Through workshops and seminars as organized in school, students can have mentors who they can visit during holidays for short-term work practices; the macroeconomic trend could be revealed to mentee students where the students can begin to build interest on businesses based on information shared at the workshop and by their mentors. The students could also begin to identify business 
opportunities from the topics discussed during workshops and seminars, and ultimately, the students can begin to learn how to write feasibility studies by attending workshops and seminars in school prior to graduation.

\section{Schools Adoption of Positive Social Change Philosophy}

The management of the schools should take responsibility to change the paradigm that is currently not working where students graduate without the promise of employment; to a system that works by promoting positive social change philosophy among graduates in Nigeria. To substantiate this recommendation, I refer to themes 1-11 in Chapter 4. School leaders could create a new paradigm that would contribute to positive social change among students that business ideas could come from a combination of individual activities such as studying competitors, being innovative, through a customer service attitude, business management knowledge, use of social media positively, having a mentor, attending workshops, studying macroeconomics trends, identifying gaps to be filled, promotion of existing product, and learning to write a feasibility study.

\section{Implications}

\section{Implication to Practice}

Leaders of government at the various levels of authority for policy making, implementation, job creation and the education subsector need to adopt entrepreneurship as a baseline study for all professions to provide an alternative after graduation rather than seek employment. The results from the study provided evidence of how leaders of tertiary institutions' commitment to entrepreneurship education have led to the creation 
of employment that empowered the entrepreneur towards national growth, development. As the result provided the empirical evidence needed to support entrepreneurship education and skill development.

\section{Implication to Social Change}

The research findings indicated that learning entrepreneurship at the university level had a potential implication of positive social change in the lives of the young unemployed adult in Nigeria as they could be self-employed upon graduation. Unemployment problems will be better addressed through the knowledge through the outcome of the study as future students at the university level take the study of entrepreneurship serious to provide a sure alternative upon graduation where employment opportunities did not exist. Results from the study indicate that graduates from universities offering entrepreneurship as a baseline study have a shift in paradigm from the search of white collar job to become self-employed and employer of labor.

\section{Implication to Theory}

The findings from this study have undergirded the theoretical framework regarding the body of knowledge and professional practice that would help leaders of Nigerian educational sector to resolve the problems of unemployment. The research findings provided additional information of how undergraduates from 21-25 years old could acquire entrepreneurship skills to become self-employed and employers of labor. Future scholars of leadership and management could find the information useful on the need to take a look at the entrepreneurship skill development as a means of resolving the unemployment dilemma in the region and support societal growth and development. The 
results of this research could benefit the leadership of educational institutions as it could help leaders to understand better how to manage the educational policy as it relates to entrepreneurship skills development, job creation, and unemployment reduction. The study has contributed to the body of knowledge on entrepreneurship development in Nigeria as it could provide the basis for future research by students and researchers concerning entrepreneurship education policies and its impact on societal growth and development.

\section{Conclusion}

This topic of this study was Pathways to Entrepreneurship Training towards Addressing Youth Unemployment in Nigeria. Influenced by the theory of planned behavior, the findings from this study came from the young entrepreneurs and knowledge shared to provide a common understanding concerning how university undergraduates from 21-25 years old could obtain entrepreneurial knowledge required for selfemployment in Nigeria. The key findings from this study are demonstration of the need for continuous research on knowledge and positive social change initiatives to reduce the unemployment deficit in Nigeria to improve the provision of entrepreneurial knowledge for students in tertiary institutions. 


\section{References}

Abdoh, H. A. \& Varela, O. (2018). Product market competition, cash flow and corporate investment. Managerial Finance, 44, 207-221. doi:10.1108/MF-03-2017-0072

Abdullahi, A. A., Adekeye, D. S., \& Balogun, O. S. (2014). A 'nation' in wilderness: Youth and insurgency in Nigeria. South African Review of Sociology, 45, 78-96. doi:10.1080/21528586.2014.917886

Abend, G. (2013). The origins of business ethics in American universities, 1902-1936. Business Ethics Quarterly, 23, 171-205. doi:10.5840/beq201323214

Acharya, A. S., Prakash, A., Saxena, P., \& Nigam, A. (2013). Sampling: Why and how of it. Indian Journal of Medical Specialties, 4, 330-333. doi:10.7713/ijms.2013.0032

Achinewhu-Nworgu, E. F., Azaiki, S. A., Babalola, S. S., \& Achinewhu, C. C. (2016). Strategies for improving the employability skills and life chances of youths in Nigeria. BCES Conference Proceedings, 14, 276-282. doi:10.15242/iicbe.c.2016.0068

Ackah-Baidoo, P. (2016). Review article: Youth unemployment in resource-rich SubSaharan Africa: A critical review. The Extractive Industries and Society, 3, 249261. doi:10.1016/j.exis.2015.11.010

Adams, D. P., \& Miles, T. P. (2013). The application of Belmont Report principles to policy development. Journal of Gerontological Nursing, 39, 16-21. doi:10.3928/00989134-20131028-07

Adekiya, Adewale A., \& Ibrahim F. (2016). Entrepreneurship intention among students. The antecedent role of culture and entrepreneurship training and development. 
International Journal of Management Education 14, 116-132.

doi:10.1016/j.ijme.2016.03.001

Ahlin, B., Drnovsek, M., \& Hisrich, R. (2014). Entrepreneurs' creativity and firm innovation: The moderating role of entrepreneurial self-efficacy. Small Business Economics, 43, 101-117. doi:10.1007/s11187-013-9531-7

Akesson, M., Skalen, P., Edvardssen, B., \& Stalhammar, A. (2016). Value proposition test-driving for service innovation. How frontline employees innovate value propositions. Journal of Service Theory and Practice, 26, 338-362.

doi:10.1108/JSTP-10-2014-0242

Akhuemonkhan, I. A., Raimi, L., Patel, A. M., \& Fadipe, A. O. (2014). Harnessing the potentials of technology incubation centers (TICs) as tools for fast-tracking entrepreneurship development and actualization of the vision 20:2020 in Nigeria. Humanomics, 30, 349-372. doi:10.1108/H-11-2013-0069

Al Saifi, S. A., Dillon, S., \& McQueen, R. (2016). The relationship between face to face social networks and knowledge sharing: An exploratory study of manufacturing firms. Journal of Knowledge Management, 20, 308-326. doi:10.1108/JKM-072015-0251

Aligba, A. O., \& Fusch, G. E. (2017). Entrepreneurial motivations and characteristics of Niger Delta youths: An exploratory study. Journal of Social Change, 9, 87-99. doi:10.5590/JOSC.2017.09.1.08 
Allen, T. D., \& Poteet, M. L. (2011). Enhancing our knowledge of mentoring with a person centric approach. Industrial and Organizational Psychology, 4, 126-130. doi:10.1111/j.1754-9434.2010.01310

Aloulou, W. J. (2016). Predicting entrepreneurial intentions of final year Saudi university business students by applying the theory of planned behavior. Journal of Small Business and Enterprise Development, 23, 1142-1164. doi:10.1108/JSBED-022016-0028

Amesi, J., \& Akpomi, M. E. (2014). Entrepreneurs success and creativity in business education. Journal of Education and Practice, 5, 40-47. Retrieved from http://www.iiste.org

Andersen, J., Lyungkvist, T., \& Svensson, L. (2015). Entrepreneurially oriented in what? A business model approach to entrepreneurship. Journal of Small Business and Enterprise Development, 22, 433-499. doi:10.1108/JSBED-11-2013-0170

Anney, V. N. (2014). Ensuring the quality of the findings of qualitative research: Looking at trustworthiness criteria. Journal of Emerging Trends in Educational Research and Policy Studies, 5, 272-281. Retrieved from http://jeteraps.scholarlinkresearch.com/

Anseel, F., Beatty, A., Shen, W., Lievens, F., \& Sackett, P. (2015). How are we doing after 30 years? A meta-analytic review of the antecedents and outcomes of feedback-seeking behavior. Journal of Management, 41, 318-348. doi:10.1177/0149206313484521 
Arthur, S. J., Hisrich, R. D., \& Cabrera, Á. (2012). The importance of education in the entrepreneurial process: A world view. Journal of Small Business and Enterprise Development, 19, 500-514. doi:10.1108/14626001211250180

Asghar, M. Z., Hakkarainen, P. S., \& Nada, N. (2016). An analysis of the relation-ship between the components of entrepreneurship education and the antecedents of theory of planned behavior. Pakistan Journal of Commerce and Social Sciences, 10, 45-68. doi:10.1108/PJCS-02-2015-0078

Baah-Boateng, W. (2015) Unemployment in Ghana: A cross sectional analysis from demand and supply perspectives. African Journal of Economic and Management Studies, 6, 490, 402-415, doi:10.1108/AJEMS-11-2014-0089

Babalola, D., \& Ayuba, C. (2015). Youth unemployment and armed insurrection in postmilitary Nigeria: The contending issues. The Journal of Social, Political, and Economic Studies, 40, 263-288. doi:10.1709293648-14872

Badulescu, D., \& Cadar, O. (2016). Romania: Many entrepreneurs but few innovators. Annals of the University of Oradea, Economic Science Series, 25, 465-475. Retrieved from https://mpra.ub.unimuenchen.de/78924/1/MPRA_paper_78924.pdf

Bailey, L. F. (2014). The origin and success of qualitative research. International Journal of Market Research, 56, 167-184. doi:10.2501/IJMR- 2014-013

Baired, K., \& Munir, R. (2015). The effectiveness of workshop based seminars, Asian Review of Accounting, 23, 293-312. doi:10.1108/ARA-03-2014-0038 
Baker, T., \& Welter, F. (2017). Come on out of the ghetto, please. Building the future of entrepreneurship research. International Journal of Entrepreneurial Behavior and Research, 23, 170-184. doi:10.1108/IJEBR-02-2016-0065

Banerjee-Batist, R. (2014). The role of attachment and mentoring in junior faculty's job satisfaction. American Journal of Management, 14, 1-2. Retrieved from http://www.na-businesspress.com

Barr, S. H., Baker, T., Markham, S. K., \& Kingon, A. I. (2009). Bridging the valley of death: Lessons learned from 14 years of commercialization of technology education. Academy of Management Learning and Education, 8, 370-388. doi:10.5465/AMLE.2009.44287937

Ben-ner, A., \& Ellman, M. (2013). The contributions of behavioral economics to understanding and advancing the sustainability of worker cooperatives. Journal of Entrepreneurial and Organizational Diversity, 2, 75-100. doi:10.5947/jeod.2013.005

Bennett, D. H., \& Woods, C. G. (2014). Review: Painful and painless channelopathies. The Lancet Neurology, 13, 587-599. doi:10.1016/S14744422(14)70024-9

Berger, R. (2015). Now I see it, now I don't: Researcher's position and reflexivity in qualitative research. Qualitative Research. 15, 219-234. doi:10.1177 /1468794112468475 
Binnui, A., \& Cowling, M. (2016). A conceptual framework for measuring entrepreneurship and innovation of young hi-technology firms. GSTF Business Review, 4, 32-47. doi:10.5176/2010-4804_4.3.383

Bloomberg, L. D., \& Volpe, M. (2012). Completing your qualitative dissertation: A road map from beginning to end. Thousand Oaks, CA: Sage.

Boccuzzo, G., \& Gianecchini, M. (2015). Measuring young graduates’ job quality through a composite indicator. Social Indicators Research, 122, 453-478. doi:10.1007/s11205-014-0695-6

Bojanc, R., \& Jerman-Blazic, B. (2013). A quantitative model for information security risk management. Engineering Management Journal, 25, 25-37. doi:10.1080/10429247.2013.11431972

Boukamcha, F. (2015). Impact of training on entrepreneurial intention: An interactive cognitive perspective. European Business Review, 27, 593-616. doi:10.1108/EBR-12-2014-0090

Braunack-Mayer, A., Skinner, S. R., Collins, J., Tooher, R., Proeve, C., O’Keefe, M., \& Marshall, H. (2015). Ethical challenges in school-based immunization programs for adolescents: A qualitative study. American Journal of Public Health, 105, 1399-1403. doi:10.2105/AJPH.2014.302280

Brookers, M., Altinay, L., Wang, X. L., \& Yeung, R. (2016). Opportunity identification and evaluation in franchisee business start-ups. Journal of Service Theory and Practice, 26, 889-910. doi:10.1108/JSTD-04-2015-0089 
Brouwer, A. M., \& Mosack, K. E. (2015). Expanding the theory of planned behavior to predict healthy eating behaviors: Exploring a healthy eater identity. Nutrition and Food Science, 45, 39-53. doi:10.1108/NFS-06-2014-0055

Bukar, M., Rusmawati, S., \& Shaufique Fahmi, S. (2015). Urban poverty, inequality and industry in Nigeria. International Journal of Development Issues, 3, 249-263. doi:10.1108/IJDI-06-2015-0040

Cacciotti, G., \& Hayton J.C. (2015). Fear and entrepreneurship: A review and research agenda. International Journal of Management Reviews, 17, 165-190 doi:10.1111/ijmr.12052

Cain, M. D., \& McKeon, S. B. (2016). CEO Personal risk-taking and corporate policies. Journal of Financial and Quantitative Analysis, 51, 139-164. doi:10.1017/S0022109016000041

Campbell, S. (2014). What is qualitative research. Clinical Laboratory Science, 27, 3. Retrieved from https://www.researchgate.net/home

Carter, N., Bryant-Lukosius, DiCenso, Blythe, \& Neville, A. J. (2014). The use of triangulation in qualitative research. Oncology Nursing Forum, 41, 545-547. doi:10.1188/14.ONF.545547

Casero, J. J., Gonzalez, M. A., Martinez, A. C., \& Mogollon, R. H. (2013). Institutional variables, entrepreneurial activities and economic development. Education and Training, 51, 281-305. doi:10.1108/00251741311301821

Cassar, F. A., Marshall, S., \& Cordina, M. (2014). Use of the Delphi technique to determine safety features to be included in a neonatal and pediatric prescription 
chart. International Journal of Clinical Pharmacology, 36, 1179-1189. doi:10.1007/s11096-014-0014-y.

Cassar, G. (2014). Industry and startup experience on entrepreneur forecast performance in new firms. Journal of Business Venturing, 29, 137-151. doi:10.1016/j.jbusvent.2012.10.002

Chadwick-Coule, T. (2011). Social dynamics and the strategy process: Bridging or creating a divide between trustees and staff. Nonprofit and Voluntary Sector Quarterly, 40, 33-56. doi:10.1177/0899764009354646

Chan, K., \& Chang, H. (2013). Advertising of Chinese youth: A study of public service ads in Hong Kong. Qualitative Market Research: International Journal, 16, 421435. doi:10.110/QMR-06-2013-0042

Chawla, A., \& Saxena, S. (2016). A confirmatory factor analysis of knowledge management assessment instrument in Indian higher educational institutions. International Journal of Quality and Reliability Management, 33, 1019-1029. doi:10.1108/IJQRM-07-2014-0097

Cheung, F. Y., \& To, W. M. (2015). Do task- and relation-oriented customers co-create a better quality of service? An empirical study of customer-dominant logic. Management Decision, 53, 179-197. doi:10.1108/MD-05-2014-0252

Chikweche, T., \& Fletcher, R. (2017). Entrepreneurship and ethics under extreme conditions of poverty. Exploring the realities. Society and Business Review, 12, 419. doi:10.1108/SBR-11-2015-0065 
Chun, J. U., Sosik, J. J., \& Yun, N. Y. (2012). A longitudinal study of mentor and protégé outcomes in formal mentoring relationships. Journal of Organizational Behavior, 33, 1071-1094. doi:10.1002/job.1781

Claudia, I. (2017). The role of training companies in entrepreneurial education. Annals of Constantin Brancusi' University of Targu-Jiu Economy Series, 1, 126-130. Retrieved from http://www.utgjiu.ro/revista/ec/pdf/2017-01/16_Isac\%20Claudia.p

Coad, A., Frankish, J. S., Roberts, R. G., \& Storey, D. J. (2016) Why should banks provide entrepreneurship training seminars? International Small Business Journal, 34, 733-759. doi:10.1177/0266242615593138

Collins, C. S., \& Cooper, J. E. (2014). Emotional intelligence and the qualitative researcher. International Journal of Qualitative Methods, 13, 88-103. Retrieved from http://ejournals.library.ualberta.ca/index.php/IJQM/

Cope, D. G. (2014). Methods and meaning: Credibility and trustworthiness of qualitative research. Oncology Nursing Forum, 41, 89-91. doi:10.1188/14.ONF.89-91

Corbin, J., \& Strauss, A. (2015). Basics of qualitative research: Techniques and procedures for developing grounded theory (4th ed.). Thousand Oaks, CA: Sage.

Cumming, D., Johan, S., \& Zhang, M. (2014). The economic impact of entrepreneurship: Comparing international datasets. Corporate Governance: An International Review, 22, 162-178. doi:10.1111/corg.12058

Cumming, D., \& Li, D. (2013). Public policy, entrepreneurship, and venture capital in the United States. Journal of Corporate Finance, 23, 345-367. doi:10.1016/j.jcorpfin.2013.09.005 
Davidson, K., \& Gleeson, B. (2014). The sustainability of an entrepreneurial city. International Planning Studies, 19, 173-191. doi:10.1080/13563475.2014.880334

Deakins, D., Bensemann, J., \& Battisti, M. (2016). Entrepreneurial skill and regulation: Evidence from primary sector rural entrepreneurs. International Journal of Entrepreneurial Behavior and Research, 2, 234-259. doi:10.1108/IJEBR-122014-0240

Desai, M. S., \& Von, T. J. (2008). Managing electronic information: An ethics perspective. Information Management and Computer Security, 16, 20-27. doi:10.1108/09685220810862724

Denscombe, M. (2013). The role of research proposals in business and management education. The International Journal of Management Education, 11, 142-149. doi:10.1016/J.IJMME.2013.03.001

Denzin, N. K., \& Giardina, M. D. (2014). Qualitative inquiry outside the academy. Walnut Creek, CA: Routledge.

Dieckhoff, M., \& Gash, V. (2015). Unemployed and alone? Unemployment and social participation in Europe. International Journal of Sociology and Social Policy, 35, 67-90. doi:10.1108/IJSSP-01-2014-0002

Djip, V. (2014). Entrepreneurship and SME development in post-conflict societies. Journal of Entrepreneurship and Public Policy, 3, 254-274. doi:10.1108/JEPP-09-2012-0048 
Drucker, P. F. (1986). Innovation and entrepreneurship: practices and principles. Harvard Business Review, 10, 105-109. doi:10.2307/3380320

Dunn, M. S., \& Hart-Steffes, J. S. (2012). Sustainability as moral action. New Directions for Student Services, 139, 73-82. doi:10.1002/ss.20024

Dutta, N., \& Sebel, R. S. (2013). Entrepreneurship and political risk. Journal of Entrepreneurship and Public Policy, 2, 130-143. doi:10.1108/JEPP-03-2012-0018

Dworkin, S. L. (2012). Sample size policy for qualitative studies using in-depth interviews. Archives of Sexual Behavior, 41, 1319-1320. doi:10.1007/s105080120016-6

Dziczkowski, J. (2013). Mentoring and leadership development. The Educational Forum, 77, 351-360. doi:10.1080/00131725.2013.792896

Ebiringa, O. T., Ekwenwa, K. C., \& Ebiringa I. E. (2015). Student engagement and partnering for employability skills development. Serbian Journal of Management, 10, 201-213. doi:10.5937/sjm10-7259

Edoho, F. M. (2016). Entrepreneurship paradigm in the new millennium. Journal of Entrepreneurship in Emerging Economies, 8, 279-294. doi:10.1108/JEEE-082015-0043

Emile, G. M. (2012). Paradigm for a new millennium: Social entrepreneurship. In the history of communication, Champaign, IL: University of Illinois Press. 6, 106123. doi:10.1108/JEEE-08-2015-0043 
Eva, N., \& Sendjaya, S. (2013). Creating future leaders: An examination of youth leadership development in Australia. Education and Training, 55, 584-598. doi:10.1108/ET-08-2012-0082

Fakis, A., Hilliam, R., Stoneley, H., \& Townend, M. (2014). Qualitative analysis of qualitative information from interviews: A systematic literature review. Journal of Mixed Methods Research, 8, 139-161. doi:10.1177/1558689813495111

Farhan, B., Brevetti, M., \& Laditan, D. (2016). Unemployment in Saudi Arabia: The ethical and economic impact of foreign workers on the Middle East market. Middle East Journal of Business, 11, 21-38. Retrieved from http://www.mejb.com/upgrade_flash/October2016/SaudiArabia.pdf

Fayolle, A. (2013). Personal views on the future of entrepreneurship education. Entrepreneurship and Regional Development, 25, 692-701. doi:10.1080/08985626.2013.821318

Feder, E., \& Niţu-Antonie, R. (2017). Connecting gender identity, entrepreneurial training, role models and intentions. International Journal of Gender and Entrepreneurship, 9, 87-108. doi:10.1108/IJGE-08-2016-0028

Fems, K. M., Poazi, F. D., \& Opigo, H. (2017). Entrepreneurship education as a prerequisite for graduate entrepreneurship: A study of graduate entrepreneurs in Yenagoa City. World Academy of Science, Engineering and Technology, International Journal of Social, Behavioural, Educational, Economic, Business and Industrial Engineering, 11, 726-732. doi:10.1101/1102-2015.0015 
Fletcher, A. J., \& Marchildon, G. P. (2014). Using the Delphi method for qualitative, participatory action research in health leadership. International Journal of Qualitative Methods, 13, 1-18. doi:10.1177/160940691401300101

Flicker, S., Haans, D., \& Skinner, H. (2013). Ethical dilemmas in research on internet communities. Sage Internet Research Method,14, 124-134 doi:10.4135/9781446268513

Frankfort-Nachmias, C., \& Nachmias, D. (2007). Research methods in the social sciences (7th ed.). New York, NY: Worth.

Galanakis, K., \& Giourka, P. (2017). Entrepreneurial path: Decoupling the complexity of entrepreneurial process. International Journal of Entrepreneurial Behavior and Research, 23, 317-335. doi:10.1108/IJEBR-03-2016-0079

Galindo, M., \& Mendez-Picazo, M. (2013). Innovation, entrepreneurship and economic growth. Management Decision, 51, 501-514. doi:10.1108/0025174131109625

Gambetti, R. C., Graffigna, G., \& Biraghi, S. (2012). The grounded theory approach to Consumer-brand engagement. International Journal of Market Research, 54, 659-687. doi:10.2501/IJMR-54-5-659-687

Gawel, A. (2012). Entrepreneurship and sustainability: Do they have anything in common? The Poznan University of Economics Review, 12, 5-16. Retrieved from http://puereview.ue.poznan.pl/

Gawell, M. (2014). Social entrepreneurship and the negotiation of emerging social enterprise markets: Re-considerations in Swedish policy and 
practice. International Journal of Public Sector Management, 27, 251-266. doi:10.1108/IJPSM-11-2012-0143

Ge, B., Sun, Y., Chen, Y., \& Gao, Y. (2016). Opportunity exploitation and resource exploitation. An integrated growth model for entrepreneurship. Internet Research, 26, 498-528. doi:10.1108/intR-04-2015

Gee, J., Loewenthal, D., \& Cayne, J. (2013). Phenomenological research: The case of empirical phenomenological analysis and the possibility of reverie. Counseling Psychology Review, 28, 52-62. doi:10.1111/J.2044-8341.2011. 02053

Ghosh, R., \& Reio, T. G., Jr. (2013). Career benefits associated with mentoring for mentors: A meta-analysis. Journal of Vocational Behavior, 89, 127-136. doi:10.1016/j.jvb.2013.03.011

Gielnik, M. M., Frese, M., Kahara-Kawuki, A., Katono, I. W., Kyejusa, S., Ngoma, M.,... \& Dlugosch, T. J. (2015). Action and action-regulation in entrepreneurship: evaluating a student training for promoting entrepreneurship. Academy of Management Learning and Education, 14, 69-94. doi:10.5465/amle.2012.0107

Godden, L. (2014). Essentials of a qualitative doctorate. Alberta Journal of Educational Research, 60, 610-614. Retrieved from http://ajer.journalhosting.ucalgary.ca/index.php/ajer/article/viewFile/1290/pdf_5

Goertz, G., \& Mahoney, J. (2013). Methodological Rorschach tests: Contrasting interpretations in qualitative and quantitative research. Comparative Political Studies, 46, 236-251. doi:10.1177/0010414012466376 
Goffin, K., Varnes, C. J., van der Hoven, C., \& Koners, U. (2012). Beyond the voice of the customer: Ethnographic market research. Research-Technology Management, 55, 45-53. doi:10.5437/08956308X5504063

Gorissen, P., Van Bruggen, J., \& Jochems, W. (2013). Methodological triangulation of the students' use of recorded lectures. International Journal of Learning Technology, 8, 20-40. doi:10.1504/IJLT.2013.052825

Grant, C., \& Osanloo, A. (2014). Understanding, selecting, and integrating a theoretical framework in dissertation research: Creating the blueprint for your "house." Administrative Issues Journal: Connecting Education, Practice, and Research, 4, 12-26. doi:10.1108/AIJ-11-2014-0045

Green, R. A. (2014). The Delphi technique in educational research. Sage Open, 4, 2. doi:10.1177/2158244014529773

Grimmer, B., \& Hobbins, J. (2014). Active entrepreneurs and blue-collar workers. Cultural understandings mirrored in European youth unemployment policies. International Journal of Sociology and Social Policy, 34, 559-576. doi:10.1108/IJSSP-07-2013-0084

Groenewald, T. (2004). A phenomenological research design illustrated. International Journal of Qualitative Methods, 3, 42-55. doi:10.1177/160940690400300104

Guest, G., Bunce, A., \& Johnson, L. (2006). How many interviews are enough? An experiment with data saturation and variability. Field Methods, 18, 59-82. doi:10.1177/1525822X05279903 
Gunawan, A. A. (2014). Preliminary study of classifying Indonesian entrepreneurs. Procedia - Social and Behavioral Sciences, 15, 243-250. doi:10.1016/j.sbspro.2014.02.432

Gundry, L. K., Ofstein, L. F., \& Kickul, J. R. (2014). Seeing around corners: How creativity skills in entrepreneurship education influence innovation in business. International Journal of Management Education, 12, 529-538. doi:10.1016/j.ijme.2014.03.002

Gunn, R., Durkin, C., Singh, G., \& Brown, J. (2008). Social entrepreneurship in the social policy curriculum. Social Enterprise Journal, 4, 74-80. doi:10.1108/17508610810877740

Guth, L. J., \& Asner-Self, K. K. (2017). International group work research: Guidelines in cultural contexts. Journal for Specialists in Group Work, 42, 33-53. doi:10.1080/01933922.2016.1264519

Haahr, A., Norlyk, A., \& Hall, E. O. (2013). Ethical challenges embedded in qualitative research interviews with close relatives. Nursing Ethics, 21, 6-15. doi: $10.1177 / 0969733013486370$

Hafer, R. W. (2013). Entrepreneurship and state economic growth. Journal of Entrepreneurship and Public Policy, 21, 67-79. doi:10.1108/20452101311318684

Halkias, D., Nwajiuba, C., Harkiolakis, N., Caracatsanis, S.M, (2011) Challenges facing women entrepreneurs in Nigeria, Management Research Review, 34, 221-235. doi:10.1108/01409171111102821 
Halkier, B. (2013). Yves-Chantal Gagnon, the case study as research method: A practical handbook and Gary Thomas, how to do your case study: A guide for students and researchers. Qualitative Research, 13, 107-110. doi:10.1177/1468794111436157

Handy, F., Cnaan, R. A., Brudney, J. L., Ascoli, U., Meijs, L. P., \& Ranade, S. (2000). Public perception of who is a volunteer: An examination of the net-cost approach from a cross-cultural perspective. Voluntas: International Journal of Voluntary and Nonprofit Organizations, 11, 45-65. doi:10.1023/A:1008903032393

Harper, M., \& Cole, P. (2012). Member checking: Can benefits be gained similar to group therapy? The Qualitative Report, 17, 510-517. Retrieved from http://www.nova.edu/ssss/QR/QR17-2/harper

Harvey, S. (2014). Creative synthesis: Exploring the process of extraordinary group creativity. Academy of Management Review, 39, 324-343. doi:10.5465/amr.2012.0224

Hazzan, O., \& Nutov, L. (2014). Teaching and learning qualitative research: Conducting qualitative research. Qualitative Report, 19, 1-29. Retrieved from http://tqr.nova.edu/

Hens, L., Halkias, D., \& Thurman, P. W. (2015). Entrepreneurship and sustainability: Business solutions for poverty alleviation from around the world. Environment, Development, and Sustainability, 17, 689-690. doi:10.1007/s10668-015-9641-2

Hesse-Bieber, S. N., \& Leavy, P. (2006). The practice of qualitative research. Thousand Oaks, CA: Sage. 
Heuer, A., \& Kolvereid, L. (2014). Education in entrepreneurship and the theory of planned behavior. European Journal of Training and Development, 38, 506-523. doi:10.1108/EJTD-02-2013-0019

Ho, Z. J. (2012). What makes hotel expatriates remain in their overseas assignments: A grounded theory study. The Qualitative Report, 17, 1-22. Retrieved from http://nsuworks.nova.edu/tqr/vol17/iss26/1

Hollebeek, L. D., \& Andreassen, T. W. (2018). The S-D logic-informed hamburger model of service innovation and its implication for engagement and value. Journal of Service Marketing, 32, 1-7. doi:10.1108/JSM-11-2017-0389

Hollweck, T. T. (2015). Case study research design and methods (5th ed.). Canadian Journal of Program Evaluation, 30, 108-110. doi:10.3138/cjpe.30.1.108

Houghton, C., Casey, D., Shaw, D., \& Murphy, K. (2013). Rigor in qualitative case-study research. Nurse Researcher, 20, 12-17. Retrieved from http://journals.rcni.com/journal/nr

Huang, H., Chang, Y., Yeh, C., \& Liao, C. (2014). Promote the price promotion. The effects of price promotions on customer evaluations in coffee chain stores, International Journal of Contemporary Hospitality Management, 26, 1065-1082. doi:10.1108/IJCHM-05-2013-0204

Humbert, A. L., \& Brindley, C. (2015). Challenging the concept of risk in relation to women's entrepreneurship. Gender in Management: An International Journal, 30, 2-25. doi:1108/GM-10-2013-0120 
Hyett, N., Kenny, A., \& Dickson-Swift, V (2014). Methodology or method? A critical review of qualitative case study reports. International Journal of Qualitative Studies on Health and Well-being, 9, 1-12. doi:10.3402/qhw.v9.23606

Imaroh, T. S. (2016). Entrepreneurship education as a strategy for improving the economic independence and competitive ability of society in Asian economic community (AEC) ERA. International Journal of Organizational Innovation, 9, 287-294. Retrieved from https://journals.indexcopernicus.com/journal/15268

Inkle, T. A. (2013). Creativity, innovation and entrepreneurship: The case of H. Wayne Huizenga. Journal of the International Academy for Case Studies, 19, 71-85. doi:10.1007/978-1-4614-3858-8_100076

Irwin, A. S., Slay, J., Choo, K. R., \& Lui, L. (2014). Money laundering and terrorism financing in virtual environment: A feasibility study. Journal of Money Laundering Control, 17, 50-75. doi:10.1108/JMLC-06-2013-0019

Ivana, G. I. (2016). Book review: Joost Beuving and Geert de Vries, doing qualitative research: The craft of naturalistic inquiry. Qualitative Research, 16, 741742. doi:10.1177/1468794115618005

Jacqueline, O., Werner, E., András, G., Kari, H., David, L., Janine, L., \& ... Paola, V. (2015). Five characteristics of youth unemployment in Europe. Sage Open, 5, 119. doi:10.1177/2158244015574962

Janssens, R. M. J. P. A., Van Zadelhhoff, E., Loo, G. V., Widdershoven, G. A. M., \& Molewijk, B. A. C. (2014). Evaluation and perceived results of moral case 
deliberation: A mixed methods study. Nursing Ethics, 22, 1-11. doi:10.1177/0969733014557115

Johnson, J. S., \& Bloch, H. W. (2015). Qualitative sales research: An exposition of grounded theory. Journal of Personal Selling and Sales Management, 35, 262273. doi:10.1080/08853134.2014.954581

Kaiser, K. (2009). Protecting respondent confidentiality in qualitative research. Qualitative Health Research, 19, 1632-1641. doi:10.1177/104973230935087

Kani, J. (2017). Evernote in the research consultation. A feasibility study. Reference Service Review, 45, 67-76. doi:10.1108/RSR-05-2016-0034

Kasseeah, H. (2016). Investigating the impact of entrepreneurship on economic development: A regional analysis. Journal of Small Business and Enterprise Development, 23, 896-916. doi:10.1108/JSBED-09-2015-0130

Katz, R. S. (2003). Political data in 2002. European Journal of Political Research, 42, 873-879. doi:10.1111/j.0304-4130.2003.00109

Katz, J. (2015). A theory of qualitative methodology: The social system of analytic fieldwork. Methods: African Review of Social Sciences Methodology, 1, 131-146. doi:10.1080/23754745.2015.1017282

Kautonen, T., Van Gelderen, M., \& Tornikoski, E. (2013). Predicting entrepreneurial behavior: A test of the theory of planned behavior. Applied Economics, 45, 697707. Retrieved from https://hal.archives-ouvertes.fr/hal-00741505/document 
Keel, A., \& Padgett, D. (2015). The effect of adjacent competitors and promotion on brand sales. Journal of Consumer Markets, 32, 43-50. doi:10.1108/JCM-02-20140860

Kenny, M., \& Fourie, R. (2014). Tracing the history of grounded theory methodology: From formation to fragmentation. Qualitative Report, 19, 1-9. Retrieved from http://nsuworks.nova.edu/tqr/vol19/iss52/1

Khan, S. (2014). Qualitative research method: Phenomenology. Asian Social Science, 10, 298-310. doi:10.5539/ass.v10n21p298.

Khoreva, V., \& Vaiman, V. (2015). Intent vs. action: Talented employees and leadership development. Personnel Review, 44, 200-216. doi:10.1108/PR-10-2013-0191

Kirkwood, A., \& Price, L. (2013). Examining some assumptions and limitations of research on the effects of emerging technologies for teaching and learning in higher education. British Journal of Educational Technology, 44, 536-543. doi:10.1111/bjet.12049

Koe, W., Omar, R., \& Majid, I. A. (2014). Factors associated with propensity for sustainable entrepreneurship. Procedia - Social and Behavioral Sciences, 130, 6574. doi:10.1016/j.sbspro.2014.04.009

Komic, D., Marusic, S. L., \& Ana, M. (2015). Research integrity and research ethics in professional codes of ethics: Survey of terminology used by professional organizations across research disciplines. Journal PLUS One, 10, 1-13. doi:10.1371/journal.pone.0133662 
Korsgaad, S., Anderson, A., \& Gaddefors, J. (2016). Entrepreneurship as re-sourcing towards a new image of entrepreneurship in time of financial, economic, and social spatial crisis. Journal of Enterprising Communities: People and Places in the Global Economy, 2, 178-202. doi:10.1108/JEC-03-2014-0002

Kuckertz, A., \& Wagner, M. (2010). The influence of sustainability orientation on entrepreneurial intentions: Investigating the role of business experience. Journal of Business Venturing, 25, 524-539. doi:10.1016/j.jbusvent.2009.09.001

Kvale, S., \& Brinkmann, S. (2015). Interviews: Learning the craft of qualitative research. Thousand Oaks, CA: Sage.

Kwong, C., \& Thompson, P. (2016). The when and why: Student entrepreneurial aspirations. Journal of Small Business Management, 54, 299-318. doi: $10.1111 /$ jsbm. 12146

Lafuente, E., Stoian, M., \& Rialp, J. (2015). From export entry to de-internationalization through entrepreneurial attributes. Journal of Small Business and Enterprise Development, 22, 21-37. doi:10.1108/JSBED-09-2012-0101

Laksmana, I., \& Yang, Y. (2015). Product market competition and corporate investment decisions. Review of Accounting and Finance, 14, 128-148. doi:10.1108/RAF-112013-0123

Lassalle, P. \& McElwee, G. (2016). Polish entrepreneurs in Glasgow and entrepreneurial opportunity structure. International Journal of Entrepreneurial Behavior and Research, 22, 260-281. doi:10.1108/IJEBR-01-2016-0012 
Lee, S., Yoo, Y., \& Yun, S. (2015). Sharing my knowledge: An international perspective. Journal of Management Psychology, 30, 986-1002. doi:10.1108/JMP-11-20130355

Leedy, P. D., \& Ormrod, J. E. (2013). Practical research: Planning and design (10th ed.). Boston, MA: Pearson Education, Inc.

Lejonberg, E., Elstad, E., \& Christophersen, K. (2015). Mentor education. Challenging mentors beliefs about mentoring. International Journal of Mentoring and Coaching, 4, 142-158. doi:10.1108/IJMCE-10-2014-0034

Lewis, S. (2015). Qualitative inquiry and research resign: Choosing among five approaches. Health Promotion Practice, 16, 473-475. doi:10.1177/1524839915580941

Li, M., \& Nguyen, B. (2017). When will firms share information and collaborate to achieve innovation? A review of collaboration strategies. The Bottom Line, 30, 65-86. doi:10.1108/BL-12-2016-0039

Lorz, M., Mueller, S., \& Volery, T. (2013). Entrepreneurship education: A systematic review of the methods in impact studies. Journal of Enterprising Culture, 21, 123-151. doi:10.1142/S0218495813500064

Lynne, A., \& Bolanle Felicia, A. (2016). Factors influencing women participation in home ownership in Nigeria. Property Management, 34, 67-78. doi:10.1108/PM$12-2014-0053$ 
Macht, S. A., \& Ball, S. (2016). Authentic alignment: A new framework of entrepreneurship education. Education and Training, 58, 926-944. doi:10.1108/ET-07-2015-0063

Magd, H. A., \& McCoy, M. P. (2014). Entrepreneurship in Oman: Paving the way for a sustainable future. Procedia Economics and Finance, 15, 1632-1640. doi:10.1016/S2212-5671(14)00634-0

Maloney, M. E. (2012). Ethical mentorship: The dilemma of success or failure. Clinics in Dermatology, 30, 210-215. doi:10.1016/j.clindermatol.2011.06.009

Mandel, R \& Noyes, E (2016), Survey of experiential entrepreneurship education offerings among top undergraduate entrepreneurship programs. Education and Training, 58, 164-178. doi:10.1108/ET-06-2014-0067

Manning, J. \& Kunkel, A. (2014). Researching interpersonal relationships: Qualitative Methods, studies, and analysis. Thousand Oaks, CA: Sage.

Marcotte, C. (2014). Entrepreneurship and innovation in emerging economies conceptual, methodological and contextual issues. International Journal of Entrepreneurial Behavior and Research, 20, 42-65. doi:10.1108/IJEBR-09-2012-0089

Maritz, A., \& Brown, C. R. (2013). Illuminating the black box of entrepreneurship education programs. Education and Training, 55, 234-252. doi:10.1108/00400911311309305

Maritz, A., Jones, C., \& Shwetzer, C. (2015). The status of entrepreneurship education in Australian universities. Education and Training, 57, 1020-1035. doi:10.1108/ET04-2015-0026 
Marland, A., \& Giasson, T. (2013). Investigating political marketing using mixed method: The case for campaign spending data. Journal of Public Affairs, 13, 391402. doi:10.1002/pa.1492

Marlen Christin, J., Zuzana, R., \& Helmut, K. (2016). Emergent risks in business process change projects. Business Process Management Journal, 4, 791-811. doi:10.1108/BPMJ-01-2015-0002

Marshall, B., Cardon, P., Poddar, A., \& Fontenot, R. (2013). Does sample size matter in qualitative research? A review of qualitative interviews in research. Journal of Computer Information Systems, 54, 11-22. Retrieved from http://www.tandfonline.com/loi/ucis20

Marshall, C., \& Rossman, G. B (2014). Designing qualitative research (5th ed.). London, England: Sage.

Martin, C. (2016). Impact of new forms of learning in interest driven communities to future pathways for youth. On the Horizon, 24, 227-234. doi:10.1108/ITH-042016-0012

Maxwell, J. A. (2013). Qualitative research design: An interactive approach (3rd ed.). Thousand Oaks, CA: Sage.

McCleland, D. C. (1965). Achievement and entrepreneurship: A longitudinal study. Journal of Personality and Social Psychology, 1, 389-392. Retrieved from https://www.ncbi.nlm.nih.gov/pubmed/14328753 
McCusker, K., \& Gunaydin, S. (2015). Research using qualitative, quantitative or mixed methods and choice based on the research. Perfusion, 30, 537-542. doi: $10.1177 / 0267659114559116$

McNaughton, R. B., \& Gray, B. (2017). Entrepreneurship and resilient communities introductions to the special issues. Journal of Enterprising Communities: People and Places in the Global Economy, 11, 2-19. doi:10.1108/JEC-01-2016-0002

Medeiros, A (2016), Dynamics of change: Why reactivity matters, Communication of the ACM, 59, 42-47. doi:10.1145/2948989

Menkiti, M., \& Ward, T. (2016). Keeping the business afloat. Worldwide Hospitality and Tourism Themes, 8, 216-220. doi:10.1108/WHATT-11-2015-0045

Mertens, D. M. (2016). Assumptions at the philosophical and programmatic levels in evaluation. Evaluation and Program Planning, 59, 102-108. doi:10.1016/j.evalprogplan.2016.05.010

Mia, L., \& Winata, L. (2014). Manufacturing strategy and organizational performance: The role of competition and MAS information. Journal of Accounting and Organizational Change, 10, 83-115. doi:10.1108/JAOC-10-2011-0048

Micozzi, A., \& Lucarelli, C. (2016). Heterogeneity in entrepreneurial intent: The role of gender across countries. International Journal of Gender and Entrepreneurship, 8, 173-194. doi:10.1108/JJGE-06-2015-0021

Miles, M.B. \& Huberman, A.M. (1994). Qualitative data analysis (2nd ed.). Thousand Oaks, CA: Sage Publications. 
Miles, M. B., Huberman, A. M. \& Saldana, J. (2014). Qualitative data analysis: A methods sourcebook (3rd ed.). Thousand Oaks, CA: Sage.

Mohamad, N., Lim, H., Yusof, N., \& Soon, J. (2015). Estimating the effect of entrepreneur education on graduates' intention to be entrepreneurs. Education and Training, 57, 874-890. doi:10.1108/ET-03-2014-0030

Monette, D. R., Sullivan, T. J. \& DeJong, C. R. (2008). Applied social research: A tool for the human services (7th ed.). Belmont, CA.: CENGAGE Learning

Morgan, K. (2016). Collective entrepreneurship: The Basque model of innovation. European Planning Studies, 24, 1544-1560. doi:10.1080/09654313.2016.1151483

Morris, P. W. G., \& Pinto, J. K. (Eds.). (2007). The Wiley guide to project, program and portfolio management (1st ed.). Hoboken, NJ: John Wiley \& Sons.

Morrow, N., \& Nkwake, A. M. (2016). Assumption-aware tools and agency: An interrogation of the primary artifacts of the program evaluation and design profession in working with complex evaluands and complex contexts. Evaluation and Program Planning, 59, 141-153. doi:10.1016/j.evalprogplan.2016.05.011

Morse, A. L., \& McEvoy, C. D. (2014). Qualitative research in sport management: Case study as a methodological approach. Qualitative Report, 19, 1-13. Retrieved from: http://eds.a.ebscohost.com.ezp.waldenulibrary.org Morse, J. (2015). Using qualitative methods to access the pain experience. British 282 Journal of Pain, 9, 26-31. doi:10.1177/2049463714550507

Morse, J., \& Cheek, J. (2015). Introducing qualitatively-driven mixed-method 
designs. Qualitative Health Research, 25, 731-733.

doi: $10.1177 / 1049732315583299$

Mulloth, B., Kickul, J. R., \& Gundry, L. K. (2016). Driving technology innovation through social entrepreneurship at Prezi. Journal of Small Business and Enterprise Development, 23, 753-767. doi:10.1108/JSBED-08-2015-0111

Munn, Z., Porritt, K., Lockwood, C., Aromataris, E., \& Pearson, A. (2014). Establishing confidence in the output of qualitative research synthesis: The Conqual approach. BMC Medical Research Methodology, 14, 1-7. doi:10.1186/1471228814108

Mushketova, N., Bydanova, E., \& Rovel, G. (2018). National strategy for promotion of Russain University in the world market of education services. International Journal of Educational Management, 32, 46-56. doi:10.1108/IJEM-10-2016-0207

Mutchler, M. G., McKay, T., McDavitt, B., \& Gordon, K. K. (2013). Using peer ethnography to address health disparities among young urban Black and Latino men who have sex with men. American Journal of Public Health, 103, 849-852. doi:10.2015/AJPH.2012.300988

Myers, M. D. (2013). Qualitative research in business management (2nd ed.) Thousand Oaks, CA: Sage.

Nadal, K. L., Davidoff, K. C., Davis, L. S., Wong, Y., Marshall, D., \& McKenzie, V. (2015). A qualitative approach to intersectional micro-aggressions: Understanding influences of race, ethnicity, gender, sexuality, and religion. Qualitative Psychology, 2, 147-163. doi:10.1037/qup0000026 
Ndubisi, N. O. (2014). Entrepreneurship and service innovation. Journal of Business and Industrial Marketing, 29, 449-453. doi:10.1108/JBIM-07-2013-0148

Neiva, E. R., Odelius, C. C., \& Ramos, L. D. (2015). The organizational change process: Its influence on competences learned on the Job. Brazilian Administration Review, 12, 324-347. doi:10.1590/1807-7692bar2015140082

Nimon, K., Zientek, L. R., \& Henson, R. K. (2012). The assumption of a reliable instrument and other pitfalls to avoid when considering the reliability of data. Frontiers in Psychology, 3, 1-39. doi:10.3389/fpsyq.2012.00102

Nielsen, M., \& Suna Lowe, S. (2015). DesUni: University entrepreneurship education through design thinking. Education and Training, 8, 977-991. doi:10.1108/ET-092014-0121

Nielsen, S. L., \& Gartner, W. B. (2017). Am I a student and or entrepreneur? Multiple identities in student entrepreneurship. Education and Training, 59, 135-154. doi:10.1108/ET-09-2014-0122

Nielson, P. S. (2016). An organizational taxonomy of entrepreneurship policy delivery structures. Journal of Small Business and Enterprise Development, 23, 514-527. doi:10.1108/JSBED-08-2013-0110

O'Cass, A., \& Griffin, D. (2015). Eliciting positive social change: Marketing's capacity to drive prosocial behaviors. Marketing Intelligence and Planning, 33, 826-843. doi:10.1108/MIP-02-2014-0027 
O'Connor, A. (2013). A conceptual framework for entrepreneurship education policy: Meeting government and economic purposes. Journal of Business Venturing, 28, 546-563. doi:10.1016/j.jbusvent.2012.07.003

Ofili, O. U. (2014). Challenges facing entrepreneurship in Nigeria. International Journal of Business and Management, 9, 1-17. doi:10.5539/ijbm.v9n12p258x

Okpara, C. I. (2012). Right to a clean and healthy environment: The panacea to the Niger Delta struggle. Journal of Politics and Law, 5, 3-8. Retrieved from http://www.ccsenet.org/jpl

Olanrewaju, A., Anavhe, P., \& Hai, T. K. (2016). A framework for affordable housing governance for the Nigerian property market. Procedia Engineering, 164, 307314. doi:10.1016/j.proeng.2016.11.624

Orji, A., Nwosu, E. O., Anthony-Orji, O. I., \& Mba, P. N. (2016). ICT usage and unemployment rate nexus in Nigeria: An empirical analysis. Journal of Internet Banking and Commerce, 21, 1-13. Retrieved from http://www.icommercecentral.com/open-access/ict-usage-and-unemploymentrate-nexus-in-nigeria-an-empirical-analysis.php?aid=73325

Othman, N., \& Nasrudin, N. (2016). Entrepreneurship education programs in Malaysian polytechnic. Education and Training, 58, 882-898. doi:10.1108/ET-11-2014-0136

Ovadia, J. S. (2014). Original article: Local content and natural resource governance: The cases of Angola and Nigeria. The Extractive Industries and Society, 1, 137-146. doi:10.1016/j.exis.2014.08.002 
Owualah, S. I., \& Obokoh, L. O. (2008). Tackling youth restiveness in the Niger Delta region of Nigeria through entrepreneurship. Journal of Enterprising Communities: People and Places in the Global Economy, 2, 168-179. doi:10.1108/17506200810879989

Oye, C., Sorensen, N. O, \& Glasdam, S. (2016). Qualitative research ethics on the spot. Nursing Ethics, 23, 455-464. doi:10.1177/096973301456702

Pare, G., Trudel, M-C., Jaana, M., \& Kitsiou, M. (2015). Synthesizing information systems knowledge: A typology of literature reviews. Information and Management, 52, 183-199. doi:10.1016/j.im.2014.08.008

Parker, L. (2014). Qualitative perspectives: Through a methodological lens. Qualitative Research in Accounting and Management, 11, 13-28. doi:10.1108/QRAM-022014-0013

Patton, M. Q. (2002). Qualitative research and evaluation methods (3rd ed.). Thousand Oaks, CA: Sage.

Patton, M. Q. (2015). Qualitative research and evaluation methods (4th ed.). Thousand Oaks, CA: Sage.

Peacemaker, B., \& Roseberry, M. (2017). Creating a sustainable graduate student workshop series. Reference Services Review, 45, 562-574. doi:10.1108/RSR-042017-0010

Pefanis Schlee, R., Stewart, R., \& Summers, D. (2013). Training students for entrepreneurial activities: Lessons from a social venture plan competition. Journal 
of Entrepreneurship Education, 16, 125-138. Retrieved from

http://www.alliedacademies.org/articles/jeevol16si2013.pdf\#page=131

Peng, W., \& Weichun, Z. (2011). Mediating role of creative identity in the influence of transformational leadership on creativity: Is there a multilevel effect. Journal of Leadership and Organizational Studies, 18, 25-39.

doi: $10.1177 / 1548051810368549$

Pepper, S. D. (2010). The business of Sigint: The role of modern management in the transformation of GCHQ. Public Policy and Administration, 25, 85-97. doi:10.1177/0952076709347080

Phan, P., Jing, Z., \& Abrahamson, E. (2008). Special issue on creativity, innovation and entrepreneurship in China. Management and Organization Review, 4, 151-152. doi:10.1111/j.1740-8784.2007.00099.

Plieth, H., Bullinger, A. C., \& Hansen, E. G. (2012). Sustainable entrepreneurship in the apparel industry: the case of manomama. The Journal of Corporate Citizenship, 45, 123-136. Retrieved from https://papers.ssrn.com/sol3/papers.cfm?abstract_id=2065858

Project Management Institute. (2013). A guide to the project management body of knowledge 5th ed. Newtown Square, PA: Author.

Qiuying, L., Yue, W., Udechukwu, O., Alasdair, M., \& Maxwell, C. (2014). Enterprise risk management and firm value within China's insurance industry. Acta Commercii, 14, 1-10. doi:10.4102/ac.v14i1.198 
Raimi, L., Akhuemonkhan, I., \& Ogunjirin, O. D. (2015). Corporate social responsibility and entrepreneurship (CSRE): Antidotes to poverty, insecurity and underdevelopment in Nigeria. Social Responsibility Journal, 11, 56-81. doi:10.1108/SRJ-11-2012-0138

Rauch, A., \& Hulsink, W. (2015). Putting entrepreneurship education where the intention to act lies: An Investigation into the impact of entrepreneurship education on entrepreneurial behavior. Academy of Management Learning and Education, 14, 187-204. doi:10.5465/amle.2012.0293

Ravitch, S. M., \& Carl, N. M. (2016). Qualitative research: Bridging the conceptual, theoretical, and methodological. Thousand Oaks, CA: Sage.

Reuter, J. (2013). Five steps to a recession proof career. Industrial and Commercial Training, 45, 60-63. doi:10.1108/0019781311296719

Richardson, T. M., Earnhardt, M. P., \& Marion, J. W. (2015). Is project management still an accidental profession. A qualitative study of career trajectory. Sage Open, 5, 110, doi: $10.1177 / 2158244015572098$

Ritchie, J., Lewis, J., Nicholls, C. M., \& Ormston, R. (2013). Qualitative research practice: A guide for social science students and researchers. Thousand Oaks, CA: Sage.

Robinson, O. C. (2014). Sampling in interview-based qualitative research: A theoretical and practical guide. Qualitative Research in Psychology, 11, 25-41. doi:10.1080/14780887.2013.801543 
Robinson, P., \& Josien, L. (2014). Entrepreneurial education: using the challenge in theory and practice. Journal of Entrepreneurship Education, 17, 172-185. Retrieved from http://www.alliedacademies.org/articles/jeevol1722014.pdf\#page=165

Ronkko, M., \& Lepisto, J. (2015). Finnish students' teachers' critical conception of entrepreneurship education. Journal of Enterprising Communities: People and Places in the Global Economy, 9, 61-75. doi:10.1108/JEC-03-2013-0003

Ross, J. D., Clarke, A., \& Kettles, A. M. (2014). Mental health nurse prescribing: Using a constructivist approach to investigate the nurse-patient relationship. Journal of Psychiatric and Mental Health Nursing, 21, 1-10. doi:10.1111/jpm.12039

Rubin, H. J., \& Rubin, I. S. (2012). Qualitative interviewing: The art of hearing data (3rd ed.). Thousand Oaks, CA: Sage.

Rubin, M. (2015). The promise and perils of hybrid moral semantics for naturalistic moral realism. Philosophical Studies, 172, 691-710. doi:10.1007/s11098-014$0329-5$

Ruiz, J., Soriano, D. R., \& Coduras, A. (2016). Challenges in measuring readiness for entrepreneurship. Management Decision, 54, 1022-1046. doi:10.1108/MD-072014-0493

Samanakoopt, N., Songkram, N., \& Thongdeelert, P. (2015). Online collaboration model using systems thinking to enhance leadership of agricultural undergraduate students: The Conceptual Model. Procedia - Social and Behavioral Sciences, 174, 1085-1089. doi:10.1016/j.sbspro.2015.01.798 
Sanjari, M., Bahramnezhad, F., Fomani, F. K., Shoghi, M., \& Cheraghi, M. A. (2014). Ethical challenges of researchers in qualitative studies: the necessity to develop a specific guideline. Journal of Medical Ethics and History of Medicine, 7, 1-6.

Retrieved from https://www.ncbi.nlm.nih.gov/pmc/articles/PMC4263394/

Sankaran, K., \& Demangeot, C. (2017). Conceptualizing virtual communities as enablers of community-based entrepreneurship and resilience. Journal of Enterprising Communities, 11, 78-94. doi:10.1108/JEC-02-2015-0017

Santos, R. E., \& Da Silva, F. Q. (2013). Motivation to perform systematic reviews and their impact on software engineering practice. In Empirical Software Engineering and Measurement, 2013 ACM/IEEE International Symposium, 292- 295. doi:10.1109/ESEM.2013.36

Savickas, M. (2012). Life design: A paradigm for career intervention in the 21st century. Journal of Counseling and Development, 90, 13-19. doi:10.1111/j.15566676.2012.00002.x

Scharber, C., Isaacson, K., Pyscher, T., \& Lewis, C. (2016). Participatory culture meets critical practice. Documentary film production in a youth internship program. English Teaching: Practice and Critique, 15, 355-374. doi:10.1108/ETPC-012016-0021

Schmidt, J. J., Soper, J. C., \& Bernaciak, J. (2013). Creativity in the entrepreneurship program: a survey of the directors of award winning programs. Journal of Entrepreneurship Education, 16, 31-44. doi:10.1007/978-1-4614-3858-8_482 
Scholtz, B., Calitz, A., \& Haupt, R. (2018). A business intelligence framework for sustainability information management in higher education. International Journal of Sustainability in Higher Education, 19, 266-290. doi:10.1108/IJSHE-06-20160118

Schumpeter, J. A. (1934). The theory of economic development: An inquiry into profit, capital, credit, interest, and the business cycle. Cambridge, MA: Harvard University Press.

Secundo, G., \& Elia, G. (2014). A performance measurement system for academic entrepreneurship: A case study. Measuring Business Excellence, 18, 23-37. doi:10.1108/MBE-11-2013-006

Seidman, I. (2013). Interviewing as qualitative research: A guide for researchers in education and the social sciences. New York, NY: Teachers College Press.

Seikkula-Leino, J., Satuvuori, T., Ruskovaara, E., \& Hannula, H. (2015). How do Finnish teacher educators implement entrepreneurship education. Education and Training, 57, 392-404. doi:10.1108/ET-03-2013-0029

Seitz, S. (2016). Pixilated partnerships, overcoming obstacles in qualitative interviews via Skype: A research note. Qualitative Research, 16, 229-235. doi:10.1177/1468794115577011

Sharma, C., \& Setia, R. (2015). Macroeconomic fundamentals and dynamics of the India rupee dollar exchange rate. Journal of Financial Economic Policy, 7, 301-326. doi:10.1108/JFEP-11-2014-0069 
Shen, S., Murzintcev, N., Song, C., \& Cheng, C. (2017). Information retrieval of a disaster event from cross-platform social media. Information Discovery and Delivery, 45, 220-226. doi:10.1108/IDD-01-2017-0003

Shenton, A. K. (2004). Strategies for ensuring trustworthiness in qualitative research projects. Education for Information, 22, 63-75. doi:10.3233/EFI-2004-22201

Sidique, S. F., Rahman, A. A., \& Hook, L. S. (2015). Relationship among local content policy, indigenous oil firms participation and job creation in Nigeria: A theoretical concept. Journal of Developing Areas, 49, 425-437. doi:10.1353/jda.2015.0129

Simundic, A. M. (2013). Bias in research. Biochemia Medica, 23, 12-15. doi:10.11613/BM.2013.003

Singh, R., \& Nayak J. K. (2016) Parent-adolescent conflict and choice of conflict resolution strategy: Familial holiday planning. International Journal of Conflict Management, 27, 88-115, doi:10.1108/IJCMA-04-2014-0025

Sinkovics, R. R., \& Alfoldi, E. A. (2012). Progressive focusing and trustworthiness in qualitative research: The enabling role of computer-assisted qualitative data analysis software (CAQDAS). Management International Review, 52, 817-845. doi:10.1007/s1157501201405

Sobel, P., \& Reding, K. (2004). Aligning corporate governance with enterprise risk management: Melding enterprise risk management with governance means directors, senior management, internal and external auditors, and risk owners must work interdependently. Management Accounting Quarterly, 5, 29-37. 
Retrieved from https://www.questia.com/library/journal/1G1 118890702/aligning-corporate-governance-with-enterprise-risk

Sommer, C. A., Markopoulos, P., \& Goggins, S. L. (2013). Mentoring master's level students: Drawing upon the wisdom of Athena as mentor in Homer's Odyssey. Journal of Poetry Therapy, 26, 1-12. doi:10.1080/08893675.2013.764049

Sommestad, T., Karlzen, H., \& Hallberg, J. (2015). The sufficiency of theory of planned behavior for explaining information security policy compliance. Information and Computer Security, 23, 200-217. doi:10.1108/ICS-04-2014-0025

Sserwanga, A., Kiconco, R. I., Nystrand, M., \& Mindra, R. (2014). Social entrepreneurship and post conflict recovery in Uganda. Journal of Enterprising Communities, 8, 300. doi:10.11088/JEC-02-2014-0001

St-Jean, E., \& Audet, J. (2013). The effect of mentor intervention style in novice entrepreneur mentoring relationships. Mentoring and Tutoring: Partnership in Learning, 21, 96-119. doi:10.1080/13611267.2013.784061

Stahl, B., Doherty, N., Shaw, M., \& Janicke, H. (2014). Critical theory as an approach to the ethics of information security. Science and Engineering Ethics, 20, 675-699. doi:10.1007/s11948-013-9496-6

Stephan, U., Patterson, M., Kelly, C., \& Mair, J. (2016). Organizations driving positive social change. Journal of Management, 42, 1250-1281. doi:10.1177/0149206316633268 
Stulz, R. M., \& Nocco, B. W. (2006). Enterprise risk management: Theory and practice. Journal of Applied Corporate Finance, 18, 8-20. doi:10.1111/j.17456622.2006.00106.

Su, H. Y. (2014). Business ethics and the development of intellectual capital. Journal of Business Ethics, 119, 87-98. doi:10.1007/s10551-013-1623-4

Sue, V. M., \& Ritter, L. A. (2012). Conducting online surveys (2nd ed.). Thousand Oaks, CA: Sage.

Tadajewski, M. (2016). Focus groups: History, epistemology and non-individualistic consumer research. Consumption, Markets, and Culture, 19, 319-345. doi:10.1080/10253866.2015.1104038

Tan, E. M., \& Goh, D. H. (2015). Presenting social media information on mobile devices using multiple contexts. Aslib Journal of Information Management, 67, 182-202. doi:10.1108/AJIM-09-2014-0124

Tanha, H., Dempsey, M., \& Hallahan, T. (2014). Macroeconomic information and implied volatility. Evidence from Australian index options. Review of Behavioral finance, 6, 46-62. doi:10.1108/RBF-01-2014-0006

Tarling, C. A., \& Harry Matlay, E., (2016). Influence of early exposure to family business experience on developing entrepreneurs. Education and Training, 58, 733-750. doi:10.1108/ET-03-2016-0050

Terjesen, S., \& Sullivan, S. E. (2011). The role of developmental relationships in the transition to entrepreneurship: A qualitative study and agenda for future research. 
Career Development International, 16, 482-506.

doi:10.1108/13620431111168895

Thaddeus, E. O., Chinemerem, E. K., \& Edith, E. I. (2015). Student engagement and partnering for employability skill development. Serbian Journal of Management, 10, 201-213. doi:10.5937/sjm10-7259

Thomas, R., \& Quinlan, E. (2014). Teaching and learning focus group facilitation: An encounter with experiential learning in a graduate sociology classroom. Transformative Dialogues: Teaching \& Learning Journal, 7, 1-15. Retrieved from www.kpu.ca/td

Thomson, R. (2015). What is qualitative longitudinal research. London, England: Sage. Thoradeniya, P., Lee, J., Tan, R., \& Ferreira, A. (2015). Sustainability reporting and the theory of planned behavior. Accounting Auditing and Accountability Journal, 28, 1099-1137. doi:10.1108/AAAJ-08-2013-1449

Tight, M. (2016). Phenomenography: the development and application of an innovative research design in higher education research. International Journal of Social Research Methodology, 19, 319-338. doi:10.1080/13645579.2015.1010284.

Ting, S., X. Feng, L., \& Qin, W. (2017). The effect of entrepreneur mentoring and its determinant in the Chinese context. Management Decision, 55, 1410-1425. doi:10.1108/MD-07-2016-0477

Tobin, G. A. and Begley, C. M. (2004), Methodological rigor within a qualitative framework. Journal of Advanced Nursing, 48, 388-396. doi:10.1111/j.13652648.2004.03207.x 
Tschannen-Moran, M., Bankole, R.A., Mitchell, R.M., Dennis M., \&Moore, D.M., (2013) Student academic optimism: A confirmatory factor analysis, Journal of Educational Administration, 51, 150-175. doi:10.1108/09578231311304689

Urbano, D., Aparicio, S., Guerrero, M., Noguera, M., \& Torrent-Sellens, J. (2016). Institutional determinants of student employer entrepreneurs at Catalan universities. Technological Forecasting and Social Change, 123, 271-282. doi:10.1016/j.techfore.2016.06.021

Valand, M. S., \& George, S. (2014). The socio-materiality of designing organizational change. Journal of Organizational Change Management, 27, 391-406. doi:10.1108/JOCM-06-2013-0094

Valliere, D. (2014). Culture values and entrepreneurial motivation in Bhutan. Journal of Enterprising Communities: People and Places in the Global Economy, 8, 126146. doi:10.1108/JEC-02-2013-0002

Valliere, D. (2017). Multidimensional entrepreneurial intent: An internationally validated measurement approach. International Journal of Entrepreneurial Behavior and Research, 23, 59-77. doi:10.1108/IJEBR-08-2015-0182

Vanevenhoven, J., \& Liguori, E. (2013). The impact of entrepreneurship education: Introducing the entrepreneurship education project. Journal of Small Business Management, 51, 315-328. doi:10.1111/jsbm.12026

Van Maanen, J. V. (2015). The present of things past: Ethnography and career studies. Human Relations, 68, 35-53. doi:10.1177/0018726714552287 
Wagner, D., Vollmar, G., \& Wagner, H. (2014). The impact of information technology on knowledge creation. An affordance approach to social media. Journal of Enterprise Information Management, 27, 31-34. doi:10.1108/JEIM-09-2012-0063

Wagner, M., \& Kuckertz, A. (2009). The influence of sustainability orientation on entrepreneurial intentions. Academy of Management Annual Meeting Proceedings, 2009, 1-6. doi:10.5465/AMBPP.2009.44251798

Walsh, G. S., \& Cunningha, J. A. (2017). Regenerative failure and attribution. Examining the underlying processes affecting entrepreneurial learning. International Journal of Entrepreneurial Behavior and Research, 23, 688-707. doi:10.1108/IJEBR-032015-0072

Wanie, C. M., Oben, E. E., Molombe, J. M., \& Tassah, I. T. (2017). Youth advocacy for efficient hostel management and affordable university students' housing in Buea, Cameroon. International Journal of Housing Markets and Analysis, 10, 81-111. doi:10.1108/IJHMA-01-2016-0012

Weis L. \& Fine M. (2012) Critical bifocality and circuits of privilege: Expanding critical ethnographic theory and design. Harvard Educational Review, 82, 173-201. doi:10.17763/haer.82.2.v1jx34n441532242

Wisdom, J. P., Cavaleri, M. A., Onwuegbuzie, A. J., \& Green, H. (2012). Methodological reporting in qualitative, quantitative, and mixed methods health services research articles. Health Services Research, 47, 721-745. doi:10.1111/j.14756773.2011 .01344$. 
Witell, L., Gustafsson, A., \& Johnson, M. D. (2014). The effect of customer information during new product development on profit from goods and services. European Journal of Marketing, 48, 1709-1730. doi:10.1108/EJM-03-2011-0119

Witon, A. (2015). Spatial diversity in the socio-economic development in Sub-Saharan Africa as measured by a composite index. Entrepreneurial Business and Economics Review, 3, 75-85. doi:10.15678/EBER.2015.030106

Wu, J., Kung, H. Y., \& Lin, T. M. (2017). Influence of customer participation on information technology service. Industrial Management and Data Systems, 117, 1077-1092. doi:10.1108/IMDS-03-2016-0104

Wu, J., Wen, N., Dou, W., \& Chen. J. (2015). Exploring the effectiveness of consumer creativity in online marketing communications. European Journal of Marketing, 49, 262-276. doi:10.1108/EJM-03-2013-0148

Yaghoubi F., A., Karimi, S., \& Motaghed, M. (2017). The role of entrepreneurial knowledge as a competence in shaping Iranian students' career intentions to start a new digital business. European Journal of Training and Development, 41, 83100. doi:10.1108/EJTD-07-2016-0054

Yilmaz, K. (2013). Comparison of quantitative and qualitative research traditions: Epistemological, theoretical, and methodological differences. European Journal of Education, 48, 311-325. doi:10.1111/ejed.12014

Yousaf, U., Shamim, A., Siddiqui, A., \& Raina, M. (2015). Studying the influence of entrepreneurial attributes. Subjective norms and perceived desirability on 
entrepreneurial intentions. Journal of Entrepreneurship in Emerging Economics, 7, 23-34. doi:10.1108/JEEE-03-2014-0005

Yin, R. K. (2014). Case study research: Designs and methods (5th ed.). Thousand Oaks, CA: Sage.

Yuksel, P., \& Yildirim, S. (2015). Theoretical frameworks, methods, and procedures for conducting phenomenological studies in educational settings. Turkish Online Journal of Qualitative Inquiry, 6, 1-20. doi:10.17569/tojqi.59813 


\section{Appendix A: Original Interview Questions}

The interview questions were sent to experts on research and would be contacted through email after obtaining their qualifications from faculty expert directory (FED) of Walden University. The research question and the interview questions were presented to the experts for feedback is as follows:

\section{Research Question}

The research question for this qualitative multiple case study is: How can undergraduates from 21-25 years old acquire knowledge on entrepreneurship skills required for successful self-employment?

\section{Interview Questions}

1. What are the contributions of higher education in the acquisition of entrepreneurial knowledge towards your pursuit of entrepreneurship?

2. What challenges have you encountered after acquiring entrepreneurial knowledge?

3. What strategies have you used to address the challenges mentioned in Question 2 above?

4. What were the contributions of your parents towards your acquisition of entrepreneurial knowledge?

5. What is the motivation for being self-employed?

6. How does your choice of career influence your course of study in the university?

7. How has your interest influenced your choice of self-employed career?

8. What other factors or life experiences shaped your decision to become an entrepreneur? 


\section{Appendix B: Request to Participate in an Expert Validation}

Dear Dr. ...

My name is Edward Agbai, a Ph.D. student in Management with specialization in Leadership and Organizational Change. I am working on the methodology section of my proposal at Walden University, in accordance with the design of my study and advice of my Chair (Dr. Richard Schuttler); I am conducting an expert validation to check for the alignment of the exploratory case study research question to the interview questions. I am humbly requesting for your assistance and expertise in reviewing my interview questions and check if the interview questions align with my exploratory case study research question.

Your input and feedback as qualitative research subject matter expertise (SME) would enable me to make the necessary revisions and improve the quality of my work. Attached is an abridged proposal containing the title page, problem statement, purpose statement, research question, and interview questions. If you require additional information, I could email you the whole proposal. I would appreciate if you could provide feedback by next week to enable me to generate an acceptable dissertation proposal. Thank in advance for your kind consideration.

Yours Sincerely, Edward Agbai 
Appendix C: Revised Interview Questions Following Research Experts' Feedback

1. What degree of entrepreneurial knowledge did you acquire in the university that prepares you towards your pursuit of entrepreneurship?

2. What challenges have you encountered after acquiring entrepreneurial knowledge?

3. What strategies have you used to address the challenges mentioned in question 2 above?

4. What were the contributions of your parents towards your acquisition of entrepreneurial knowledge?

5. What are the motivational factors you derived from being self-employed?

6. What are some of your university degree experience that influenced your becoming an entrepreneur?

7. How has your personal interest in becoming self-employed influenced your choice of entrepreneurial career?

8. What did you have to learn after you started your business?

9. What other factors or life experiences shaped your decision to become an entrepreneur? 
Appendix D: Interview Protocol

Location of Interview:

Date of Interview:

Start Time:

Finish Time:

Hi, thank you for agreeing to be part of the study. The interview will take about 30 minutes. I will be asking you questions relating to pathways to entrepreneurship training addressing youth unemployment in Nigeria, a study that focuses on how undergraduates from ages 21-25 years old acquire knowledge on entrepreneurship skills. The purpose of this qualitative exploratory multiple case study is to gain a robust common understanding of how undergraduates from 21-25 years old can obtain entrepreneurial knowledge required for self-employment in Nigeria. Do I have your permission to tape-record the interview for me to get an inclusive record of your responses? The interview will involve note taking as you respond to the questions. Are there any questions or clarifications you would like me to make before we begin? You may stop the interview at any time based on the consent agreement you signed. Are you ready to begin?

Research Question: The research question that would guide this study is: How can undergraduates from 21-25 years old acquire knowledge on entrepreneurship skills required for successful self-employment?

\section{Interview Questions}


1. What degree of entrepreneurial knowledge did you acquire in the university that prepares you towards your pursuit of entrepreneurship?

2. What challenges have you encountered after acquiring entrepreneurial knowledge?

3. What strategies have you used to address the challenges mentioned in question 2 above?

4. What were the contributions of your parents towards your acquisition of entrepreneurial knowledge?

5. What are the motivational factors you derived from being self-employed?

6. What are some of your university degree experience that influenced your becoming an entrepreneur?

7. How has your personal interest in becoming self-employed influenced your choice of entrepreneurial career?

8. What did you have to learn after you started your business?

9. What other factors or life experiences shaped your decision to become an entrepreneur?

Thanks again for your participation in this study. 


\section{Appendix E: Email to Research Participants}

I am a doctoral student at Walden University inviting you to participate in my research about pathways to entrepreneurship training addressing youth unemployment in Nigeria, a study that focuses on how undergraduates from 21-25 years old acquire knowledge on entrepreneurship skills. The purpose of this interview is to gain more understanding of how you gained knowledge on entrepreneurial skill to become selfemployed. I believe that your participation could facilitate the acquisition of the required information relating to the research topic. I am thus seeking individuals to interview to learn more about knowledge gained on entrepreneurial skills.

The study is essential as the research findings might reveal how graduates gain knowledge on entrepreneurial skills to become self-employed. Moreover, the research outcome may add to the existing body of literature and gain robust understanding on how undergraduates 21-25 years old in Nigeria can acquire knowledge on entrepreneurship skills required for self-employment through the provision of a suitable environment for entrepreneurial skill development. Lastly, the study has potential implications for effecting positive social change in the lives of individuals and the local communities in Delta State, Nigeria, through the application of the research findings. If you are interesting in taking part in the study or need more information, you can reply to this email.

Thanking you in anticipation and looking forward to hearing from you. Edward Agbai 